PLAN DE NEGOCIOS PARA LA CREACIÓN DE UNA COMERCIALIZADORA INTERNACIONAL DE UCHUVA CONVENCIONAL EN FRESCO EN EL MUNICIPIO DE ARCABUCO DEPARTAMENTO DE BOYACA

GINA ALEJANDRA CORREDOR GAUNA

DIANA MARCELA ENGATIVA TAMAYO

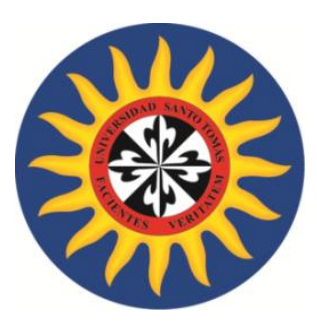

UNIVERSIDAD SANTO TOMAS

DIVISION DE CIENCIAS ADMINISTRATIVAS Y CONTABLES

FACULTAD DE ADMINISTRACIÓN DE EMPRESAS

TUNJA

2014 
PLAN DE NEGOCIOS PARA LA CREACIÓN DE UNA COMERCIALIZADORA INTERNACIONAL DE UCHUVA CONVENCIONAL EN FRESCO EN EL MUNICIPIO DE ARCABUCO DEPARTAMENTO DE BOYACA

TRABAJO DE GRADO PARA OPTAR EL TITULO DE ADMINISTRADORAS DE EMPRESAS

Presentado por las estudiantes:

GINA ALEJANDRA CORREDOR GAUNA

DIANA MARCELA ENGATIVA TAMAYO

Director:

JAVIER CASAS OCHOA.

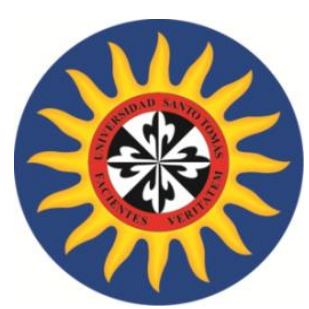

UNIVERSIDAD SANTO TOMAS

DIVISION DE CIENCIAS ADMINISTRATIVAS Y CONTABLES

FACULTAD DE ADMINISTRACIÓN DE EMPRESAS

TUNJA

2014 
Nota de aceptación:

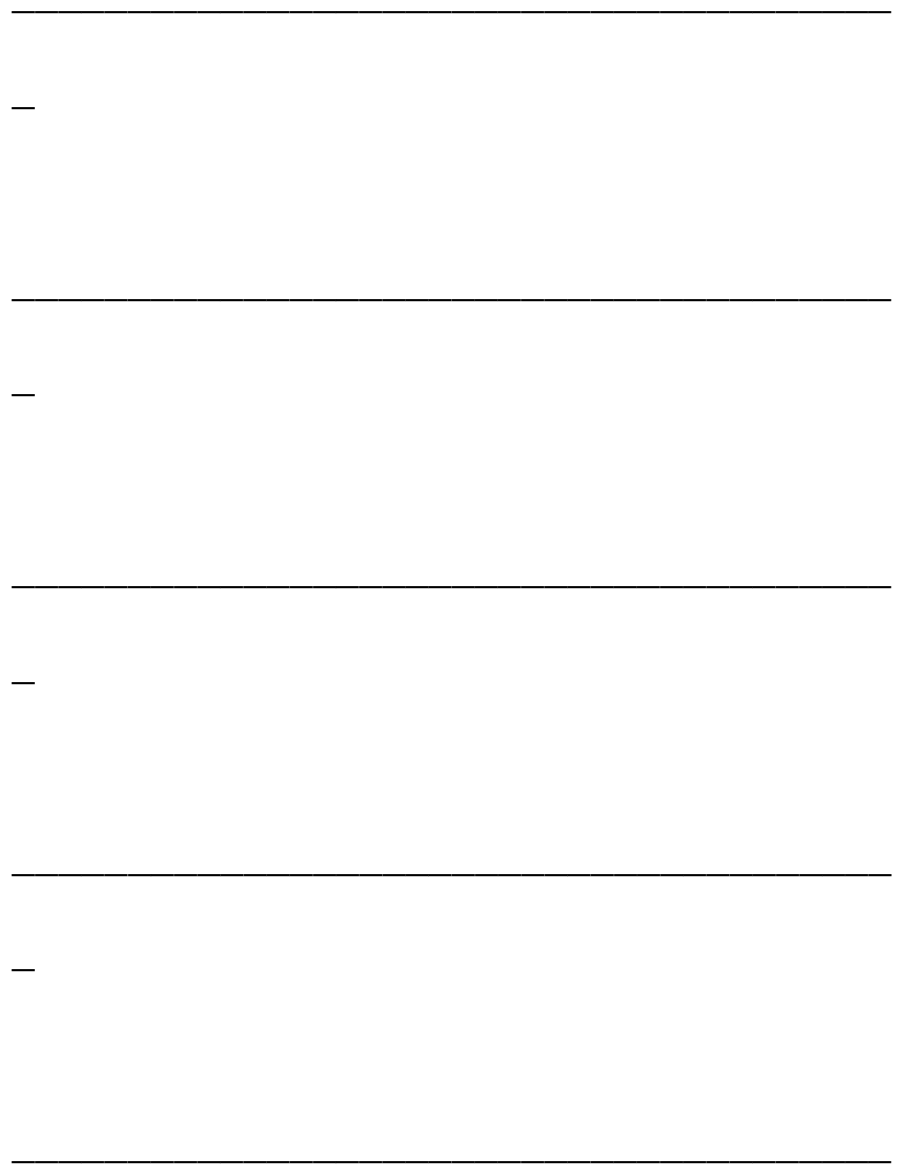


Firma del presidente del Jurado

Firma del Jurado

Firma del Jurado 
Tunja, febrero de 2014 


\section{DEDICATORIA}

Con todo mi cariño y mi amor para las personas que hicieron todo en la vida para que pudiéramos lograr nuestros sueños, por motivarnos día a día y darnos la mano cuando sentíamos que el camino se terminaba

En espacial a nuestros padres por ser quienes apoyan en el cumplimiento de esta meta, gracias a su sacrificio, esfuerzo somos quien somos.

Gracias por ser el bastón que acompaña cada día en cada una de nuestras caídas y ser el motor para cumplir nuestros sueños. 


\section{AGRADECIMIENTO}

A dios por permitirnos tener un logro más en nuestras vidas

A nuestro director de proyecto JAVIER CASAS quien fue nuestro guía con su experiencia, por la paciencia y valiosa entrega a lo largo del proyecto para su culminación.

A los docentes de la facultad, ya que con su formación y guía académica fue posible alcanzar esta meta.

A todas las personas que colaboraron con algunos puntos clave de este libro, por su sabiduría y experiencia. 


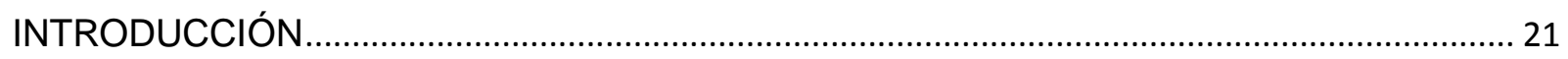

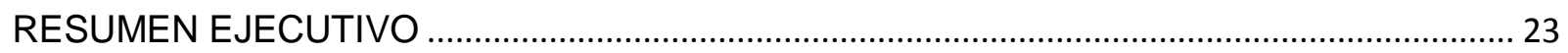

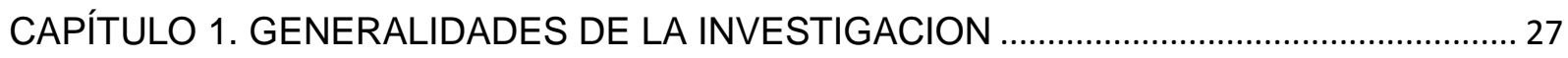

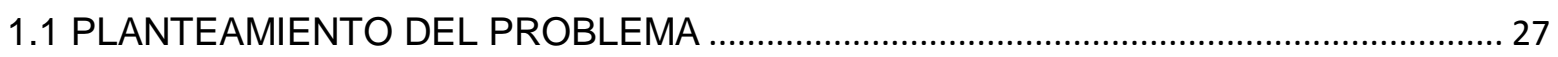

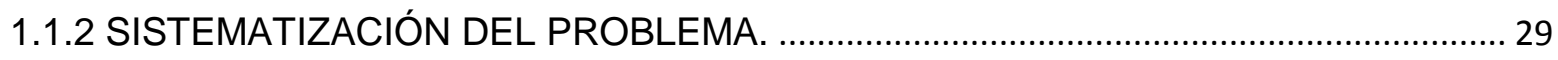

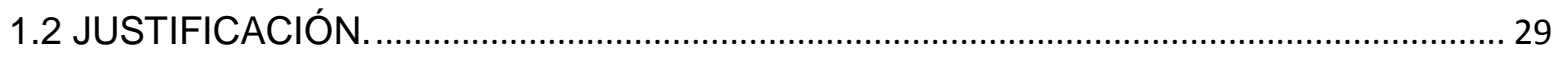

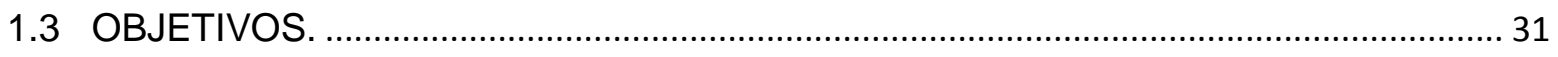

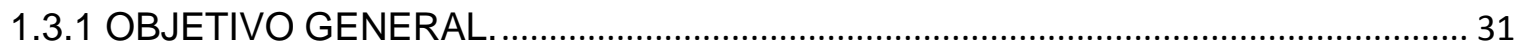

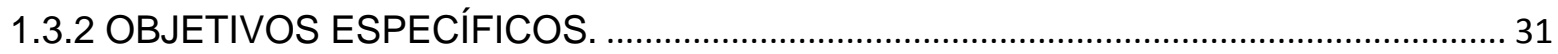

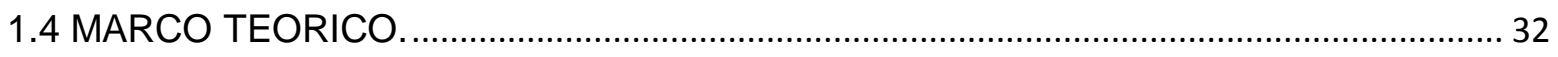

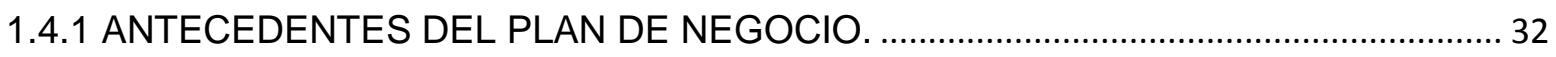

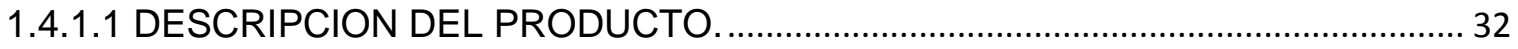

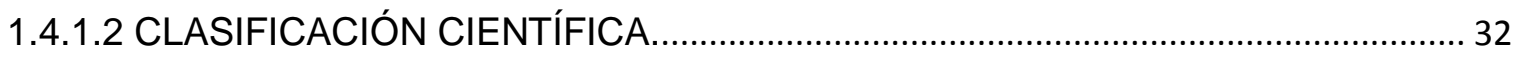

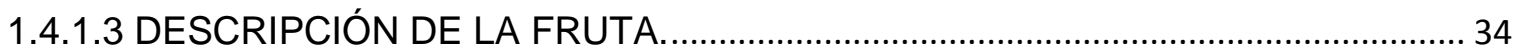

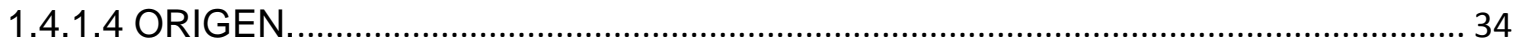

1.4.1.5 ATRIBUTOS DE LA UCHUVA. ……………………………………………..... 35

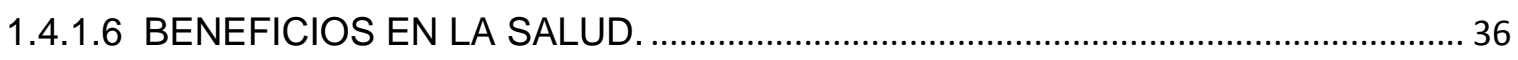

1.4.1.7. PROPIEDADES MEDICINALES DE LA UCHUVA, ............................................. 36

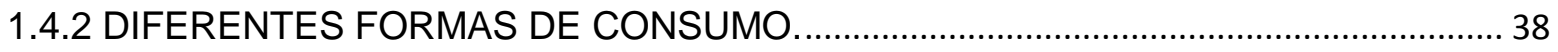

1.4.3 OTROS PRODUCTOS DERIVADOS DE LA UCHUVA................................................ 38

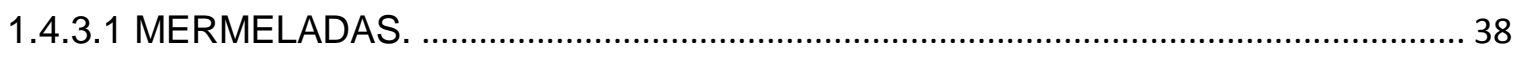

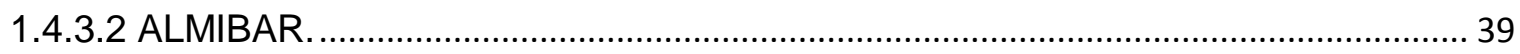

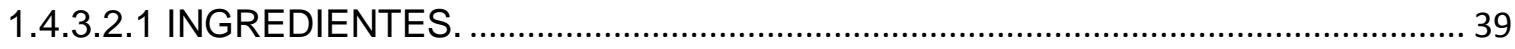

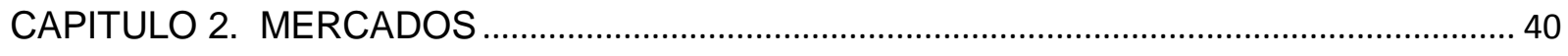

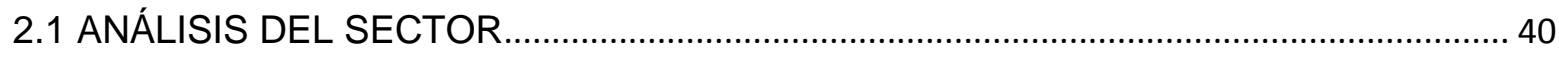

2.2 COMPORTAMIENTO DEL PRODUCTO A NIVEL INTERNACIONAL ............................ 43 


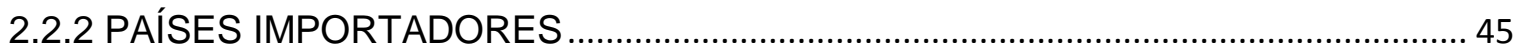

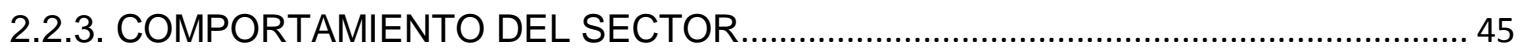

2.3 PRINCIPALES ASOCIACIONES DE PRODUCTORES EN COLOMBIA .......................... 47

2.3.1. PARTICIPACION DE LA UCHUVA EN EL MERCADO NACIONAL........................ 48

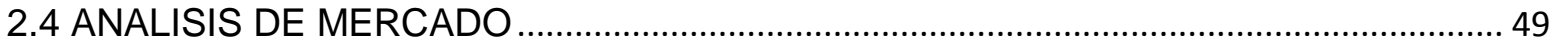

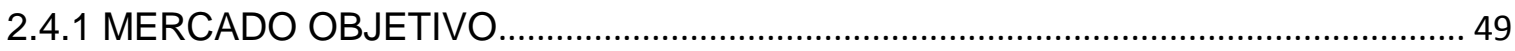

2.4.2. MATRIZ DE PRESELECCIÓN DE MERCADOS DE EXPORTACIÓN ....................50

2.4.3 ELABORACION DE LA MATRIZ …………………………………………........ 51

2.4.3.1. ANALISIS DE MATRIZ Y SELECCIÓN DE MERCADOS A EXPORTAR ..........51

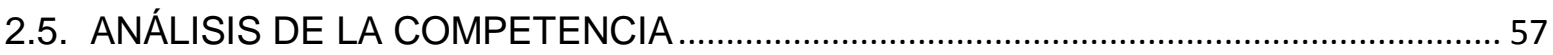

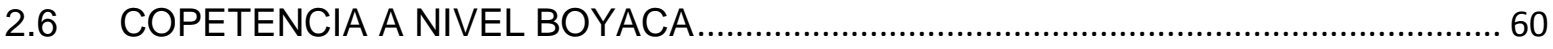

2.6.1 ASOCIACIONES BOYACENCES DE PRODUCTORES DE UCHUVA ..................... 60

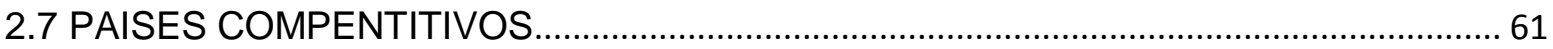

2.8 COMPETENCIA DEPARTAMENTAL Y NACIONAL DE COMERCIALIZADORAS

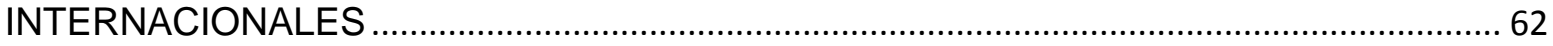

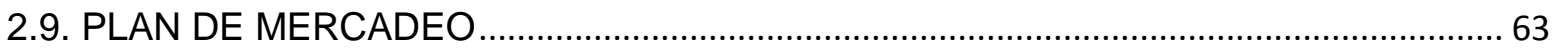

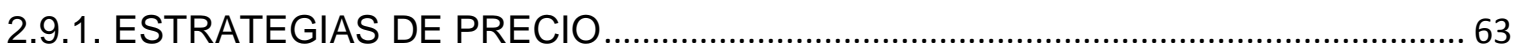

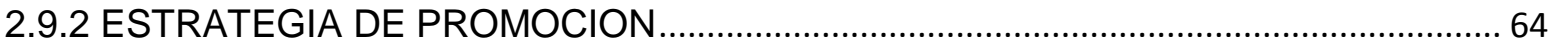

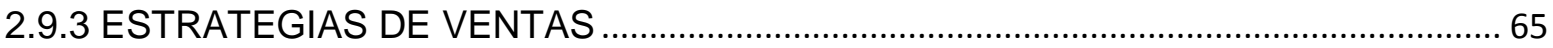

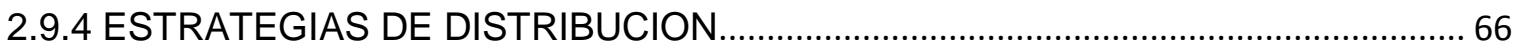

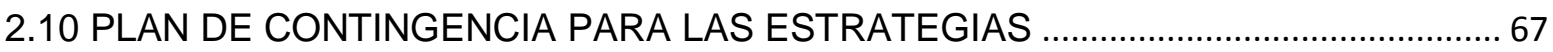

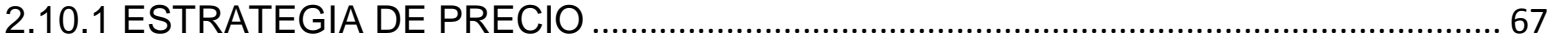

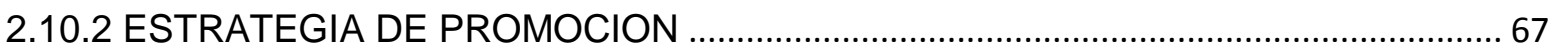

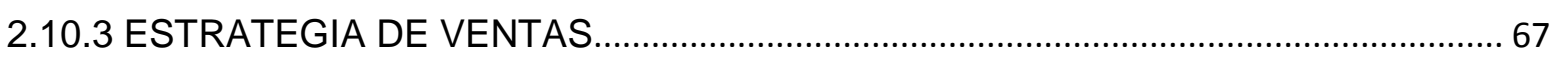

2.10. 4 ESTRATEGIA DE DISTRIBUCION ............................................................................. 67

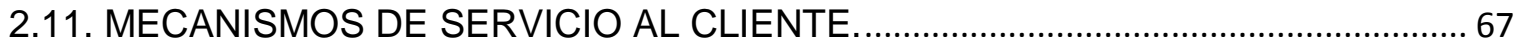

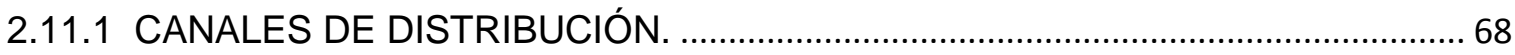

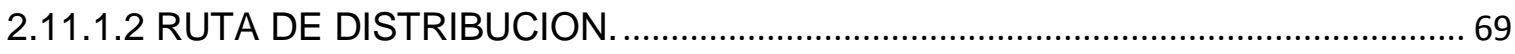

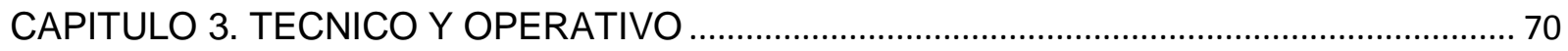

3.1 FICHA TÉCNICA DEL PRODUCTO Y COMPONENTE NUTRICIONAL....................... 70 


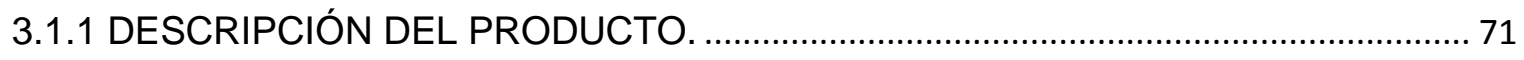

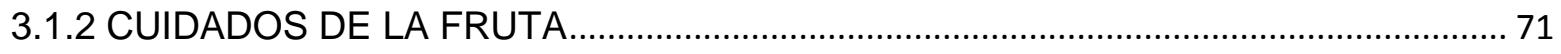

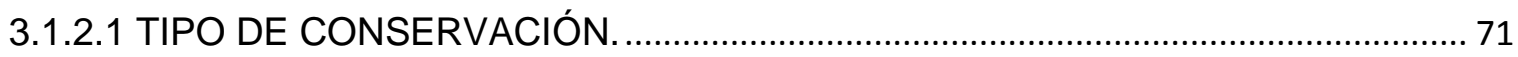

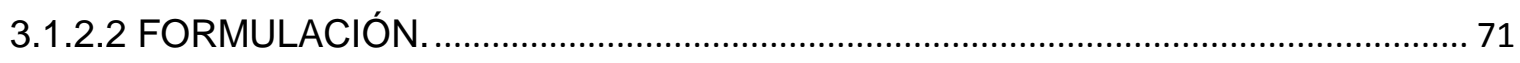

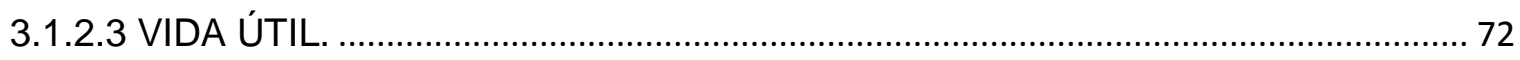

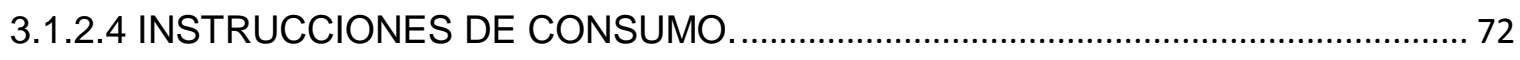

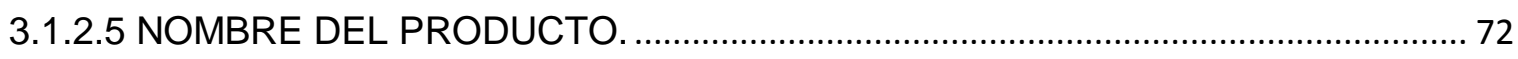

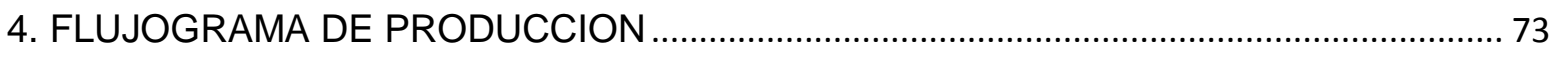

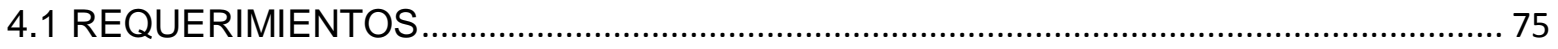

4.1.1 UTENCILIOS DEL PERSONAL (SEGURIDAD INDUSTRIAL) .................................... 81

5.2 LOCALIZACION Y UBICACIÓN DE LA PLANTA........................................................ 85

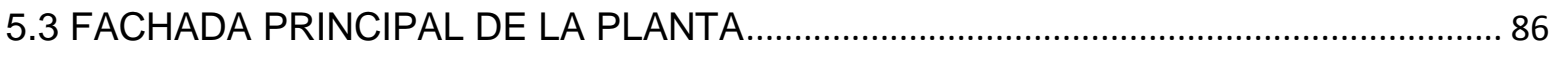

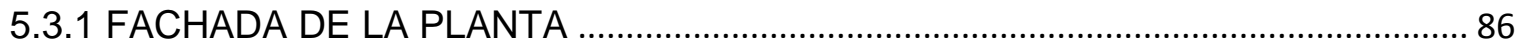

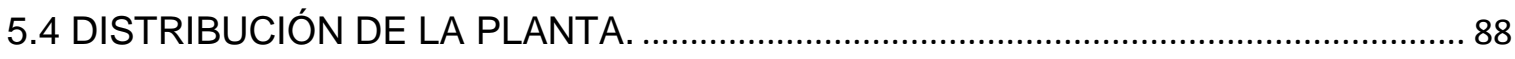

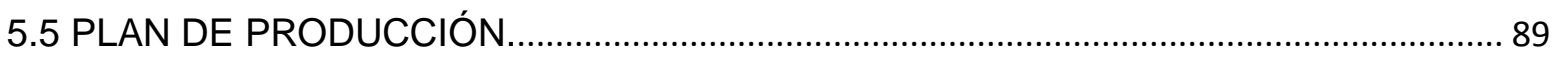

5.5.1 CONTROL DE CALIDAD. .................................................................................... 89

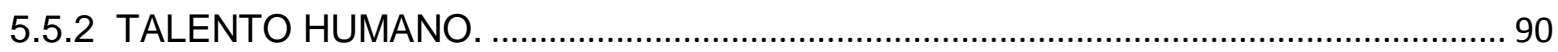

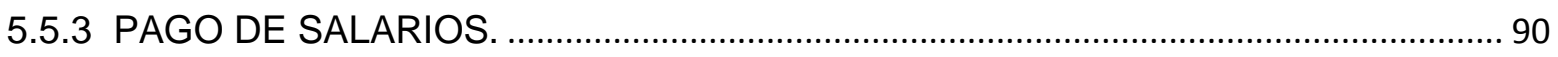

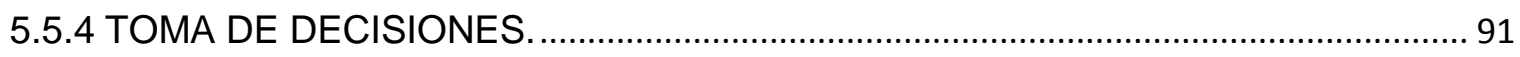

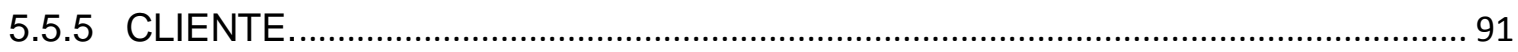

5.5.6 MECANISMO DE COMPRAS (NEGOCIACIONES) ................................................ 92

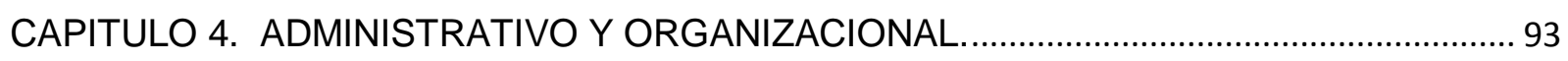

4.1 TIPO DE COMERCIALIZADORA INTERNACIONAL ...................................................... 93

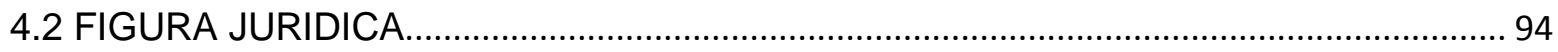

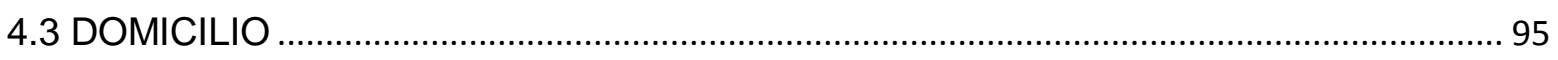

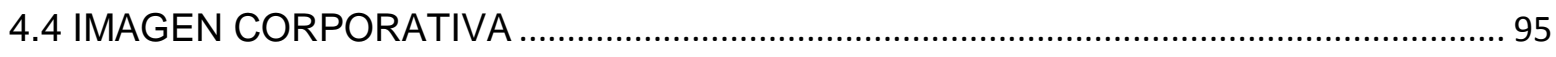

4.5 ESTRUCTURA ORGANIZACIONAL …………………................................................. 96

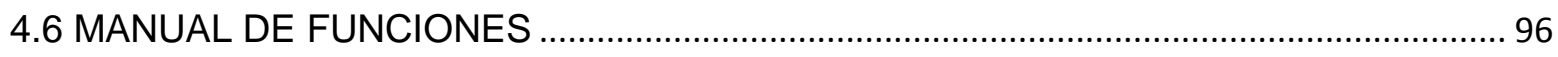

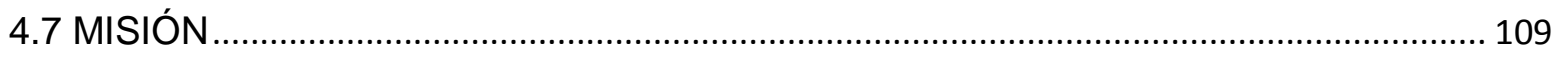

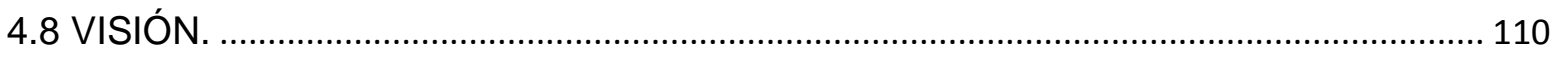

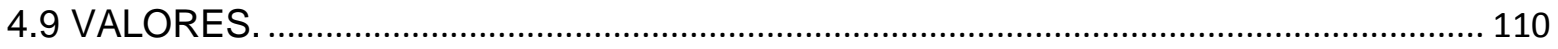




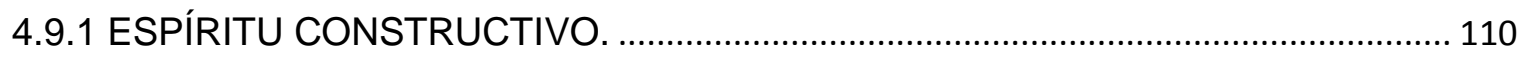

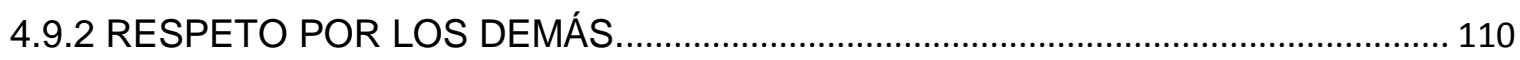

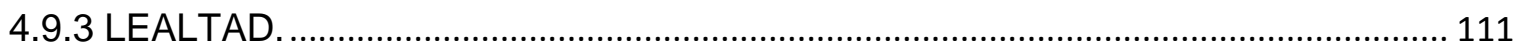

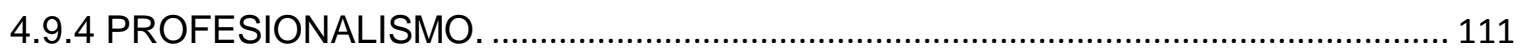

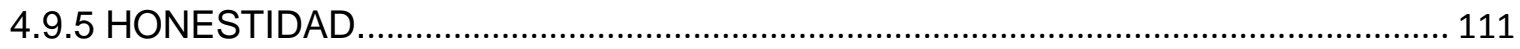

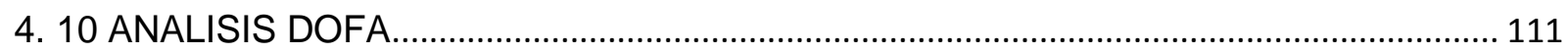

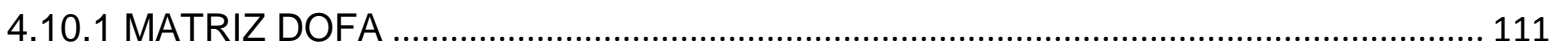

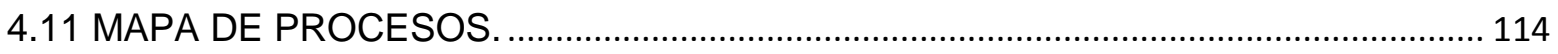

CAPITULO 5. DE EVALUACION ECONOMICA Y FINANCIERA ……………………........... 115

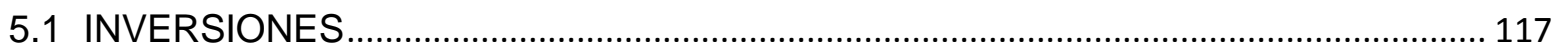

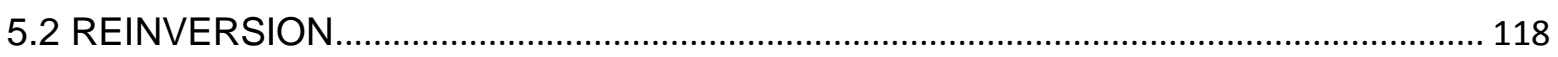

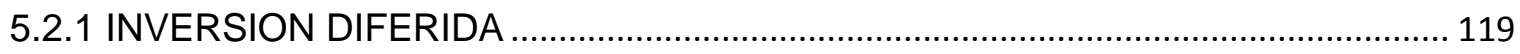

5.3 COSTOS DE INSUMOS ………………………..................................................... 120

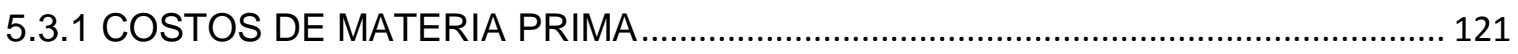

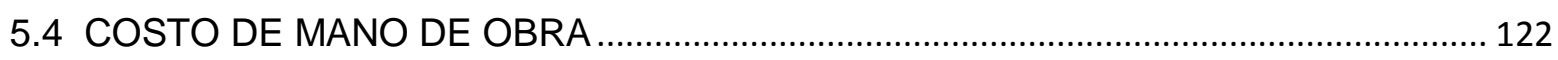

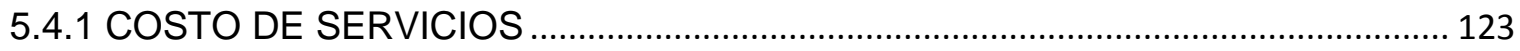

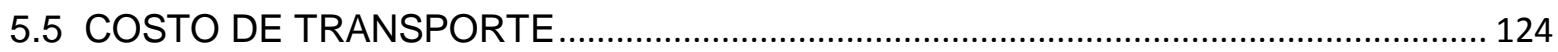

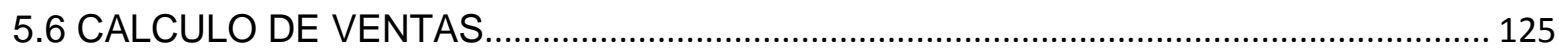

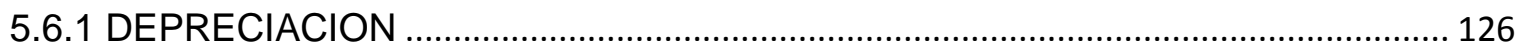

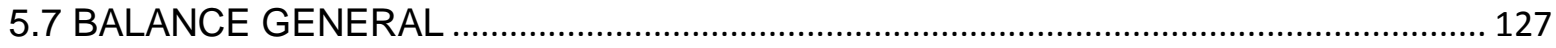

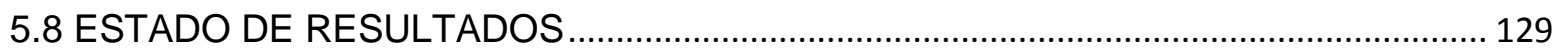

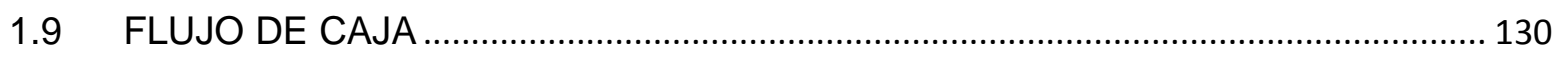

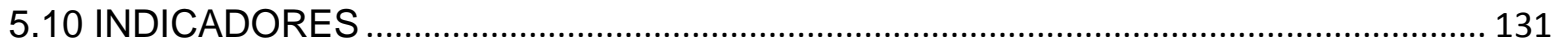

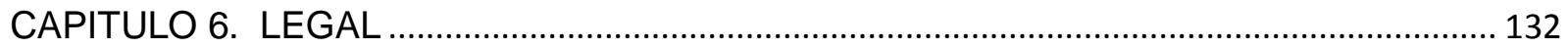

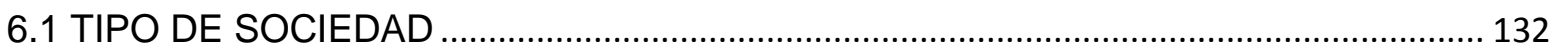

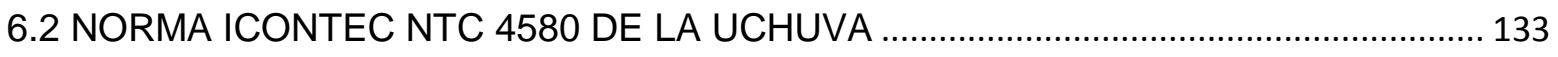

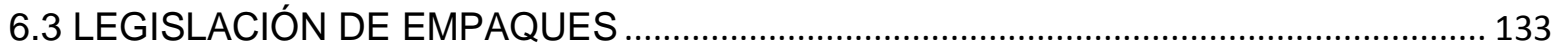

6.4 NORMA DE BUENAS PRÁCTICAS AGRÍCOLAS (BPA) …………............................ 133

6.5 NORMA DE CALIDAD ICONTEC PARA LA UCHUVA. ……………………................ 134

6.6 NORMA SISTEMA DE ANÁLISIS DE PELIGROS Y DE PUNTOS CRÍTICOS DE CONTROL (HACCP) Y DIRECTRICES PARA SU APLICACIÓN …...................................... 135 


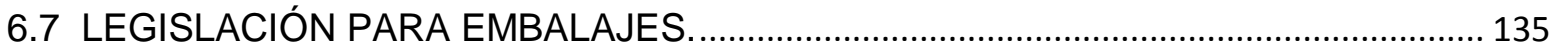

6.8 EL INSTITUTO COLOMBIANO AGROPECUARIO ICA. .............................................. 136

6.9 NORMA BUSINESS ALLIANCE FOR SECURE COMMERCE …………………..... 137

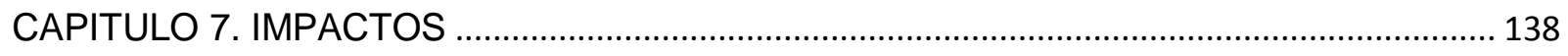

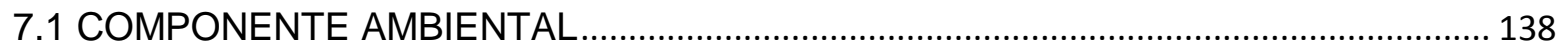

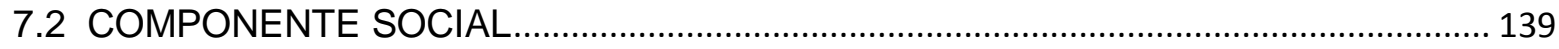

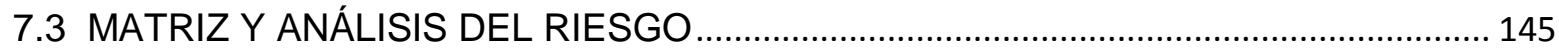

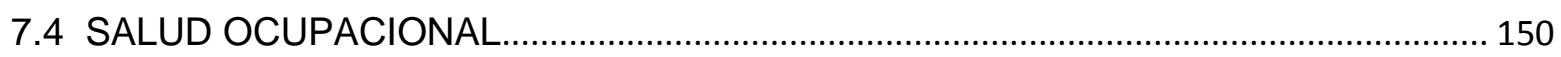

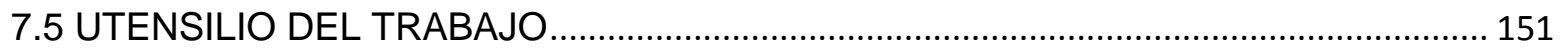

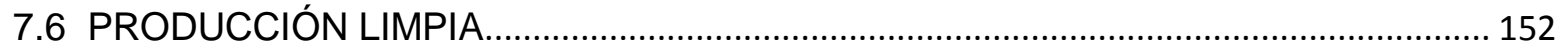

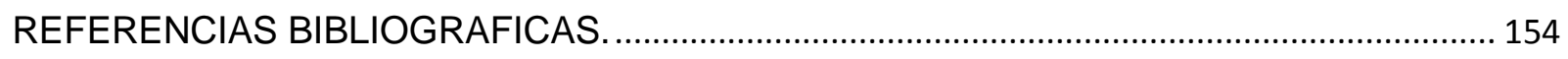

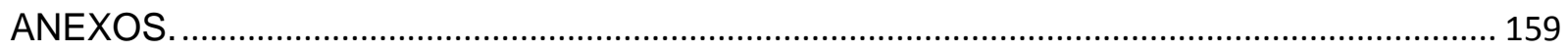

CONCLUSIONES. 


\section{LISTA DE GRAFICOS}

Pág

Grafica1. EXPORTACIONES DE UCHUVA - COLOMBIA ..........................45

Grafica 2. EXPORTACIONES COLOMBIANAS DE UCHUVA .......................45

Grafica 3. EXPORTACION DE UCHUVA EN EL PAIS DE DESTINO ................46

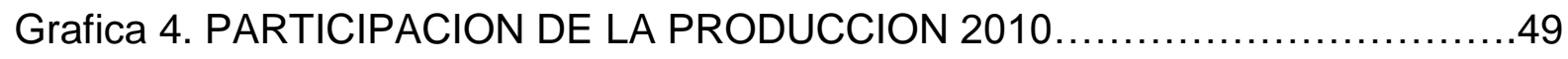

Grafica 5. EXPORTACIONES COLOMBIANAS UCHUVA $\ldots \ldots \ldots \ldots \ldots \ldots \ldots \ldots . \ldots \ldots 7$

Grafica 6. ESTRATEGIAS DE PROMOCION Y PUBLICIDAD ......................67 


\section{LISTA DE FIGURAS}

Pág

Figura 1. CLASIFICACION CIENTIFICA DE LA UCHUVA ..........................33

Figura 2. CANAL DE DISTRIBUCION PARA LA EXPORTACION ....................71

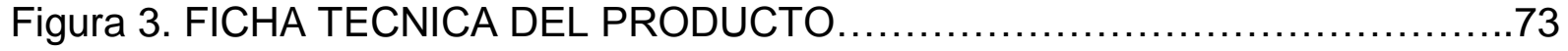

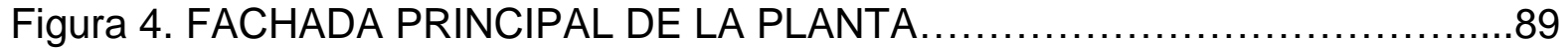

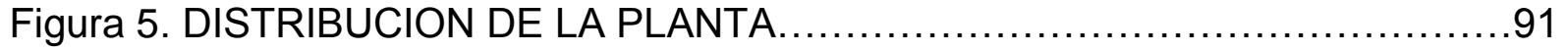

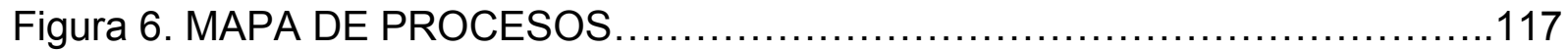




\section{LISTA DE CUADROS}

Pág.

Cuadro 1. PRINCIPALES EMPRESAS EN EL SECTOR FRUTICOLA ................59

Cuadro 2. ASOCIACIONES BOYACENCES DE PRODUCTORES DE UCHUVA....62

Cuadro 3. COMPETENCIA DEPARTAMENTAL ...................................65

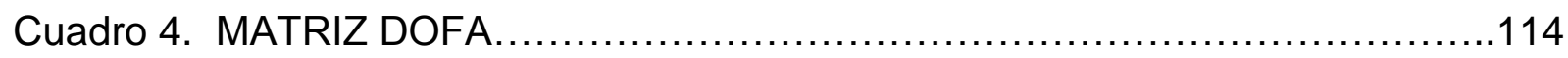

Cuadro 5. PLANES DE MITIGACION........................................144

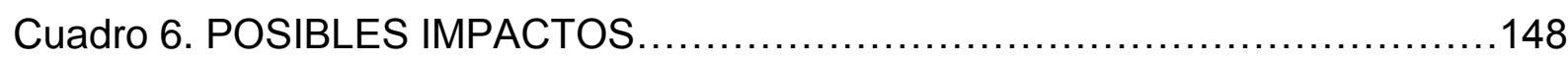

Cuadro 7. ANALISIS Y RIESGOS DE MATERIAS PRIMAS .........................149

Cuadro 8. ANALISIS DE RIESGOS EN EL PROCESO DE PRODUCTIVO ...........151

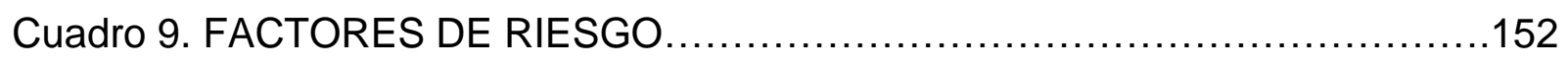

Cuadro 10. MEDIDAS DE CONTROL ................................................153 


\section{LISTA DE TABLAS}

Pág

Tabla1 .PRINCIPALES ASOCIACIONES DE PRODUCTORES DE UCHUVA EN

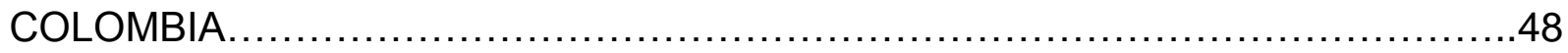

Tabla 2. MATRIZ DE PRESELECCION DE MERCADOS DE EXPORTACION...... 51

Tabla 3. MAQUINARIA, EQUIPOS HERRAMIENTAS Y UTENSILIOS ................78

Tabla 4. UTENSILIOS DEL PERSONAL. ......................................... 84

Tabla 5. MANUAL DE FUNCIONES................................................. 99

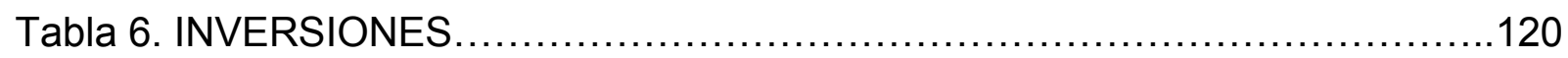

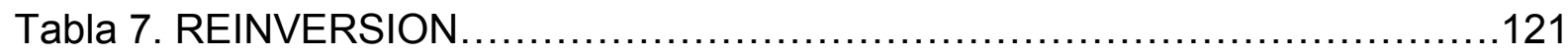

Tabla 8. INVERSION DIFERIDA...............................................

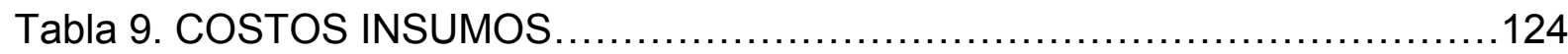

Tabla 10. COSTOS MATERIA PRIMA .............................................

Tabla 11. COSTOS MANO DE OBRA ............................................126

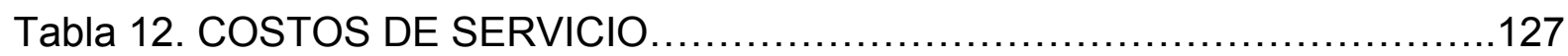

Tabla 13. COSTOS DE TRANSPORTE ..........................................

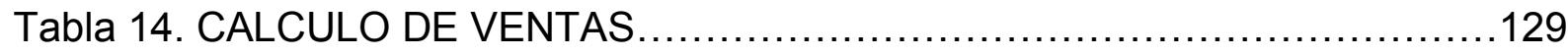




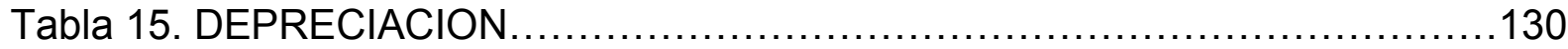

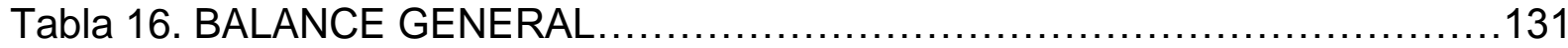

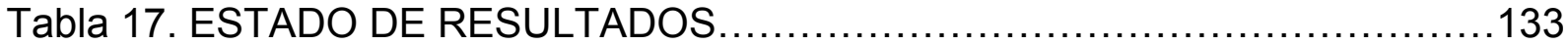

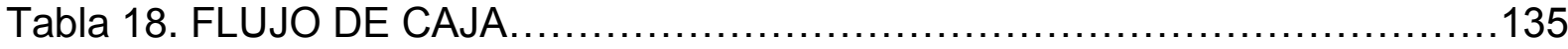

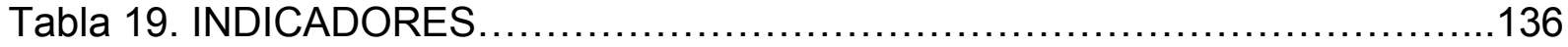




\section{LISTA DE MAPAS}

Pág

Mapa 1. ARCABUCO -BARRANQUILLA ........................................ 72

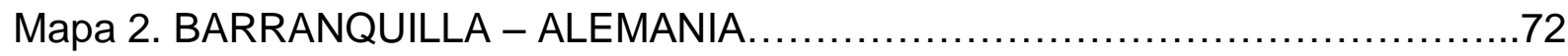

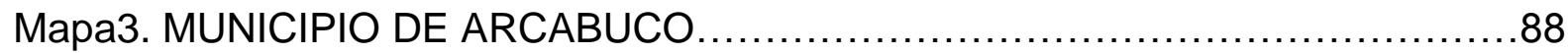




\section{LISTA DE FOTOS}

Pág

Foto 1. FACHADA DE LA BODEGA ACTALMENTE ................................ 89

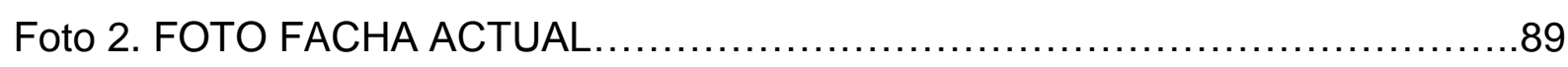




\section{INTRODUCCIÓN}

La uchuva considerada una fruta oriunda de los Andes, con origen Americano, posee excelentes propiedades nutricionales y ante todo, curativas. Se le conoce con nombres como los de uvilla, guchuva, vejigon, topetorope, aguaymanto, alquequenje, topo- topo, cupali, poga poga, tomate silvestre, tomatillo, 'cape gooseberry' ( en inglés), judaskirsche en Alemania y coqueret du perou, en Francia.

El departamento de Boyacá, como uno de los mayores productores de esta exótica fruta, cuenta con un gran potencial de exportación, destacándose para ello municipios como Ventaquemada, San miguel de Sema, Tuta, Ramiriqui, Ciénega y Santa Sofía donde se ha identificado la oportunidad de aprovechar mejor la producción de uchuva cultivada en la región dándole gran importancia a este fruto en el mercado extranjero ya que en el mercado nacional no se está aprovechando como debería, puesto que los productores no están capacitados o preparados para la internacionalización del producto, simplemente se conforman con el mercado nacional y no tienen una visión que podría llegar a obtener mayor rentabilidad en sus empresas, ingresos más altos y así mejorar su calidad de vida. 
El presente documento de plan de negocios expone los aspectos más importantes encaminados a la creación de una comercializadora internacional de uchuva convencional en fresco, toda vez que se cuenta con ventajas tan importantes como las de que su cultivo y producción en el municipio de Arcabuco Boyacá que se realizó con el fin de conocer los beneficios de la uchuva y sobre todo la acogida que esta tiene en el mercado extranjero, destacando así los altos estándares de calidad exigidos por dicho mercado. Se señalara un método de selección de la fruta, su empacado, y distribución hasta llegar a su consumidor final como lo es el mercado extranjero.

El presente estudio se constituye en un aporte importante para el desarrollo agrícola de la región, en cuanto desataca las potencialidades que tienen nuestros productos agrícolas en el mercado internacional. Así mismo establece posibilidades de mejora de los ingresos y la calidad de vida del municipio de Arcabuco y de pequeños productores del departamento de Boyacá. 


\section{RESUMEN EJECUTIVO}

\section{CAPITULO 1. GENERALIDADES DE LA INVESTIGACION}

La falta de una visión emprendedora que identifique las oportunidades que brinda el sector agroindustrial y haciendo un análisis de la situación regional y departamental podemos ver que en Boyacá gracias a sus terrenos aptos para el cultivo de uchuva es un departamento que puede aportar gran cantidad de producción de la misma para ser comercializada en el exterior con altos estándares de calidad y así obtener mayor rentabilidad mejorando a su vez la calidad de vida para cada una de las familias boyacenses.

\section{CAPITULO 2. MERCADOS}

En el presente capítulo se abordan los siguientes temas, donde se realiza un análisis del sector, segmentos del mercado de la uchuva, la estructura actual del mercado, estimación del mercado potencial, importaciones y exportaciones de la uchuva.

En este capítulo se puede observar además que la uchuva se encuentra dentro de la cadena hortofrutícola siendo así la uchuva la fruta más competitiva frente a las 
demás, adicionalmente se destaca como una de las más apetecidas por el mercado extranjero por tratarse de una fruta exótica.

\section{CAPITULO 3. TECNICO Y OPERATIVO.}

En este módulo se describen todas las características técnicas del producto, dentro de ellas encontramos: Ubicación de la planta, diseño de planta, procesos de producción, mapa de procesos, necesidades y requerimientos en maquinaria, plan de producción, costo de materia prima precios actuales, plan de compras, consumo de materia prima por unidad por producto.

\section{CAPITULO 4. ADMINISTRATIVO Y ORGANIZACIONAL.}

El módulo de organización contiene el análisis de debilidades, oportunidades, fortalezas y amenazas que se identifican en el producto, la estructura organizacional donde describe los niveles directivos, administrativos y operativos con su manual de funciones. Igualmente los aspectos legales para la constitución de la empresa el tipo de sociedad que se conformaría y normas que regulan la actividad económica. 


\section{CAPITULO 5. DE EVALUACION ECONOMICA Y FINANCIERA.}

En este capítulo se encontrara el estado de resultados, el balance general los cuales serán analizados como fuente de información primordial para que los directivos de la empresa tomen decisiones con relación a la información que se encuentran en los balances lo cual permitirá un mejor entendimiento de los movimientos de la organización.

CAPITULO 6. LEGAL

El tipo de empresa que se escogió para este proyecto fue el de una comercializadora internacional ya que tiene varios beneficios, los cuales dentro de este serán vistos y desarrollados en este capítulo, así como se verán los permisos, licencias y requisitos que se necesitan a la hora de la exportación. 
CAPITULO 7. IMPACTOS.

Este módulo muestra como tal el fin de las metas propuestas a nivel social de la empresa constituida, con la ayuda de la salud ocupacional que se entornara dentro de la planta, el impacto social y el impacto ambiental que tendrá la misma. 


\section{CAPÍTULO 1. GENERALIDADES DE LA INVESTIGACION}

\subsection{PLANTEAMIENTO DEL PROBLEMA}

La falta de una visión emprendedora que identifique las oportunidades que brinda el sector agroindustrial lleva a que la uchuva se encuentre en el mercado de la región en su forma natural sin ninguna transformación y se está desaprovechando la oportunidad de comercializarla y exportarla no solo en fresco con las exigencias del mercado internacional y con valor más significativo, esto hace que exista un aumento del desempleo y pobreza por la ausencia de oferta laboral que ayude al mejoramiento de los ingresos de las familias boyacenses y así mejorar su bienestar.

Haciendo una análisis de la situación regional y departamental se encuentra que en Boyacá son muy pocas las empresas que se dedican a la exportación de uchuva ya que esto ayuda a obtener los altos estándares de calidad exigidos por el mercado extranjero.

Boyacá ha sido destacado como un departamento productor de uchuva y en gran cantidad debido a su calidad de terrenos aptos para el cultivo de esta fruta y a pesar de ello no se aprovecha de forma adecuada este recurso y se comercializa 
como se extrae de la planta cuando debería seleccionarse y empacarse de tal manera que sea mejor recibida en el mercado extranjero y así obtener una mejor rentabilidad.

Actualmente el $80 \%$ de la producción de uchuva se exporta al mercado extranjero, el $15 \%$ se queda en el mercado local y el $5 \%$ se pierde, estas cifras demuestran que la uchuva colombiana tiene una gran acogida en el mercado internacional ${ }^{1}$. Es muy importante generar valor agregado con el procesamiento de esta fruta ya que se busca que el mercado nacional y extranjero conozca un producto procesado listo para el consumo y hecho en Colombia.

Según datos de agosto de 2011 de la Secretaria de Fomento Agropecuario, dirección de mercadeo (ver cuadro1). ${ }^{2}$ En el departamento de Boyacá las plantas sembradas se aproximan a las 276.000 con una producción total de 3.450 toneladas anuales. En su gran mayoría se exportan a mercados internacionales en fresco sin ningún valor agregado y el restante es para el consumo nacional.

\footnotetext{
${ }^{1}$ http://repository.lasalle.edu.co/bitstream/10185/5146/1/12002004.pdf

2 Secretaria de fomento agropecuario, dirección de mercadeo Gobernación de Boyacá “ óscar González"
} 


\subsubsection{SISTEMATIZACIÓN DEL PROBLEMA.}

¿Qué tan factible, viable y rentable es la creación de una comercializadora internacional de Uchuva convencional en fresco en el Municipio de Arcabuco Boyacá?

\subsection{JUSTIFICACIÓN.}

Hoy en día en el departamento de Boyacá, la uchuva es uno de los productos cultivados por las familias campesinas en varios municipios dentro de estos se destacan, Ramiriqui, Ciénega, Ventaquemada siendo estos los que más aportan producción al departamento en cuanto a esta fruta, los siguen municipios como Sanmiguel de Sema, Floresta, Umbita, Arcabuco, Soraca, Santa Sofía, Villa de Leyva y Tuta los cuales cumplen con las condiciones favorables que se requieren para su Producción. ${ }^{3}$

La creación de una comercializadora internacional de uchuva se convierte en una oportunidad en el sector agroindustrial de procesar la fruta para ofrecer al consumidor un producto con altos estándares de calidad.

La uchuva es una fruta exótica que posee propiedades curativas y nutricionales y con un valor agregado como lo es su selección, hace que el producto sea

\footnotetext{
${ }^{3}$ Fuente: Secretaría de Fomento Agropecuario - Dirección de Mercadeo.AUTOR: AMELIA CEPEDA MORA
} 2009. 
más atractivo. Se busca cubrir el segmento de mercado Alemán donde se dará a conocer el producto a quienes serán nuestros consumidores finales, ya que es un país donde se prefieren las frutas exóticas especialmente las que provienen de Colombia.

El presente plan de negocios para la creación de una comercializadora internacional de uchuva en fresco, se constituye en el municipio de Arcabuco una excelente oportunidad para de una parte, darle un valor agregado a la producción de uchuva y de otra, poner en práctica los conocimientos adquiridos en la carrera de Administración de Empresas.

El plan de negocio permitirá que un grupo de pequeños productores mejoren sus ingresos y vean la oportunidad de transformar sus productos, ofrecerlos al mercado y así motivarlos a tener una visión emprendedora para que así identifiquen las ventajas que brinda el sector agroindustrial, ya que la región ofrece fácil acceso a las materias primas y esto disminuye costos generando mayor rentabilidad a la empresa. 


\subsection{OBJETIVOS.}

\subsubsection{OBJETIVO GENERAL.}

Elaborar un Plan de Negocio por medio del cual se evidencia la factibilidad, viabilidad y rentabilidad frente a la creación de una comercializadora internacional de Uchuva en fresco en el Municipio de Arcabuco Boyacá.

\subsubsection{OBJETIVOS ESPECÍFICOS.}

- Realizar un estudio de mercado estableciendo condiciones de oferta y demanda para el producto

- Hacer un estudio técnico que determine la disponibilidad de maquinaria, materia prima y mano de obra

- Determinar la estructura organizacional y administrativa, tipo de sociedad que se implementara y aspectos legales a seguir.

- Realizar el estudio administrativo, legal, social, ambiental pertinente

- Realizar un estudio financiero que permita establecer la rentabilidad del proyecto y determinar punto de equilibrio 


\subsection{MARCO TEORICO.}

\subsubsection{ANTECEDENTES DEL PLAN DE NEGOCIO.}

\subsubsection{DESCRIPCION DEL PRODUCTO.}

El aguaymanto o uchuva, (Physalis peruvianaL.) pertenece a la familia de las solanáceas, por lo tanto posee características similares a la familia de la papa, el tomate y el tabaco, aun cuando su crecimiento es arbustivo.

\subsubsection{CLASIFICACIÓN CIENTÍFICA.}

Figura 1. CLASIFICACION CIENTIFICA DE LA UCHUVA

\begin{tabular}{ll|}
\hline & Physalis peruviana \\
& Clasificación científica \\
Reino: & Plantae \\
División: & Magnoliophyta \\
Clase: & Magnoliopsida \\
\hline
\end{tabular}




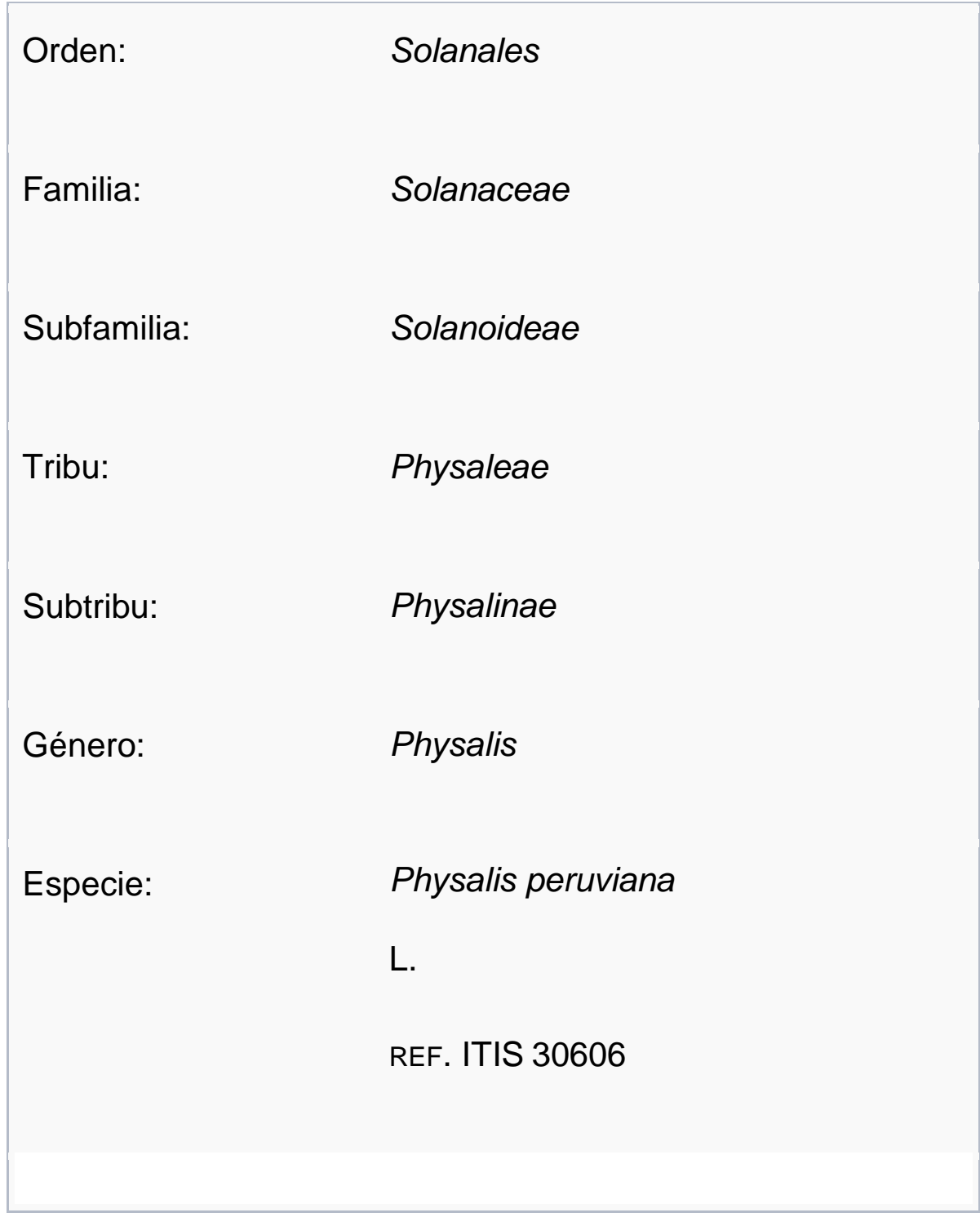

Fuente: Tomado de la página http://es.wikipedia.org/wiki/Physalis peruviana 


\subsubsection{DESCRIPCIÓN DE LA FRUTA.}

Posee una fruta redonda, amarilla, dulce y pequeña (entre 1,25 y $2 \mathrm{~cm}$ de diámetro). Se puede consumir sola, en almíbar, postres y con otras frutas dulces. Su estructura interna es similar a un tomate en miniatura

El arbusto de la uchuva se caracteriza por ser ramificado de ramaje caído, y normalmente crece hasta un metro de altura, aunque si se estaca, poda y se le da un buen cuidado esta planta puede llegar a los dos metros de altura. Posee flores amarillas y con forma de campana que son fácilmente polinizadas por insectos y el viento.

\subsubsection{ORIGEN.}

Es una fruta originaria de América, donde se conocen más de 50 especies en estado silvestre. Aunque se conoce desde épocas precolombinas y es un alimento silvestre tradicional en zonas andinas, fue descrita en tiempos modernos en la región de Tierra dentro, departamento del Cauca, Colombia y su primer cultivo en la zona fue a escala semicomercial.

Hoy ha conquistado importantes mercados en la Unión Europea y Estados Unidos. Sus principales consumidores son Inglaterra y Alemania. Actualmente se cultiva en Perú, Colombia, Ecuador, California, Sudáfrica, Australia, Kenia, India, Egipto, el Caribe, Asia y Hawái. 


\subsubsection{ATRIBUTOS DE LA UCHUVA.}

Se caracteriza por ser una excelente fuente de provitamina A (3.000 I.U. de caroteno por 100 g) y vitamina C. También posee algunas del complejo de vitamina B. Además la proteína $(0,3 \%)$ y el fósforo (55\%) que contiene son excepcionalmente altos para una fruta.

Actualmente, tiene un importante uso con fines terapéuticos, pues según los expertos ayuda a purificar la sangre, tonifica el nervio óptico y alivia afecciones bucofaríngeas. Se recomienda para personas con diabetes de todo tipo, favorece el tratamiento de las personas con problemas de la próstata gracias a sus propiedades diuréticas y además es utilizada como tranquilizante natural por su contenido de flavonoides, sirve también para control de amibiasis.

Según investigaciones por ser digestivo, ayuda a prevenir cáncer del estómago, colon y del intestino. ${ }^{4}$

${ }^{4}$ http://es.scribd.com/doc/60586337/25/Atributos-de-la-uchuva. 


\subsubsection{BENEFICIOS EN LA SALUD.}

El fruto de la uvilla tiene un sabor dulce, posee propiedades nutricionales importantes, entre las que se puede mencionar las siguientes: reconstruye y fortifica el nervio óptico; elimina la albúmina de los riñones; ayuda a la purificación de la sangre; eficaz en el tratamiento de las afecciones de la garganta; adelgazante, se recomienda la preparación de jugos, infusiones con las hojas y consumo del fruto en fresco; ideal para los diabéticos, consumo sin restricciones; aconsejable para los niños, porque ayuda a la eliminación de parásitos intestinales (amebas); favorece el tratamiento de las personas con problemas de próstata, por sus propiedades diuréticas y constituye un excelente tranquilizante debido al contenido de flavonoides. ${ }^{5}$

\subsubsection{PROPIEDADES MEDICINALES DE LA UCHUVA,}

La uvilla posee propiedades medicinales importantes, entre las que se puede mencionar las siguientes:

- Reconstruye y fortifica el nervio óptico.

- Elimina la albúmina de los riñones.

${ }^{5}$ http://co.globedia.com/uvilla-uchuva-fruta-grandes-beneficios-salud-belleza. 
- Ayuda a la purificación de la sangre.

- Eficaz en el tratamiento de las afecciones de la garganta.

- Adelgazante, se recomienda la preparación de jugos, infusión es con las hojas y consumo del fruto en fresco.

- Ideal para los diabéticos, consumo sin restricciones.

- Aconsejable para los niños, porque ayuda a la eliminación de parásitos intestinales (amebas).

- Favorece el tratamiento de las persona con problemas de próstata por sus propiedades diuréticas.

- Constituye un excelente tranquilizante debido al contenido de flavonoides. ${ }^{6}$

${ }^{6} \mathrm{MAG}, 2006$. 


\subsubsection{DIFERENTES FORMAS DE CONSUMO.}

La uchuva se puede consumir fresca, sola o en ensaladas, dándole un toque agridulce a las comidas. En algunos países como Colombia y Perú ya se está procesando para obtener productos como mermelada, yogurt, dulces, helados, conservas enlatadas y licores. También sirven de elemento decorativo (de la misma forma que una cereza) para adornar tortas y pasteles.

\subsubsection{OTROS PRODUCTOS DERIVADOS DE LA UCHUVA.}

\subsubsection{MERMELADAS.}

Estos productos se pueden elaborar a partir de una fruta fresca y pulpas, son pastosos y fluidos, se permite en él, la presencia de trozos o frutas enteras.

Se le agrega azúcar y se permite la adición de otras sustancias como pectinas (la cual permite que el producto tenga más consistencia), colorantes, saborizantes y sustancias preservantes (que alargan el tiempo de vida útil del producto).

Las mermeladas se obtienen a partir de concentración de la pulpa por medio del calor. Como son concentrados no tienen gran cantidad de agua pero si gran cantidad de azúcar, esto contribuye a que no se desarrollen en ellas los microorganismos; Se puede conservar en temperatura ambiente de $14^{\circ} \mathrm{C}$ a $18^{\circ} \mathrm{C}$. 
Nota: Si el producto se elabora sin observar mínimas normas de higiene se puede contaminar. $^{7}$

\subsubsection{ALMIBAR.}

\subsection{INGREDIENTES.}

1 Libra de uchuvas.

1 Libra de azúcar morena.

1 taza de agua.

Hervir en agua por dos minutos para quitar el sabor amargo.

Prepare un almíbar con una libra de azúcar morena y una taza de agua.

Cuando empiece a espesar, agregue la fruta y déjela a fuego lento por 15 minutos. $^{8}$

\footnotetext{
${ }^{7}$ Guía de procesos para la elaboración de néctares, mermeladas uvas pasas y vinos .diana Ximena Suarez Moreno año 2003. Editorial convenio Andrés Bello.

${ }^{8}$ http://www.colombiaexport.com/frutexpo/Uchuva.htm.
} 


\section{CAPITULO 2. MERCADOS}

\subsection{ANÁLISIS DEL SECTOR}

En el presente capitulo se abordan los siguientes temas, donde se realiza un análisis del sector, segmentos del mercado de la uchuva, la estructura actual del mercado, estimación del mercado potencial, importaciones y exportaciones de la uchuva.

En los últimos años, el comportamiento de la cadena Hortofrutícola ha sido bastante favorable, ya que según el Acuerdo de Competitividad de Productos Hortofrutícolas Promisorios Exportables de Colombia, firmado en el 2001, los frutales de exportación son aquellos que se constituyen en productos promisorios exportables de primera generación, debido a que presentaron los mayores niveles de ventas al exterior durante el año 2000, sirviendo de base para la firma del acuerdo. Dentro de estos productos se tiene un conjunto conformado por seis frutas: banano bocadillo (ó bananito), mango, granadilla, pitahaya, tomate de árbol y uchuva siendo la uchuva uno de los más competidores frente a los otros productos, adicionalmente se destaca que esta fruta es una de las más apetecidas en el mercado extranjero por tratarse de una fruta exótica.

El área cosechada de frutas frescas no ha mostrado una gran expansión en el ámbito mundial y por lo tanto la oferta no ha cambiado de manera significativa. Además, el comercio es bajo con respecto a la producción, lo que indica que en cada país la mayor parte de la producción de frutas se dirige hacia el mercado 
interno, sobre todo porque se trata de productos perecederos y relativamente nuevos en el mercado. Sin embargo, con las nuevas tendencias del consumo mundial, donde las preferencias se dirigen hacia alimentos frescos, sanos e inocuos que tengan un alto contenido de vitaminas, proteínas y fibra, se espera que estos productos presenten una amplia expansión de su demanda, sin embargo, aunque los productos exóticos colombianos se encuentran dentro de las nuevas preferencias del consumo mundial por ser productos novedosos, convenientes, inocuos y con altas calidades nutricionales, el desempeño de los frutales promisorios ha sido lento, difícil y muy fluctuante, con bajos volúmenes y poca continuidad, insuficiente para posicionarse como los más consumidos del mundo y también posicionar el país y así lograr el desarrollo de una verdadera diversificación exportadora del sector Frutícola.

La alta dispersión de la producción exportable, revela la falta de núcleos productivos regionales que permitan el desarrollo de economías de escala y el aprovechamiento de externalidades.

Las exportaciones de bananito, mango, granadilla, pitahaya, tomate de árbol y uchuva, representaron el $3.8 \%$ del total de frutas vendidas por Colombia al exterior en el año $2003^{9}$.

Si a este total se le descuentan las exportaciones de banano y plátano (que constituyen el $95 \%$ del valor exportado), tan sólo los seis productos promisorios

\footnotetext{
${ }^{9}$ http://www.asohofrucol.com.co/archivos/Cadenas/caracterizacion frutales exporta 2005.pdf
} 
exportables, representan el $88.8 \%$, revelando su gran importancia económica en la canasta exportadora de frutas frescas. A pesar del balance productivo y comercial positivo de la canasta de frutas promisorias exportables, en la práctica su inserción en los mercados internacionales presenta obstáculos debido a que no se cuenta con una oferta permanente y significativa, lo que se traduce en volúmenes exportados menores a los que potencialmente pueden ser demandados y precios más altos que los de otros productos.

Los productos promisorios exportables de primera generación, como se anotaba, fueron aquellos que después del banano presentaron los mayores niveles de ventas al exterior durante el año 2000, y según se definió en el acuerdo de competitividad de productos Hortofrutícolas Promisorios Exportables de Colombia son: Banano bocadillo (ó bananito), mango, granadilla, pitahaya, tomate de árbol y uchuva $^{10}$

Según datos del Ministerio de Agricultura, la producción del sector de frutas frescas en Colombia ${ }^{11}$ en el año 2002 alcanzó un valor de \$757.311 millones de pesos de 1994 y se observa una creciente participación de estos productos en el

\footnotetext{
${ }^{10}$ En el "Acuerdo de competitividad de productos hortofrutícolas promisorios exportables en Colombia, 2001", se distingue entre productos promisorios exportables de primera generación, a la cual pertenecen las seis frutas mencionadas y productos promisorios exportables de segunda generación, que incluye todas las demás frutas y hortalizas que potencialmente podría exportar Colombia y a las cuales pretenden hacerse extensivas en el largo plazo las líneas estratégicas de acción del acuerdo. Secretaría Técnica: Corporación Colombia Internacional, Bogotá, diciembre de 2001.

${ }^{11}$ Aquí se incluyen las siguientes frutas: aguacate, badea, banano, banano de exportación, borojó, brevo, caducifolios, chirimoya, chontaduro, ciruela, cítricos, coco, curuba, dátiles, durazno, feijoa, fresa, granadilla, guanábana, guayaba, higo, limón, lulo, macadamia, mamoncillo, mandarina, mango, manzana, maracuyá, melón, mora, morón, naranja, níspero, papaya, papayuela, patilla, pera, piña, pitahaya, sagú, tamarindo, tomate de árbol, uchuva, uva y zapote.
} 
total de la agricultura sin café, pasando de participaron con el $6 \%$ en 1990 al $15 \%$ en el 2002. Esto se debe a la mayor dinámica de crecimiento del valor de la producción exhibida por los frutales (3.8\%) con respecto al total agrícola sin café cuya tasa de crecimiento fue apenas de $1.3 \%$ durante la década de los noventa. Asimismo en el 2003 el sector de frutas frescas generó un total de 109.572 empleos directos.

\subsection{COMPORTAMIENTO DEL PRODUCTO A NIVEL INTERNACIONAL}

La uchuva originaria de los Andes Suramericanos, es la especie más conocida de este género y se caracteriza por tener un fruto azucarado y con un buen contenido de vitamina $\mathrm{A}$ y $\mathrm{C}$, además de hierro y fósforo. Se cultiva en países tropicales, subtropicales e incluso templados. ${ }^{12}$

\subsubsection{PRINCIPALES PAÍSES PRODUCTORES}

Los países productores de la uchuva en el mundo están entre Perú, chile y el líder es Colombia. ${ }^{13}$ Colombia lidera esta producción por su alta tecnología en esta clase de cultivos está siendo apoyada por programas del gobierno en los diferentes departamentos de Colombia. ${ }^{14}$

\footnotetext{
${ }^{12}$ http://www.finagro.com.co/html/i portals/index.php?p origin=internal\&p name=content\&p id=MI286\&p options=

${ }^{13}$ http://ricasuchuvas.galeon.com/

${ }_{14}$ http://www.slideshare.net/guest289e51/proyecto-uchuva?from search=2
} 
Grafico No 1. EXPORTACIONES DE UCHUVA - COLOMBIA

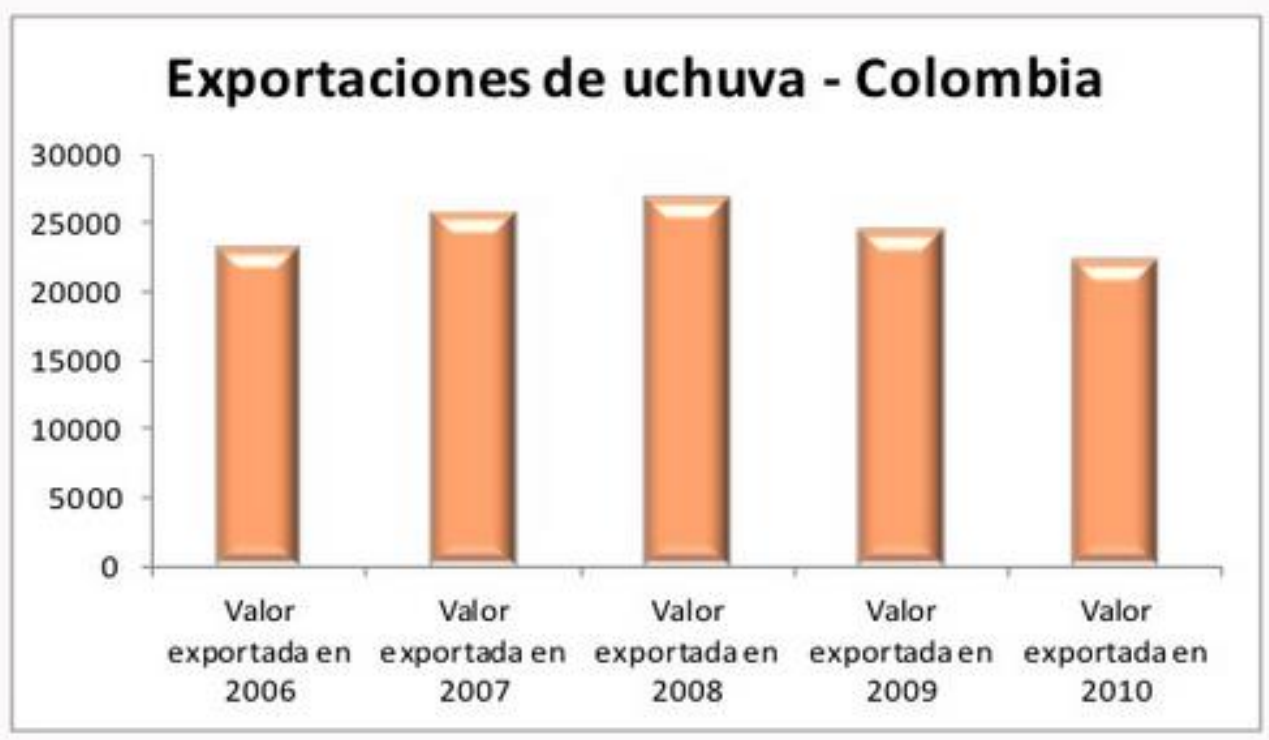

Fuente: Tomado de la pagina http://www.slideshare.net/guest289e51/proyecto-uchuva?from search=2

\section{Grafico No 2. EXPORTACIONES COLOMBIANAS DE UCHUVA \\ Exportaciones colombianas de uchuva}

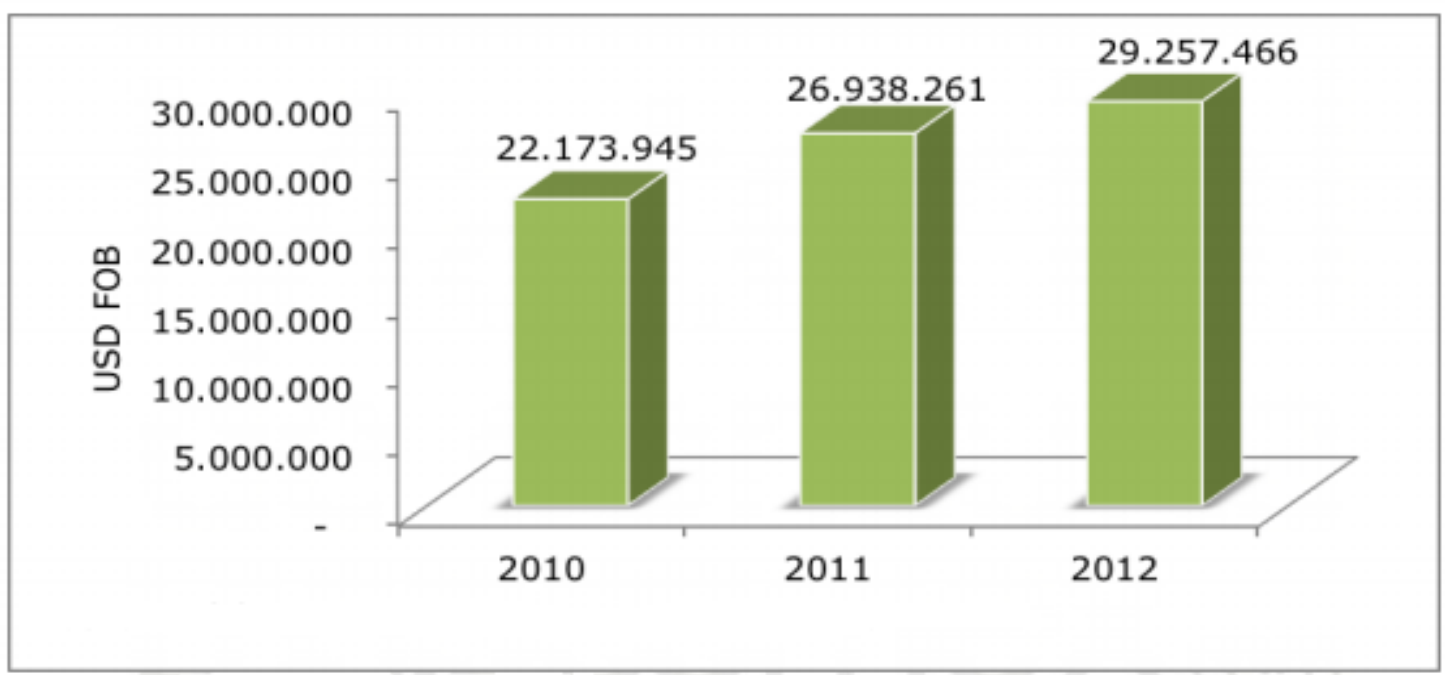

Fuente: Tomado de la pagina

http://www.legiscomex.com/BancoMedios/Documentos\%20PDF/exportaciones-estudio-frutas-

exoticas.pdf. 


\subsubsection{PAÍSES IMPORTADORES}

Entre los principales países que compran esté producto están: Holanda, Alemania, Francia, Inglaterra, España, Bélgica, Suiza, Canadá y Brasil. ${ }^{15}$

\section{Grafico N 3. EXPORTACION DE UCHUVA EN EL PAIS DE DESTINO}

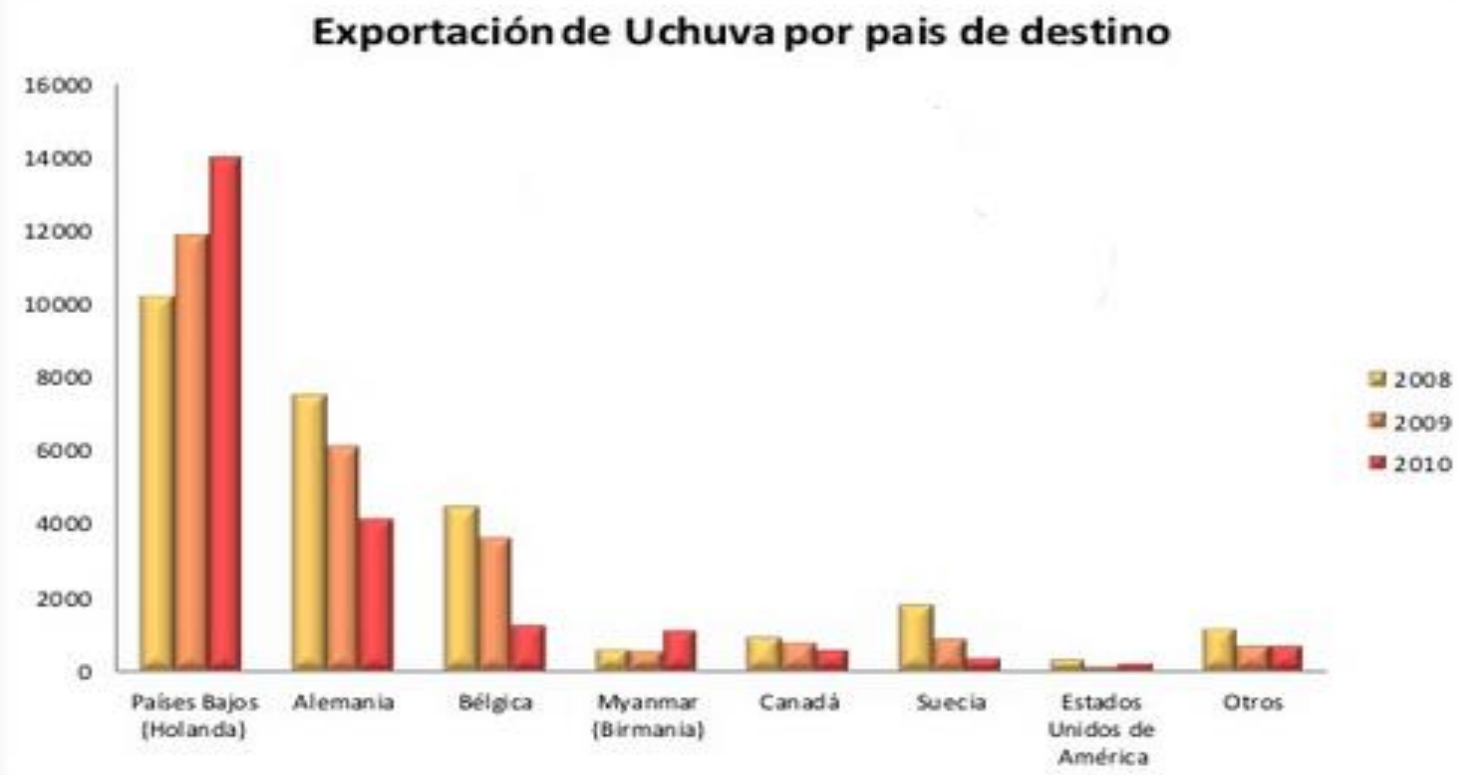

Fuente: Tomado de la pagina http://www.slideshare.net/guest289e51/proyecto-

uchuva?from search=2

\subsubsection{COMPORTAMIENTO DEL SECTOR}

En Colombia la uchuva empezó a ser un cultivo comercial desde la década de los ochenta especialmente desde 1985, cuando este producto comenzó a tener

\footnotetext{
${ }^{15}$ http://www.finagro.com.co/html/i portals/index.php?p origin=internal\&p name=content\&p id=Ml$\underline{286 \& p \text { options }=}$
} 
acogida en los mercados internacionales, donde hoy se comercializa en fresco y procesada.

En la actualidad se encuentran diferentes productos procesados a partir de la uchuva como la mermelada, la uchuva pasa y los confites de uchuva cubiertos de chocolate. Por sus características puede ser procesada para jugo, néctar, pulpa y otros productos con azúcar como el bocadillo.

Teniendo en cuenta que la producción de uchuva a nivel comercial se inició en la última década, la mayoría de productores han iniciado su siembra sin el conocimiento del manejo del cultivo y de la comercialización. El aprendizaje sobre el manejo del cultivo se hace a través de experiencias propias y de los demás productores de la misma zona. En la mayoría de los casos, el productor ha iniciado la siembra de uchuva gracias a la motivación de los cultivadores de la zona, quienes se informan entre sí de las utilidades obtenidas por la fruta en épocas de alta demanda.

A diferencia de los cultivos tradicionales, el productor de uchuva aunque no es empresario, tiene en cuenta aspectos técnicos que le permite obtener una mayor remuneración por su tarea realizada. Teniendo en cuenta que la mayor oferta de uchuva se genera en los mercados internacionales durante los meses de marzo, abril, noviembre y diciembre, el productor de uchuva planea las siembras y la recolección del fruto de tal forma que le permitan obtener una mayor producción en los meses de mayor demanda en el mercado europeo. Adicionalmente, el productor de uchuva reconoce la importancia de la calidad de la fruta y recoge la 
uchuva de acuerdo con las exigencias del consumidor en el mercado internacional; para esto tiene en cuenta el tamaño y color del capacho y de la fruta, así como su apariencia sana, limpia y libre de hongos e insectos.

Con respecto a los aspectos comerciales, se establecen dos tipos de productores: el más común, es el pequeño productor, que vende la fruta durante los meses de alta demanda a intermediarios o exportadores y en los meses de baja demanda tiene dificultades para la comercialización de la fruta. El segundo tipo de productor corresponde al productor de corte empresarial, que cuenta con un mayor grado de preparación y mantiene contratos de compra con las exportadoras, garantizando la venta de uchuva de manera permanente durante todo el año a un precio previamente establecido.

\subsection{PRINCIPALES ASOCIACIONES DE PRODUCTORES EN COLOMBIA}

A continuación se puede observar las principales asociaciones de productores de uchuva en Colombia:

Tabla No 1. PRINCIPALES ASOCIACIONES DE PRODUCTORES DE UCHUVA EN COLOMBIA.

\begin{tabular}{|l|l|}
\hline Departamento & Municipios \\
\hline Antioquia & Rionegro, Santa Rosa, Yarumal, Abejorral, Sonsón \\
\hline Boyacá & Valle de Chiquinquirá, La Candelaria, Villa de Leyva, Duitama, \\
\hline
\end{tabular}




\begin{tabular}{|l|l|}
\hline & Tunja, Paipa, Nuevo Colón \\
\hline Cundinamarca & $\begin{array}{l}\text { Sabana de Bogotá, Funza, Chía, Valle de Ubaté, Gachetá, La } \\
\text { Mesa, Mosquera, Chocontá, Villapinzón }\end{array}$ \\
\hline Cauca & $\begin{array}{l}\text { El Encanto, La Uribe, Gamboa, Piendamó, Toribío, Zona de } \\
\text { Almaquer, Sotará }\end{array}$ \\
\hline Huila & La Argentina, Plata Vieja, Humareda \\
\hline Magdalena & La Sierra Nevada \\
\hline Nariño & Ipiales, Túquerres, Pasto, La Cruz \\
\hline Tolima & Gaitana, Roncesvalles \\
\hline
\end{tabular}

Fuente: Secretaria De Fomento Agropecuario Gobernación de Boyacá. 2009.

\subsubsection{PARTICIPACION DE LA UCHUVA EN EL MERCADO NACIONAL Grafico N 4. PARTICIPACION EN LA PRODUCCION 2010}

\section{PARTICIPACION EN LA PRODUCCION 2010}

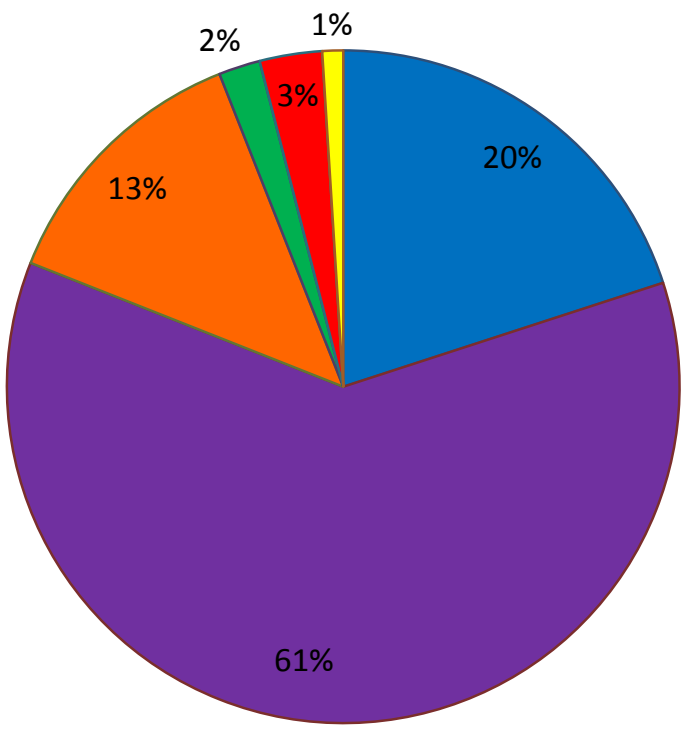

Antioquia

Boyacà

$\square$ Cundinamarca

$\square$ Norte santander

Nariño

$\square$ Cauca 
Fuente: Ministerio de Agricultura: Agronet.

\subsection{ANALISIS DE MERCADO}

En el análisis de mercado se elabora un diagnóstico del mercado objetivo, consumo aparente, consumo per cápita, magnitud de la necesidad y segmentación del mercado para así poder determinar cuál es el mercado objetivo.

\subsubsection{MERCADO OBJETIVO}

El mercado objetivo está dirigido a los consumidores que están ubicados en todo el entorno Alemán teniendo esta una población el 201282.604 .000 habitantes $^{16}$. Ya que va dirigido a los principales supermercados, proponiendo una cultura de consumo de uchuva ya que esta fruta es saludable con alto contenido nutricional, y va ser un producto familiar donde todos van a salir beneficiados.

\footnotetext{
${ }^{16}$ http://www.indexmundi.com/es/alemania/poblacion_perfil.html
} 


\subsubsection{MATRIZ DE PRESELECCIÓN DE MERCADOS DE EXPORTACIÓN}

Tabla $N^{\circ}$ 2. MATRIZ DE PRESELECCIÓN DE MERCADOS DE EXPORTACIÓN.

\begin{tabular}{|c|c|c|c|c|c|c|}
\hline & HOLANDA & ALEMANIA & FRANCIA & $\begin{array}{l}\text { VALOR } \\
\text { HOLANDA }\end{array}$ & $\begin{array}{l}\text { VALOR } \\
\text { ALEMANIA }\end{array}$ & $\begin{array}{l}\text { VALOR } \\
\text { FRANCIA }\end{array}$ \\
\hline POBLACIÓN & $\begin{array}{l}16.570 .000 \\
\text { habitantes }\end{array}$ & $\begin{array}{l}82.604 .000 \\
\text { habitantes }\end{array}$ & $\begin{array}{l}66.007 .374 \\
\text { habitantes }\end{array}$ & 1 & 3 & 2 \\
\hline INFLACIÓN & 2,602 & 2.399 & 2.117 & 1 & 2 & 3 \\
\hline $\begin{array}{ll}\text { PIB } & \text { PER } \\
\text { CAPITA } & \\
\end{array}$ & 134 & 119 & 107 & 3 & 2 & 1 \\
\hline PIB & $\begin{array}{l}\text { 792,128 MIL } \\
\text { MILLONES }\end{array}$ & $\begin{array}{l}3.33 \\
\text { BILLONES }\end{array}$ & $\begin{array}{l}2,647 \\
\text { BILLONES }\end{array}$ & 1 & 3 & 2 \\
\hline PRECIO & $\begin{array}{l}7,05 \\
\text { DOLARES }\end{array}$ & $\begin{array}{l}10.2 \\
\text { DOLARES }\end{array}$ & $\begin{array}{l}9,07 \\
\text { DOLARES }\end{array}$ & 1 & 3 & 2 \\
\hline MONEDA & EURO & EURO & EURO & 2 & 2 & 2 \\
\hline ARANCEL & $15 \%$ & $12 \%$ & $13 \%$ & 3 & 1 & 2 \\
\hline
\end{tabular}




\begin{tabular}{|l|l|l|l|l|l|l|}
\hline & & & & & & \\
\hline Competencia & 2.557 & 1.937 & 835 & 3 & 2 & 1 \\
Colombiana & Toneladas & Toneladas & Toneladas & & & \\
\hline & & & & 15 & 18 & 15 \\
\hline
\end{tabular}

Fuente: Las autoras en base al resultado que arroja el análisis de los datos de la tabla.

\subsubsection{ELABORACION DE LA MATRIZ}

Se buscan los datos más representativos en la economía de cada país y teniendo en cuenta su nivel de importancia se saca el promedio, donde nos arroja el mayor porcentaje de participación como lo es Alemania ya que es un país donde es muy comercializada la uchuva por ser una fruta exótica y preferida por los habitantes del mismo.

\subsubsection{ANALISIS DE MATRIZ Y SELECCIÓN DE MERCADOS A EXPORTAR.}

\subsubsection{SELECCIÓN DEL MERCADO}

PLAN A: MERCADO OBJETIVO: ALEMANIA. 
PLAN B: MERCADO ALTERNO: FRANCIA.

PLAN C: MERCADO CONTINGENTE: HOLANDA. ${ }^{17}$

PAIS A EXPORTAR: ALEMANIA. ${ }^{18}$

El producto se comercializara en los principales supermercados del mercado europeo inicialmente en Alemania ya que en dichos supermercados estará más al alcance de las amas de casa de los mejores restaurantes de la ciudad así los incluirán más fácilmente en su dieta diaria y en la de sus clientes quienes serán los consumidores finales. ${ }^{19}$

Dentro de las grandes cadenas de distribución podemos citar algunas como: El importador-distribuidor Direct Fruit Marketing comercializa productos frescos, frutas tropicales y exóticas procedentes de numerosos países del mundo, incluyendo Brasil, México, Perú, Ecuador, Colombia y Chile y lo suministra a sus clientes sin la mediación de agentes de importación o brokers. Esta compañía está en capacidad de realizar la adecuación de empaques o la presentación del producto de acuerdo con los requerimientos específicos de cada segmento del mercado bien sea de las grandes cadenas de supermercados o de los mayoristas en mercados terminales.

Direct Fruit Marketing e Inter-Wiechert

Trofi-Tropenfruchimporty Edeka

${ }^{17}$ http://eldia.com.do/columnas/2013/6/4/115757/Holanda-en-dificultades

${ }^{18}$ http://www.euroxpress.es/index.php/noticias/2013/6/4/guerra-comercial-ue-china-por-el-mercadoeuropeo-de-paneles-solares/

${ }^{19}$ http://www.invertia.com/noticias/fmi-revisa-baja-prevision-pib-alemania-2866168.htm 
La más grande de estas asociaciones es Markant que realizó compras en 1999 por US\$ 31,9 mil millones.

La cadena Edeka en particular se destaca por ofrecer una amplia gama de productos exóticos, incluyendo frutas tropicales. Entre los productos originados en Colombia se destaca la uchuva y, en menor proporción, la pitaya y las passifloras. Esta cadena realiza, en acuerdo con el grupo de mayoristas importadores de frutas exóticas tropicales, campañas de promoción del consumo. Hay que tener en cuenta que estos mayoristas también abastecen a las otras cadenas de distribución mencionadas. ${ }^{2021}$

\subsubsection{CONSUMO APARENTE}

Se estima que en Europa el consumo de frutas y verduras ha aumentado significativamente en los últimos años, especialmente el de los frutos exóticos dentro de ellos la uchuva, la cual consumen en jugos postres dulces y demás; este fruto exótico ha sido incluido en la dieta de las familias europeas gracias a su constante distribución en supermercados de grandes superficies donde no solo las amas de casa sino también los Hoteles y restaurantes tienen fácil acceso a este producto.

Los consumidores alemanes conceden gran importancia a la frescura y a la inocuidad en las frutas y verduras frescas, lo que ha dado lugar a un creciente

\footnotetext{
${ }^{20}$ http://interletras.com/manualCcl/Alemania/alemania17.htm.

${ }_{21}$ Manual del exportador de frutas, hortalizas y tubérculos en Colombia 2000.
} 
interés por productos orgánicos. ${ }^{22}$ De acuerdo con investigaciones realizadas en Alemania en 1998, dentro de la canasta de productos orgánicos disponibles en este mercado (el segundo más grande a nivel mundial después de Estados Unidos) las frutas y las verduras frescas son los productos de mayor demanda por parte de los consumidores alemanes, quienes además están dispuestos a pagar hasta un $52 \%$ más por estos productos orgánicos. ${ }^{23}$

Alemania es el mayor importador de productos agrícolas a nivel mundial y el segundo mercado más grande en importaciones de frutas y verduras, constituyendo así el objetivo de muchos países proveedores y uno de los mercados más competidos, que generalmente está sobre abastecido. ${ }^{24} \mathrm{De}$ acuerdo con la información de EUROSTAT, en 1998, las importaciones totales de frutas (incluyendo nueces) y verduras frescas y secas se situaron en 9.035.226 toneladas por valor de US $\$ 6.450$ millones de las cuales el $80 \%$ en volumen y el $76 \%$ en valor, corresponden a importaciones provenientes de otros países de la Unión Europea. Los principales proveedores del mercado hortofrutícola alemán son Holanda, España, Italia, Francia y Bélgica; España ha venido ganando participación en detrimento de Holanda. ${ }^{25}$

Entre enero y agosto del 2008, las exportaciones de uchuva colombianas sumaron USD19,5 millones, equivalentes a 5,7 millones de $\mathrm{kg}$ brutos, según cifras del DANE.

\footnotetext{
${ }^{22}$ El cambio estructural en el comercio alimentario europeo. En: Horticultura, abril de 1999, pág.60.

${ }^{23} \mathrm{http}: / /$ www.agronet.gov.co/www/docs agronet/200512992425 Bolet\%C3\%ADn\%20CCI.Alemaniadoc.pdf

${ }^{24}$ El mercado hortofrutícola alemán. En: Horticultura Internacional. Febrero 23 de 1999, pág. 88.

${ }^{25} \mathrm{http}: / /$ www.agronet.gov.co/www/docs agronet/200512992425 Bolet\%C3\%ADn\%20CCI.Alemaniadoc.pdf
} 
Duranel 2007, las ventas internacionales de esta fruta llegaron a USD25,6 millones (8 millones de $\mathrm{kg}$ ), lo que representó un incremento del $11 \%$, con respecto al 2006, cuando habían sumado USD23 millones.

Entre el 2005 y el 2007 se presentó un crecimiento promedio anual del 4\%, al pasar de USD23,8 millones a USD25,6 millones

\section{Grafica N 5 . EXPORTACIONES COLOMBIANAS DE UCHUVA.}

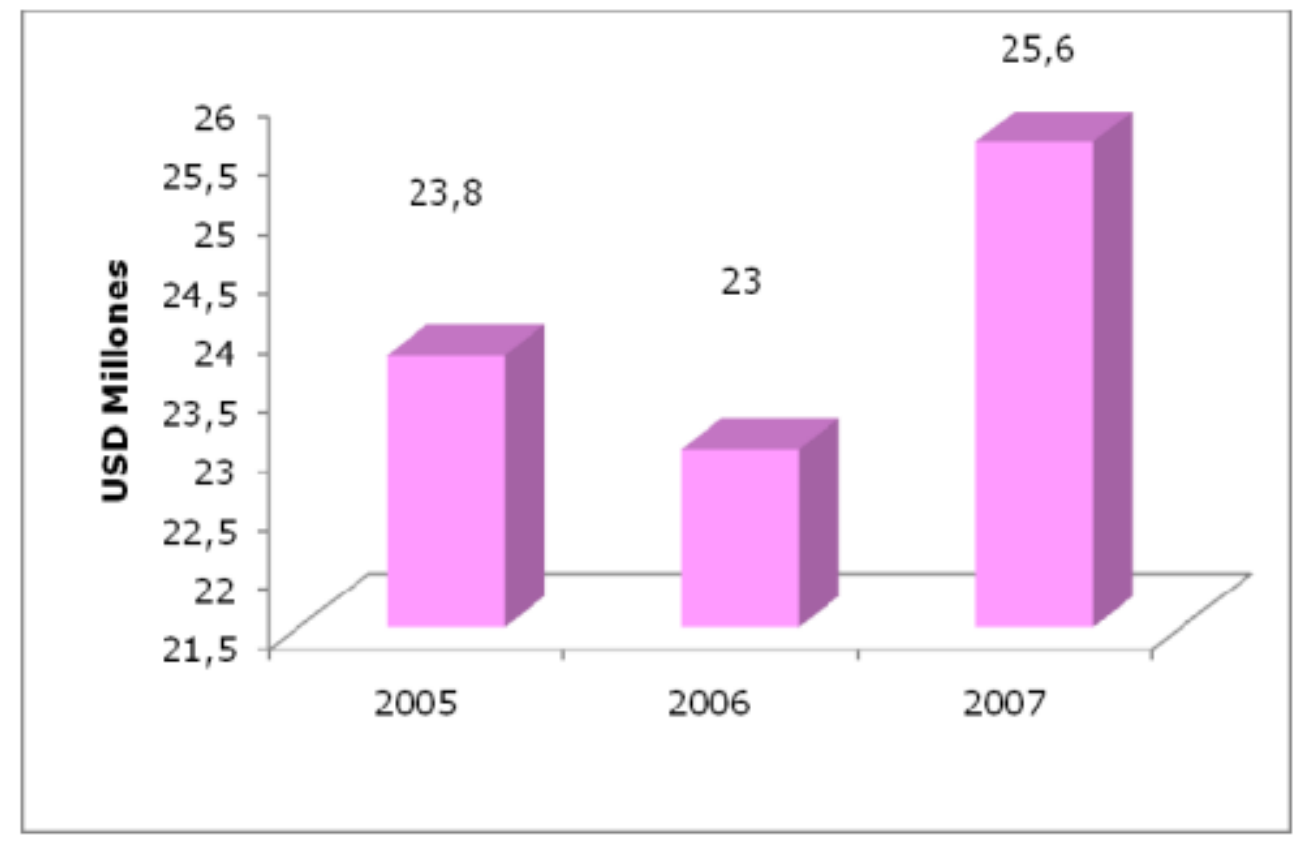

Fuente: Tomado de la pagina

http://www.legiscomex.com/BancoMedios/Documentos\%20PDF/exportaciones-estudio-frutasexoticas.pdf. 
Países bajos fue el principal destino de las exportaciones de uchuva colombiana, con USD10,2 millones, seguido por Alemania, con USD6,3 millones y Bélgica, con USD5 millones. Estos tres países concentraron el 84\% del mercado.

\subsubsection{CONSUMO PER CÁPITA}

Según datos facilitados por el Ministerio de Agricultura de Alemania, cada ciudadano en Alemania consumió el año pasado $105 \mathrm{~kg}$ de fruta (incluida la fruta en productos transformados).

La manzana sigue siendo la fruta preferida con un consumo per capita de $25,9 \mathrm{~kg}$, le sigue la banana con 10,5 kg. Entre las diferentes variedades de cítricos se han consumido $36,7 \mathrm{~kg}$. En total en el ejercicio $2011 / 12$ se consumieron un total de 8.668.000 th de fruta. Menos de una quinta parte de esta fruta procedía de la producción nacional. Las producciones nacionales se concentran en manzanas, peras, cerezas, ciruelas, fresas y otros berries. En total la cosecha nacional de fruta en 2012 ascendió a 1.255 .815 tn. ${ }^{26}$

\subsubsection{SEGMENTACIÓN DEL MERCADO}

Se debe tener en cuenta que en Alemania se encuentran más de 82.604.000 habitantes, además de esto se verifico que este segmento de mercado tiene como Demográfica muchos supermercados donde se comercializara este producto. Así

\footnotetext{
${ }^{26}$ http://www.freshplaza.es/article/75477/Alemania-aumenta-el-consumo-de-la-fruta-per-capita-ala\%C3\%B10
} 
mismo se podrá encontrar consumidores que tengan gusto por productos que le ayuden en su salud y lealtad a la marca.27

\subsection{ANÁLISIS DE LA COMPETENCIA}

Colombia cuenta con algunas empresas dedicadas a la exportación de frutas, pero son muy pocas las que le apuestan a la uchuva tipo exportación, estas empresas están ubicadas en diferentes zonas del país y poseen un gran conocimiento del consumo y las redes de distribución tanto nacionales como internacionales y esto hace de las empresas colombianas, potenciales socios estratégicos para las compañías extranjeras que decidan adelantar un plan de negocios en nuestro país.

\subsubsection{COLOMBIA PRINCIPALES EMPRESAS EN EL SECTOR FRUTíCOLA}

A continuación se puede observar las principales empresas del sector frutícola en Colombia:

Cuadro NN 1. PRINCIPALES EMPRESAS EN EL SECTOR FRUTÍCOLA

\begin{tabular}{|l|l|l|l|l|}
\hline $\begin{array}{l}\text { COMPETENCIA } \\
\text { NACIONAL }\end{array}$ & $\begin{array}{l}\text { COMPETENCIA } \\
\text { DEPARTAMENTAL }\end{array}$ & CIUDAD & DIRECCION & DATOS DEL CONTACTO \\
\hline C.I SABE LTDA. & Asociación de & Cali & & $(2) 4856574$ cel:313 726 29 \\
\hline
\end{tabular}

${ }^{27}$ http://countrymeters.info/es/Germany 


\begin{tabular}{|c|c|c|c|c|}
\hline (Cali). & $\begin{array}{l}\text { Fruticultores de } \\
\text { Palermo Asofupal. ( } \\
\text { Paipa) }\end{array}$ & & AV 2 N 5029 & $\begin{array}{l}61 \\
\text { gerencia@comercializadoras } \\
\text { abe.com }\end{array}$ \\
\hline $\begin{array}{l}\text { Cl Procodex } \\
\text { S.A.S (Bogotá). }\end{array}$ & $\begin{array}{l}\text { Asociación de } \\
\text { productores } \\
\text { agropecuarios } \\
\text { Agroesco } \\
\text { Ramiriqui) }\end{array}$ & Bogotá & $\begin{array}{l}\text { calle } 75 B \text { 64-40 } \\
\text { Barrio } \\
\text { Bolívar, detrás CC } \\
\text { Metropolis de la } \\
\text { AV.68 }\end{array}$ & $\begin{array}{l}\text { Leonardo león } \\
\text { cel:3202140921 } \\
\text { Cel:3208361121 } \\
\text { procodexsas@yahoo.com }\end{array}$ \\
\hline $\begin{array}{l}\text { Bengala Agrícola } \\
\text { S.A.S (Cali) }\end{array}$ & $\begin{array}{l}\text { Asociación de } \\
\text { productores de } \\
\text { breva Asobreva } \\
\text { (Nobsa). }\end{array}$ & Cali & $\begin{array}{l}\text { Cr1 24-56 P-7 Of } \\
707\end{array}$ & $\begin{array}{l}\text { Tel (2)4855974 } \\
\text { www.agroriocas.com }\end{array}$ \\
\hline $\begin{array}{l}\text { Exxim Colombia } \\
\text { (Cali) }\end{array}$ & $\begin{array}{l}\text { Bits and fruits } \\
\text { LTDA }\end{array}$ & Cali & Cr32 A 10 A-109 & Tel: (2) 5243901 \\
\hline Imporfenix (Cali) & & Cali & Cra 37 \# $15-124$ & $\begin{array}{l}\text { Tel : } 4184010 \\
\text { Información@imporfenix.com }\end{array}$ \\
\hline OCATI S.A & & Bogotá & & $\begin{array}{l}\text { Tel:884-4433 } \\
\text { http://www.ocati.com }\end{array}$ \\
\hline $\begin{array}{l}\text { NOVACAMPO } \\
\text { SA (sociedad de } \\
\text { comercialización } \\
\text { internación). }\end{array}$ & & $\begin{array}{l}\text { Funza } \\
\text { Cundina } \\
\text { marca }\end{array}$ & $\begin{array}{l}\text { Calle } 27 \text { No. } 7^{\text {a }}-85 \\
\text { Parque Industrial } \\
\text { Casablanca módulo } \\
7\end{array}$ & $\begin{array}{l}\text { Tel: } 8215762 \\
\text { Tel: } 8215797\end{array}$ \\
\hline
\end{tabular}




\begin{tabular}{|c|c|c|c|}
\hline $\begin{array}{l}\text { C I frutas } \\
\text { comerciales SA }\end{array}$ & Bogotá & $\mathrm{Cl} 24 \mathrm{~F} 102-23$ & $\begin{array}{l}\text { Tel. } 4132786 \\
\text { Tel.4132823 }\end{array}$ \\
\hline $\begin{array}{l}\text { Comercializadora } \\
\text { Internacional } \\
\text { CARIBBEAN } \\
\text { EXOTICS. }\end{array}$ & $\begin{array}{l}\text { Rionegr } \\
\text { o }\end{array}$ & $\begin{array}{l}\text { Vereda Cimarronas } \\
\text { Carretera a Marinilla } \\
\text { Km } 1\end{array}$ & $\begin{array}{l}\text { Tel: } 4489050 \\
\text { FAX:(574)5312999 } \\
\text { E-MAIL: } \\
\underline{\text { carex@caribbeanexotics.com }} \\
\underline{\text {.co }}\end{array}$ \\
\hline $\begin{array}{l}\text { Andes Export } \\
\text { Company EU }\end{array}$ & $\begin{array}{l}\text { Combita } \\
\text { - } \\
\text { Boyacá }\end{array}$ & km 1 vía Paipa & $\begin{array}{l}\text { Tel: (8) } 7451541 \\
\text { info@andesexport.com } \\
\text { jbeckers@andesexport.com }\end{array}$ \\
\hline $\begin{array}{ll}\text { Cl } & \text { FRIZCO } \\
\text { LTDA } & \end{array}$ & Bogotá & Calle 68\#92-56 & $\begin{array}{l}\text { Tel: } 005716958319 \text { Fax: } \\
005712760300 \\
\text { www.frizcol.com }\end{array}$ \\
\hline $\begin{array}{l}\text { Cl } \\
\text { FRUTYERREZ } \\
\text { LTDA }\end{array}$ & Bogotá & CR 132 29-57 & Tel: 4220225 \\
\hline
\end{tabular}

FUENTE: dane-calculoslegiscomex.com

${ }^{28}$ http://www.agrowww.com/productorhome.php?cod prod=05 


\subsection{COMPETENCIA A NIVEL BOYACA}

\subsubsection{ASOCIACIONES BOYACENCES DE PRODUCTORES DE UCHUVA}

Cuadro 2. Asociaciones boyacenses de productores de uchuva

\begin{tabular}{|c|c|c|c|c|c|c|}
\hline MUNICIPIO & $\underset{\mathbf{N}}{\text { ASOCIACIÓ }}$ & $\begin{array}{c}N^{\circ} \text { DE } \\
\text { SOCIO } \\
\text { S }\end{array}$ & $\begin{array}{l}\text { REPRESENTAN } \\
\text { TE LEGAL }\end{array}$ & CELULAR & $\begin{array}{c}\text { ÁREA } \\
\text { SEMBRAD } \\
\text { A }\end{array}$ & $\begin{array}{c}\text { ALIADO } \\
\text { COMERCIA } \\
L\end{array}$ \\
\hline \multirow{3}{*}{ Ramiriquí } & Asproagro & 10 & \begin{tabular}{|l|} 
Miguel Ángel \\
Ramos \\
\end{tabular} & $\begin{array}{r}312367835 \\
9 \\
\end{array}$ & 22 & Ocati \\
\hline & Agroesco & 28 & $\begin{array}{l}\text { Luis Alejandro } \\
\text { Mendoza }\end{array}$ & $\begin{array}{r}312331256 \\
3 \\
\end{array}$ & 7 & Ocati \\
\hline & Asofrucom & 6 & $\begin{array}{l}\text { Gabriel Arias } \\
\text { Escobar }\end{array}$ & $\begin{array}{r}313836563 \\
7\end{array}$ & 12 & Tesoro fruit \\
\hline \multirow{2}{*}{ Ciénega } & Asoprocien & 37 & Jairo Hernández & $\begin{array}{r}312522604 \\
6\end{array}$ & 15 & $\begin{array}{l}\text { Andes } \\
\text { Export }\end{array}$ \\
\hline & \begin{tabular}{|l|} 
Proadexco \\
sat
\end{tabular} & 25 & $\begin{array}{l}\text { CarlosAlfonso } \\
\text { Vargas }\end{array}$ & $\begin{array}{r}312546191 \\
5 \\
\end{array}$ & 5 & $\begin{array}{l}\text { Andes } \\
\text { Export }\end{array}$ \\
\hline Umbita & $\begin{array}{l}\text { AFI - } \\
\text { Asociación } \\
\text { de } \\
\text { Fruticulores } \\
\text { de Icabuco }\end{array}$ & 22 & Augusto Toro & $\begin{array}{r}311532667 \\
1\end{array}$ & 10 & Frutireyes \\
\hline \multirow{3}{*}{$\begin{array}{c}\text { Ventaquema } \\
\text { da }\end{array}$} & Afrutiboy & 17 & Rafael Moreno & $\begin{array}{r}314276716 \\
7\end{array}$ & 7 & Nativa \\
\hline & Procoaven & 24 & Nubia Leyva & $\begin{array}{r}312316496 \\
1\end{array}$ & 9 & Novacampo \\
\hline & Asoagrocol & 22 & Lourdes Pineda & $\begin{array}{r}321456390 \\
4\end{array}$ & 4 & Nativa \\
\hline $\begin{array}{l}\text { San miguel } \\
\text { de Sema }\end{array}$ & Asofrusan & 22 & Alirio Aguilar & $\begin{array}{r}314231242 \\
0 \\
\end{array}$ & 22 & $\begin{array}{l}\text { Andes } \\
\text { export }\end{array}$ \\
\hline Tuta & $\begin{array}{l}\text { Agrosolidari } \\
\text { a }\end{array}$ & 7 & Irma Caicedo & $\begin{array}{l}310576934 \\
6\end{array}$ & 7 & Tesoro fruit \\
\hline Floresta & $\begin{array}{l}\text { Asociación } \\
\text { Agroindustri } \\
\text { al de } \\
\text { Fruticultores }\end{array}$ & 39 & $\begin{array}{l}\text { JOSE JOAQUIN } \\
\text { CELY GARCIA }\end{array}$ & $\begin{array}{r}320849670 \\
0\end{array}$ & 18 & $\begin{array}{l}\text { Andes } \\
\text { Export }\end{array}$ \\
\hline $\begin{array}{l}\text { Boyaca- } \\
\text { Boyaca }\end{array}$ & $\begin{array}{l}\text { Asociacion } \\
\text { agrope. } \\
\text { Multiactiva } \\
\text { gulupita } \\
\end{array}$ & 22 & $\begin{array}{l}\text { Armando Cruz } \\
\text { Garcia }\end{array}$ & $\begin{array}{r}312583729 \\
9 \\
\end{array}$ & 15 & \\
\hline TOTALES & & 265 & & & 152 & \\
\hline
\end{tabular}




\begin{tabular}{|l|l|}
\hline $\begin{array}{l}\text { Áreas en } \\
\text { Hectáreas } \\
\text { Sembrada }\end{array}$ & 152 \\
\hline $\begin{array}{l}\text { Plantas sembradas } \\
\text { en Boyacá }\end{array}$ & 304.000 \\
\hline $\begin{array}{l}\text { Producción en } \\
\text { toneladas }\end{array}$ & 3.800 \\
\hline Tipo exportación & 2.040 \\
\hline $\begin{array}{l}\text { Numero de } \\
\text { Jornales EN 18 } \\
\text { Meses }\end{array}$ & 122.360 \\
\hline
\end{tabular}

Fuente: Gobernación De Boyacá Secretaría de Fomento Agropecuario - Dirección de Mercadeo. Agosto de 2012

\subsection{PAISES COMPENTITIVOS}

Los países que al igual que Colombia producen uchuva son:

- Costa Rica: es un buen exportador de uchuva pero no representa una competencia mayor.

- Perú: la uchuva es originaria de este país, aunque antiguamente Perú exportaba la uchuva deshidratada en el 2011 empezó a exportarla fresca así como lo ha venido haciendo Colombia

La mayor competencia se encuentra en el área Africana más específicamente en

Zimbwe ya que esta cuenta con aptas condiciones para la producción de Uchuva 
pero Colombia por sus propiedades en el suelo la uchuva obtiene mayor concentración de azúcar. ${ }^{29}$

\subsection{COMPETENCIA DEPARTAMENTAL Y NACIONAL DE COMERCIALIZADORAS INTERNACIONALES}

Cuadro 3. Competencia departamental y nacional de comercializadoras internacionales.

\begin{tabular}{|c|c|c|c|}
\hline $\begin{array}{c}\text { NOMBRE } \\
\text { ORGANIZACION }\end{array}$ & $\begin{array}{l}\text { REPRESENTANTE } \\
\text { LEGAL }\end{array}$ & CELULAR & $\mathrm{Cl}$ \\
\hline NOVACAMPO & $\begin{array}{l}\text { FERNANDO } \\
\text { MATALLANA }\end{array}$ & (091)8290615 & BOGOTA \\
\hline OCATI & $\begin{array}{l}\text { FABIO MONTOYA } \\
\text { CASTAÑO } \\
\text { SERGIO LLOREDA }\end{array}$ & $\begin{array}{c}3202749841-(091) \\
8623709 \\
3143937647\end{array}$ & \\
\hline $\begin{array}{l}\text { ANDES EXPPORT } \\
\text { COMPANY S.A }\end{array}$ & $\begin{array}{l}\text { JOHANA BECKERS } \\
\text { LUZ AMPARO } \\
\text { GIRALDO }\end{array}$ & $\begin{array}{l}3108197934 \\
3002661576\end{array}$ & TUNJA \\
\hline $\begin{array}{c}\text { FRUTAS } \\
\text { COMERCIALES }\end{array}$ & SANTIAGO ROJAS & $3134221620-4132823$ & BOGOTÁ \\
\hline $\begin{array}{l}\text { CARIBEAN } \\
\text { EXOCTIS }\end{array}$ & $\begin{array}{l}\text { ANA GABRIELA } \\
\text { MEJIA }\end{array}$ & $\begin{array}{c}\text { (4) } 4489050 \\
\text { CAREX@CARIBBEANEXO } \\
\text { TICS. COMO.CO }\end{array}$ & MEDELLIN \\
\hline FRUTIERREZ & LUZ ANGELA MOYA & $\begin{array}{c}3002192701-7589635- \\
7590043\end{array}$ & \\
\hline FRUTIREYES & $\begin{array}{l}\text { LUIS ALBERTO } \\
\text { REYES } \\
\text { GILBERTO REYES }\end{array}$ & $\begin{array}{c}3156481290-091 \\
2530120 \\
3005664203-3158551479\end{array}$ & \\
\hline $\begin{array}{c}\text { C.I FRUTAS } \\
\text { COMERCIALES S.A }\end{array}$ & HERNAN GARZON & $\begin{array}{c}3124571060-3134221620 \\
-4224999\end{array}$ & $\begin{array}{l}\text { FONTIBON } \\
\text { CLL 24F } \\
\text { No102-23 } \\
\text { BOGOTA }\end{array}$ \\
\hline $\begin{array}{c}\text { SANTANA FRUISTS } \\
\text { S.A.S }\end{array}$ & $\begin{array}{l}\text { GLADYS SOSA } \\
\text { JAVIER BARNIER }\end{array}$ & $\begin{array}{c}3183305466-(091) \\
5932800 \\
-5932808-3183305480\end{array}$ & \\
\hline NATIVA PRODUCE & JAVIER LOPEZ & 3108674037 & ZIPAQUIRA \\
\hline
\end{tabular}

${ }^{29}$ http://freddyaguaba.wikispaces.com/EXPORTACION+UCHUVA+(Freddy+A.+Guaba) 
Fuente: Fuente: Gobernación de Boyacá Secretaría De Fomento Agropecuario - Dirección de Mercadeo. Agosto de 2012

\subsection{PLAN DE MERCADEO}

A continuación se podrá observar las diferentes características que tiene este ítem para el proceso de la comercialización del producto, como lo es la estrategia del producto, estrategia de precio, estrategia de distribución y por último la estrategia de promoción o publicidad. Donde se podrá observar la calidad y el diseño del producto final.

\subsubsection{ESTRATEGIAS DE PRECIO}

- Establecer un precio con base en las percepciones de valor del comprador en vez de basarse en los costos del vendedor. ${ }^{30}$

- Ofrecer una combinación perfecta de calidad y buen servicio a un precio aceptable. $^{31}$

- Vincular características y servicios de valor agregado a las ofertas para diferenciarlas y apoyar así precios más altos, en vez de recortar precios para igualar los de la competencia. ${ }^{32}$

\footnotetext{
${ }^{30}$ http://e-learningmarketing.blogspot.com/2012/07/estrategias-de-la-determinacion-de.html

${ }^{31}$ http://e-learningmarketing.blogspot.com/2012/07/estrategias-de-la-determinacion-de.html
} 
- Mantener un precio estable en el mercado para estar en equilibrio frente a la competencia manteniendo la calidad de los productos.

\subsubsection{ESTRATEGIA DE PROMOCION}

\section{GRAFICO 6. ESTRATEGIA DE PROMOCIÓN Y PUBLICIDAD}
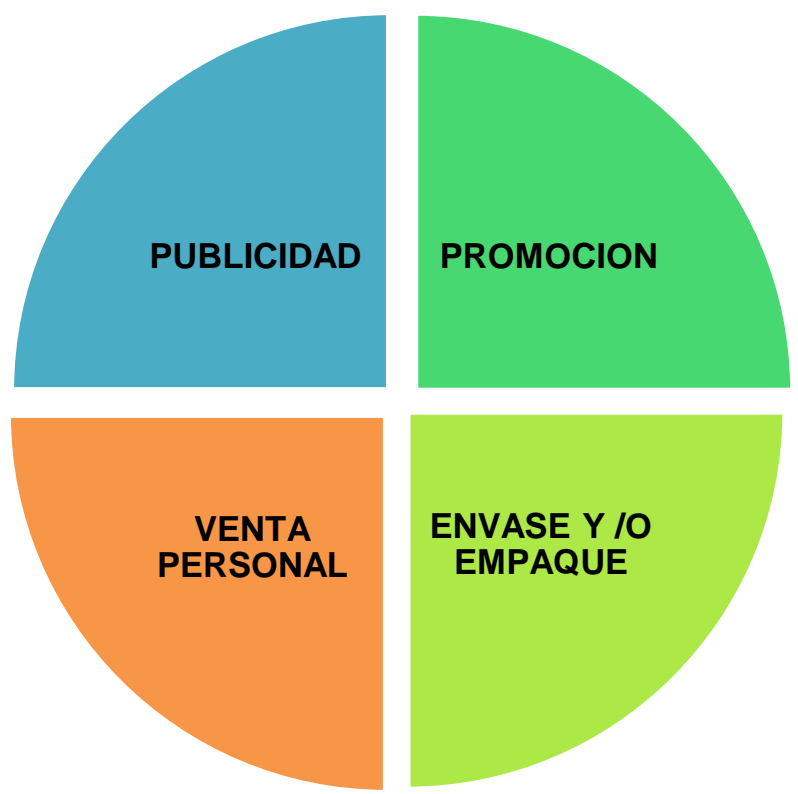

Fuente: Las Autoras

- Muestreos (envío de muestras gratuitas para dar a conocer un producto, tanto a consumidores finales como a prescriptores), ${ }^{33}$

- Participación en exposiciones, seminarios, congresos, ferias, etc. ${ }^{34}$

- Regalos (obsequios gratuitos con la compra de un producto) ${ }^{35}$

- Correo directo presentando una oferta especial ${ }^{36}$

\footnotetext{
32 http://e-learningmarketing.blogspot.com/2012/07/estrategias-de-la-determinacion-de.html

${ }^{33} \mathrm{http}$ ://www.promocion.camaramadrid.es/Principal.aspx?idemenu=2\&idsubmenu=6\&idapartado=4

${ }^{34} \mathrm{http}: / /$ www.promocion.camaramadrid.es/Principal. aspx ?idemenu=2\&idsubmenu=6\&idapartado $=4$

${ }^{35} \mathrm{http}$ ://www.promocion.camaramadrid.es/Principal.aspx ?idemenu=2\&idsubmenu=6\&idapartado=4

${ }^{36} \mathrm{http}: / /$ www.promocion.camaramadrid.es/Principal.aspx $?$ idemenu=2\&idsubmenu=6\&idapartado=4
} 


\subsubsection{ESTRATEGIAS DE VENTAS}

- Cambiar el producto: Una estrategia de ventas podría consistir en cambiar el producto, lo cual no significa tener que sacar un producto totalmente nuevo, sino que al que ya tenemos dotarlo de nuevas características, funciones, atributos, mejoras o usos, o simplemente cambiarle el diseño, la presentación, el diseño, el empaque, la etiqueta o los colores. ${ }^{37}$

- Bajar los precios: Al bajar los precios podríamos estar dándole un duro golpe a la competencia, aunque debemos tener cuidado con esta estrategia pues además de reducir nuestro margen de ganancias, por querer reducir costos, podríamos terminar reduciendo la calidad del producto.

- Brindar servicios adicionales gratuitos: Como estrategia de venta también podríamos optar por brindar servicios adicionales gratuitos tales como la entrega del producto a domicilio, la instalación del producto, el servicio de mantenimiento, nuevas garantías o políticas de devoluciones. ${ }^{38}$

- Usar redes sociales: Como estrategia de ventas también podríamos optar por usar las redes sociales tales como Facebook, Twitter o Youtube, sobre todo, si nuestro público objetivo está conformado por un público joven. ${ }^{39}$

\footnotetext{
${ }^{37} \mathrm{http}: / / \mathrm{www} . c r e c e n e g o c i o s . c o m / e s t r a t e g i a s-d e-v e n t a s /$

${ }^{38} \mathrm{http} / / / \mathrm{www} . c r e c e n e g o c i o s . c o m / e s t r a t e g i a s-d e-v e n t a s /$

${ }^{39} \mathrm{http} / / / \mathrm{www} . c r e c e n e g o c i o s . c o m / e s t r a t e g i a s-d e-v e n t a s /$
} 


\subsubsection{ESTRATEGIAS DE DISTRIBUCION}

- Distribución intensiva.-En una distribución intensiva la empresa busca el mayor número de puntos de venta posible, múltiples centros de almacenamientos para asegurar la máxima cobertura del territorio de ventas y una cifra de ventas elevadas. ${ }^{40}$

- Distribución Selectiva: Es cuando se recure a un número inferior de intermediarios disponibles, es decir solo algunos pueden vender tu producto. Esta estrategia es indicada para productos de compra reflexiva, donde el comprador realiza las comparaciones de precios y características de los productos. ${ }^{41}$

\section{- Distribución Exclusiva:}

Es cuando un solo distribuidor recibe el derecho de vender la marca y se compromete a no vender marcas competitivas en la misma categoría. Esta estrategia es útil cuando el fabricante quiere diferenciar su producto por una política de alta calidad, de prestigio o de calidad de servicio. ${ }^{42}$

\section{- Estrategia de Push "presión o empuje":}

Consiste en orientar los esfuerzos de comunicación (promoción) a los intermediarios con la finalidad de que promocionen más la marca, de almacenar el producto en cantidades importantes o de otorgarle el espacio

\footnotetext{
${ }^{40}$ http://estrategias-negocio.blogspot.com/2009/04/estrategia-marketing-distribucion.html

${ }^{41}$ http://estrategias-negocio.blogspot.com/2009/04/estrategia-marketing-distribucion.html

${ }^{42}$ http://estrategias-negocio.blogspot.com/2009/04/estrategia-marketing-distribucion.html
} 
de venta adecuado en su punto de venta o incitar a comprar a los consumidores el producto. ${ }^{43}$

\subsection{PLAN DE CONTINGENCIA PARA LAS ESTRATEGIAS}

\subsubsection{ESTRATEGIA DE PRECIO}

- Hacer pertinentes descuentos por volúmenes de pedidos. ${ }^{44}$

\subsubsection{ESTRATEGIA DE PROMOCION}

- Ofrecer descuentos u ofertas en fechas especiales

\subsubsection{ESTRATEGIA DE VENTAS}

- Ampliar líneas de productos de la compañía para ocupar los nichos y las brechas vacantes que podrían tomar los retadores. ${ }^{45}$

\subsection{ESTRATEGIA DE DISTRIBUCION}

- Utilizar los medios de información y medios de comunicación masivos para así abarcar todos los nichos de mercado

\subsection{MECANISMOS DE SERVICIO AL CLIENTE.}

\footnotetext{
${ }^{43} \mathrm{http}$ ///estrategias-negocio.blogspot.com/2009/04/estrategia-marketing-distribucion.html

${ }^{44} \mathrm{http}: / /$ descuadrando.com/Estrategias defensivas y ofensivas

45 http://7cidcaanproduccion.blogspot.com/2007/10/estrategia-de-ventas.html
} 
El servicio se realizara por pedidos y se entregara en el puerto de barranquilla lo cual será previamente pactado por el cliente.

\subsubsection{CANALES DE DISTRIBUCIÓN.}

Los canales de distribución para la exportación de la uchuva a Alemania van a ser con intermediarias.

Figura 2. CANAL DE DISTRIBUCION PARA LA EXPORTACION DE FRUTA

\section{FRESCA A ALEMANIA}

\section{PRODUCTOR}

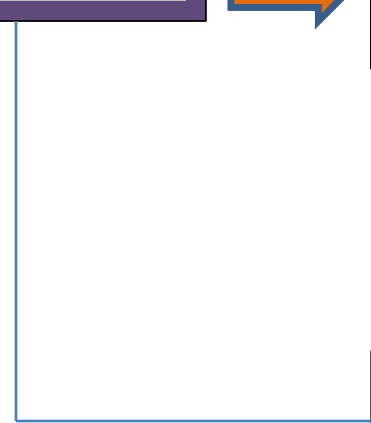

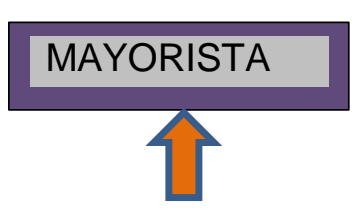

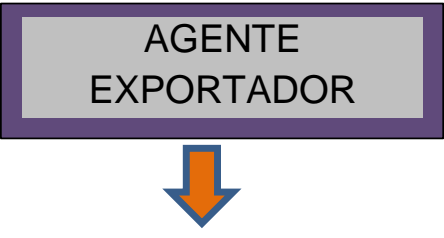

COMERCIO DE TRANSITO

Y RE- EXPORTACION

Fuente: Las autoras 


\subsubsection{RUTA DE DISTRIBUCION.}

\section{Mapa 1. Arcabuco- Barranquilla}

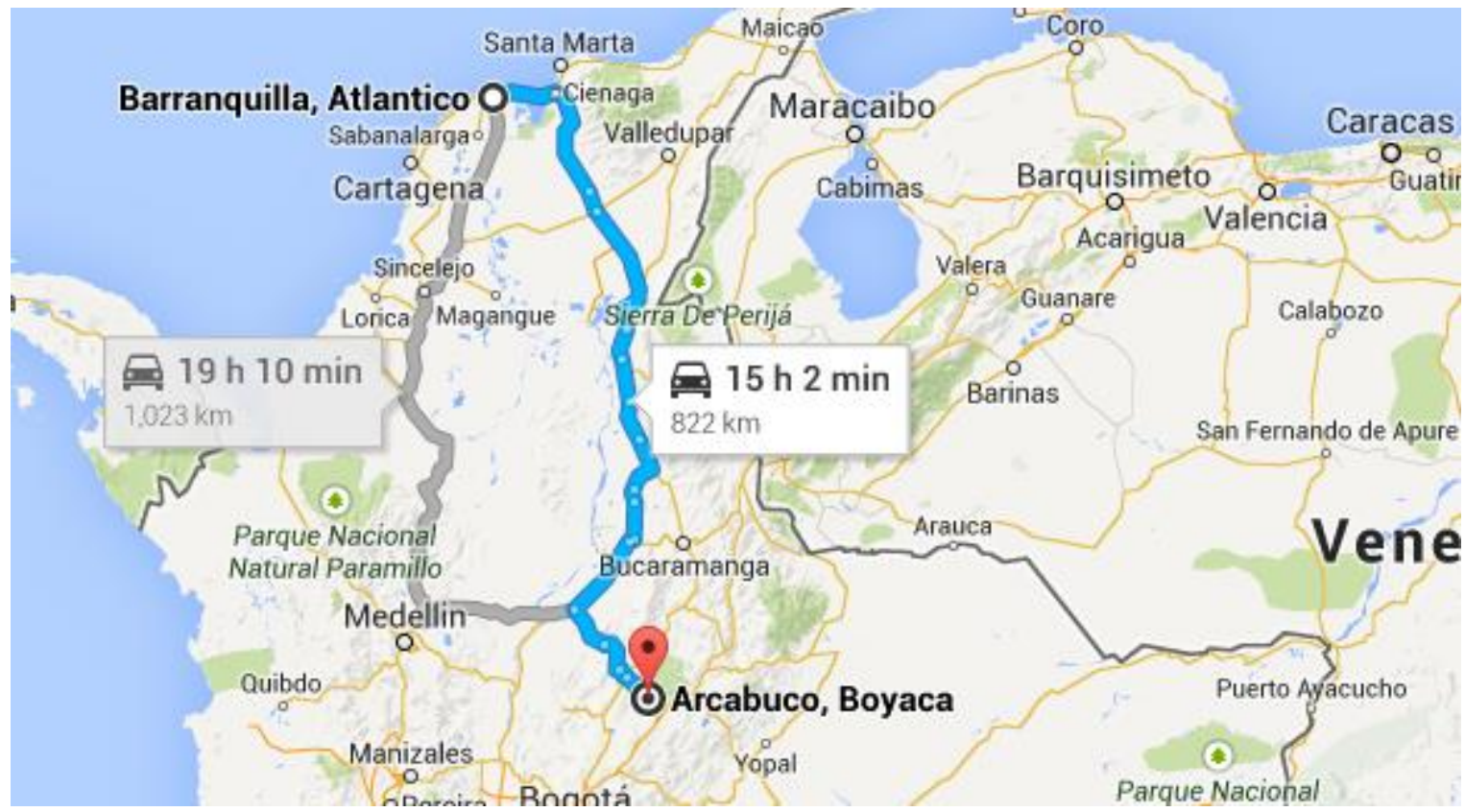

Mapa 2. Barranquilla - Alemania

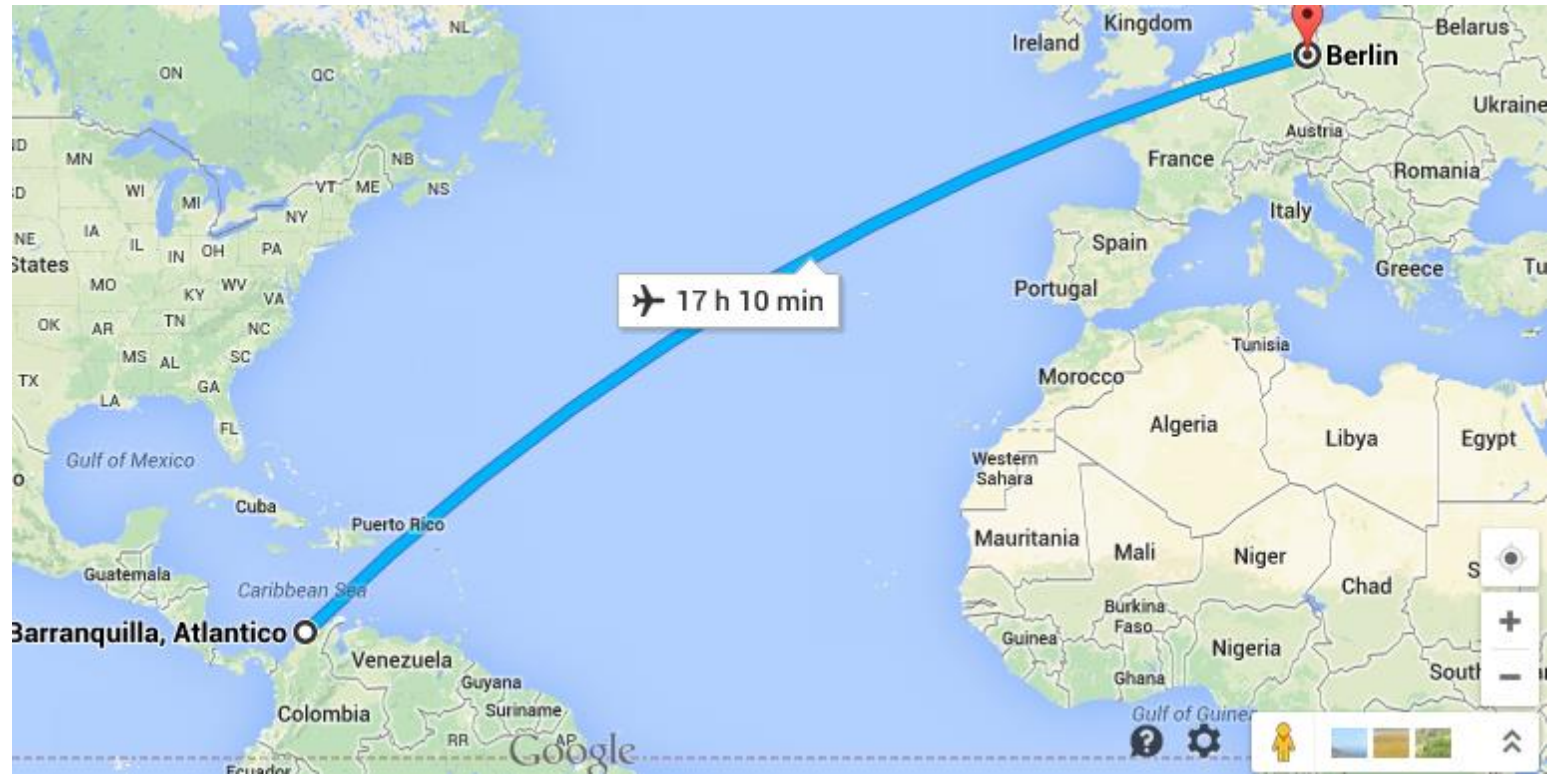




\section{CAPITULO 3. TECNICO Y OPERATIVO}

En este módulo se describen todas las características técnicas del producto, dentro de ellas encontramos:

Ubicación de la planta, diseño de planta, procesos de producción, mapa de procesos, necesidades y requerimientos en maquinaria, plan de producción, costo de materia prima precios actuales, plan de compras, consumo de materia prima por unidad por producto.

\subsection{FICHA TÉCNICA DEL PRODUCTO Y COMPONENTE NUTRICIONAL.}

FIGURA 3. FICHA TÉCNICA DEL PRODUCTO

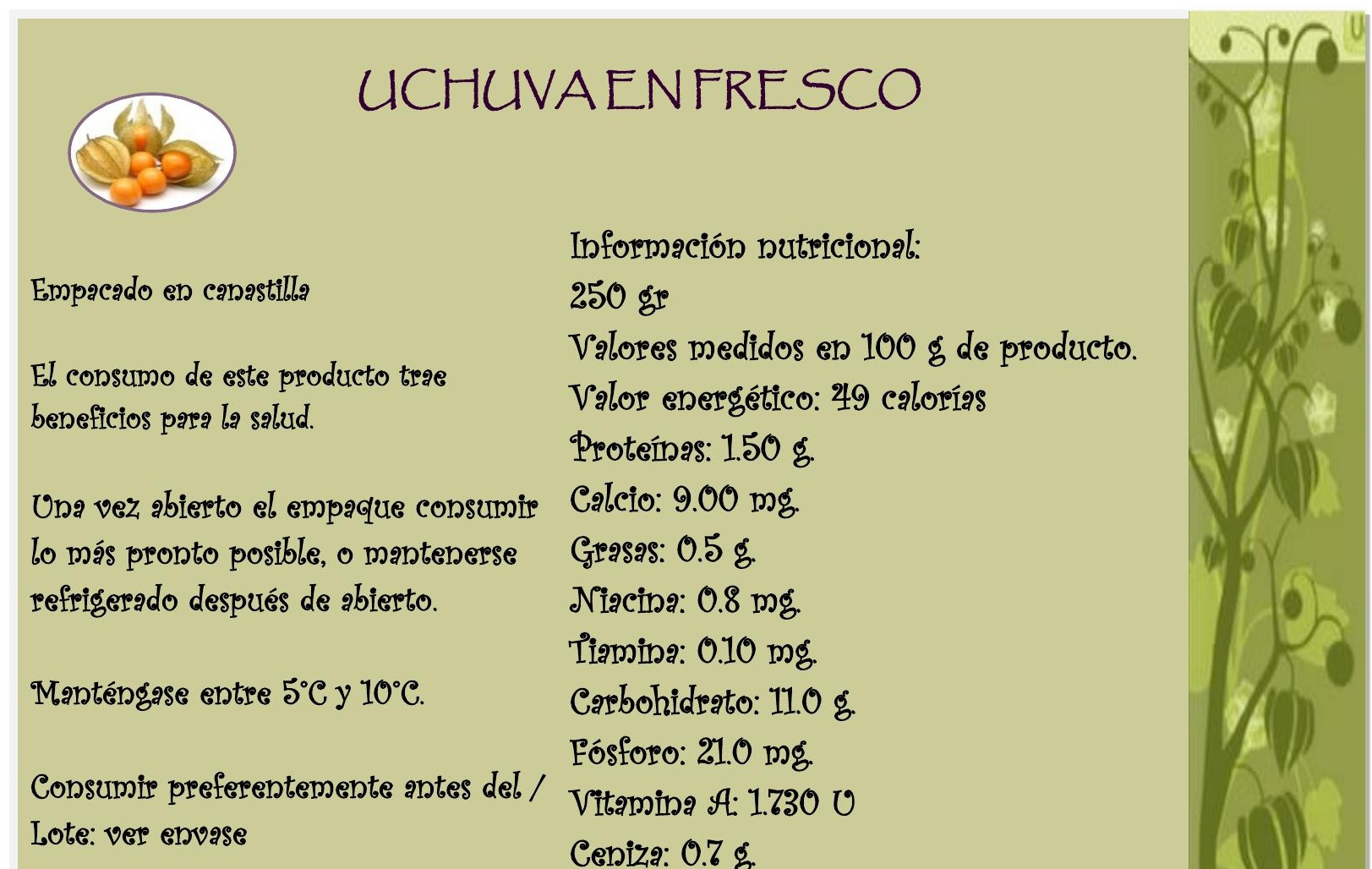


Fuente: Secretaria De Fomento Agropecuario, Dirección De Mercadeo fuente:

Fuente: Gobernación De Boyacá, Oscar González

\subsubsection{DESCRIPCIÓN DEL PRODUCTO.}

- Dimensiones (Largo x Ancho x

Alto)

$127 \times 94 \times 75 \mathrm{~mm}$.

- Material

PET

- Capacidad aprox. 250 grs.

Categoría Cestas para el embalaje de la fruta entera y verduras

Color transparente ${ }^{46}$

\subsubsection{CUIDADOS DE LA FRUTA}

\subsubsection{TIPO DE CONSERVACIÓN.}

Temperatura para su almacenamiento en cuartos fríos es de $22^{\circ} \mathrm{C} .{ }^{47}$

\subsubsection{FORMULACIÓN.}

${ }^{46} \mathrm{http}: / /$ www.productoyempaque.com/empProd_frutas/uchuva-kit-250-h53.htm

${ }^{47}$ http://www.slideshare.net/guest289e51/proyecto-uchuva 
Uchuva convencional seleccionada con altos estándares de calidad y para transporte refrigerado se debe mantener a $10^{\circ} \mathrm{C}$ y $80 \% \mathrm{HC}$.

\subsubsection{VIDA ÚTIL.}

El tiempo de vida útil estimado para esta alternativa es de 28 días, dos días de cosecha y acondicionamiento, 21 días de almacenamiento en frío (10ㄷ y $80 \%$ humedad relativa), cinco días a condiciones ambiente. ${ }^{48}$

\subsubsection{INSTRUCCIONES DE CONSUMO.}

Una vez abierto el empaque consumir lo más pronto posible, o mantenerse refrigerado después de abierto.

\subsubsection{NOMBRE DEL PRODUCTO.}

Uchuva, judaskirsche (en el mercado Alemán).

\footnotetext{
${ }^{48}$ http://www.asohofrucol.com.co/archivos/biblioteca/biblioteca_124_FRUTAS.pdf
} 


\section{FLUJOGRAMA DE PRODUCCION}

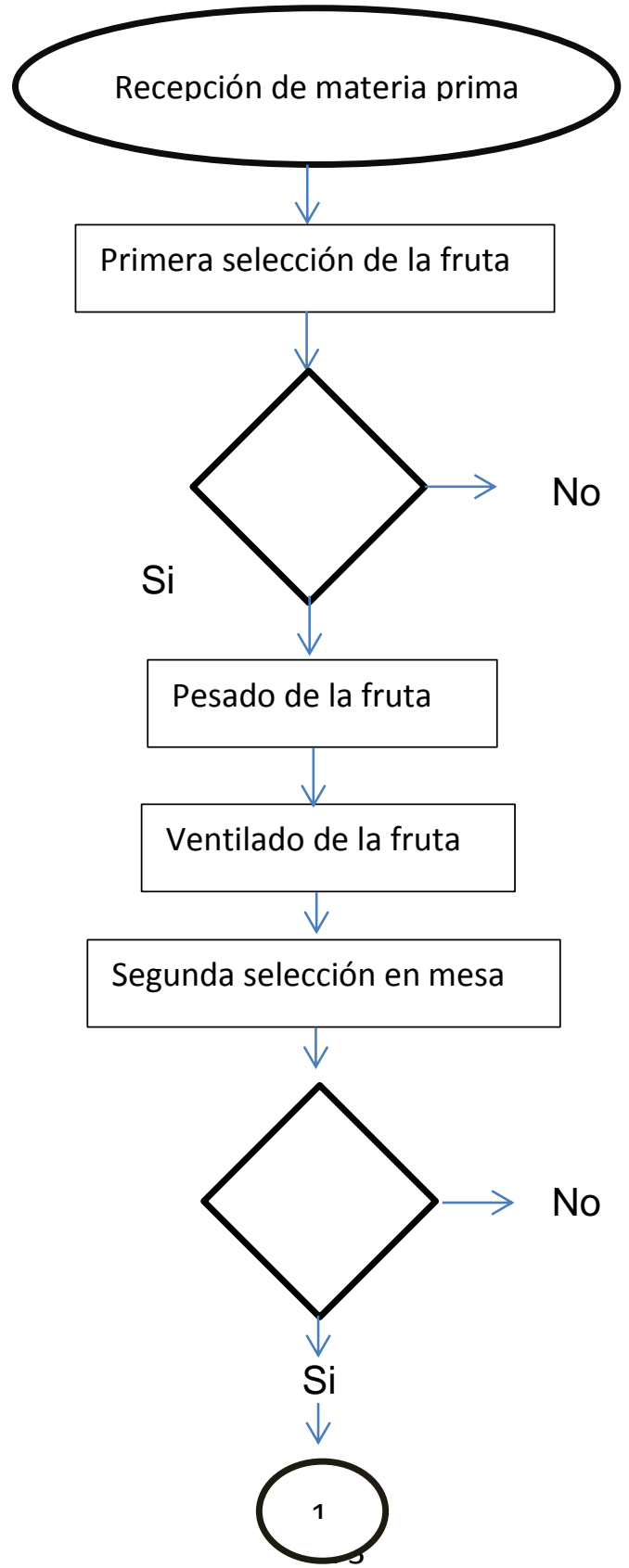




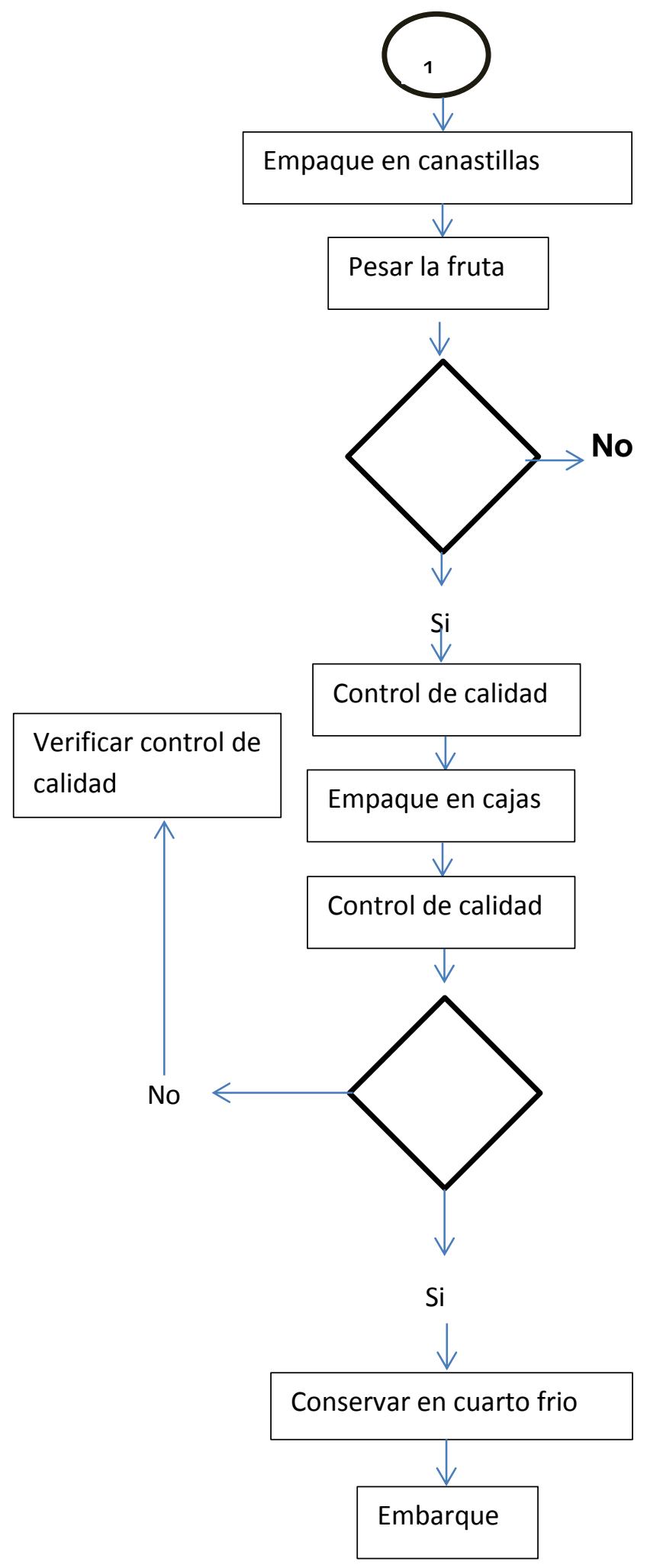




\subsection{REQUERIMIENTOS}

TABLA 3. MAQUINARIA, EQUIPOS, HERRAMIENTAS Y UTENCILICIOS

\begin{tabular}{|c|c|c|c|}
\hline NOMBRE & DESCRIPCION & USO & CANTIDAD \\
\hline 1 & $\begin{array}{l}\text { Un cuarto frío en últimas es } \\
\text { capacidad y que permite alma } \\
\text { de acuerdo a sus característica } \\
\text { Características Según la } \\
\text { legislación colombiana, los } \\
\text { cuartos fríos que se utilizan } \\
\text { para el almacenamiento de } \\
\text { alimentos deben tener en su } \\
\text { interior solo elementos de } \\
\text { acero inoxidable, en el caso } \\
\text { de las flores estos pueden } \\
\text { ser de acero galvanizado. }{ }^{49}\end{array}$ & $\begin{array}{l}\text { Udaadevera o apwag } \\
\text { cenar los productos } \\
\text { refrigerap la pruta } \\
\text { evitando que se } \\
\text { dañe. }\end{array}$ & $\begin{array}{l}\text { elador que tien } \\
\text { de una manera }\end{array}$ \\
\hline BASCULA & $\begin{array}{l}\text { Fabricada en hierro fundido, } \\
\text { cuya plataforma descansa } \\
\text { sobre cuchillas y cojinetes. } \\
\text { Capacidad Máx. } 500 \mathrm{Kg} \\
\text { Medidas equipo } \mathrm{A}^{*} \mathrm{~L}^{*} \mathrm{H}: 46 \mathrm{X} \\
61 \times 70 \mathrm{~cm} \text {. } \\
1 \text { pilón y pesas } \\
50\end{array}$ & $\begin{array}{l}\text { Las básculas son } \\
\text { instrumentos que } \\
\text { tienen como } \\
\text { objetivo pesar y } \\
\text { medir cantidades } \\
\text { de masa. Existen } \\
\text { diferentes tipos } \\
\text { de básculas, } \\
\text { entre ellas se } \\
\text { distinguen las } \\
\text { de escala y las } \\
\text { precisión, tiene } \\
\text { cuales }\end{array}$ & 4 \\
\hline
\end{tabular}

\footnotetext{
${ }^{49}$ http://www.revistalabarra.com.co/ediciones/ediciones-2007/edicion-21/refrigeracion-2/el-cuarto-frioun-sitio-para-conservar.htm

${ }^{50}$ http://articulo.mercadolibre.com.co/MCO-410384822-bascula-de-pesas-_JM
} 


\begin{tabular}{|c|c|c|c|}
\hline ग्राप & & $\begin{array}{l}\text { asignados usos } \\
\text { muy } \\
\text { específicos. }^{51}\end{array}$ & \\
\hline GRAMERAS & $\begin{array}{l}\text { Gramera mecánica modelo: } \\
\mathrm{SD} \text {, plato de } 25 \mathrm{~cm} \text {. de } \\
\text { diámetro y profundidad } 7 \mathrm{~cm} \text {., } \\
\text { carcaza acero inox, } \\
\text { maquinaria metálica, } \\
\text { capacidad disponibles: } \\
5 \mathrm{Kg} . \mathrm{X} 25 \mathrm{~g} \text {, } 3 \mathrm{~kg} \mathrm{X} 20 \mathrm{~g} \text {, o } 1 \\
\mathrm{Kg} \times 5 \mathrm{~g}^{52}\end{array}$ & $\begin{array}{l}\text { Controlar el peso } \\
\text { de las canastillas } \\
\text { que van al } \\
\text { embarque. }\end{array}$ & 15 \\
\hline GRAPADORA & $\begin{array}{l}\text { Grapadora industrial } \\
\text { multifuncional }\end{array}$ & $\begin{array}{l}\text { Una grapadora e } \\
\text { s un utensilio que } \\
\text { se emplea para } \\
\text { unir hojas de } \\
\text { papel, plástico o } \\
\text { láminas de } \\
\text { madera } \\
\text { colocando } \\
\text { una grapa } \\
\text { Recibe diversos } \\
\text { nombres }\end{array}$ & 5 \\
\hline
\end{tabular}

\footnotetext{
${ }_{52}^{51}$ http://www.basculas-y-balanzas.com/basculas.html

http://basculasguadalupe.com/index.php?route=product/product\&path=136 102131 134\&product id=17 $\underline{5}$
} 


\begin{tabular}{|c|c|c|}
\hline ESTAMPADORAS & $\begin{array}{l}\text { La serie ES-1, ES-2 y ES-3, } \\
\text { consiste en sistemas de } \\
\text { etiquetado para aplicar } \\
\text { etiquetas autoadheribles con } \\
\text { uno, dos o tres cabezales } \\
\text { aplicadores, estos equipos } \\
\text { están concebidos para } \\
\text { trabajar en forma integral o } \\
\text { autónoma, ya que cuentan } \\
\text { con su propio transportador, } \\
\text { pudiendo acoplase a líneas } \\
\text { de envasado. } \\
\text { El diseño modular de estos } \\
\text { equipos permite que por } \\
\text { medio de accesorios } \\
\text { acoplados se puedan aplicar } \\
\text { etiquetas a envases } \\
\text { cilíndricos, de caras planas, } \\
\text { ovaladas, o en la parte } \\
\text { superior, logrando } \\
\text { velocidades de hasta } 160 \\
\text { etiquetas por minuto. }\end{array}$ & $\begin{array}{l}\text { Este equipo es } \\
\text { ideal para el } \\
\text { etiquetado de } \\
\text { caras planas, } \\
\text { caras ovaladas } \\
\text { con etiquetas al } \\
\text { frente y reverso, } \\
\text { o aplicación de } \\
\text { etiquetas en } \\
\text { tapas o caras } \\
\text { superiores, cajas } \\
\text { o cualquier } \\
\text { producto que } \\
\text { pueda ser } \\
\text { transportado en } \\
\text { el transportador } \\
\text { del equipo y } \\
\text { tenga una } \\
\text { superficie } \\
\text { etiquetable, } \\
\text { pudiendo aplicar } \\
\text { una dos o tres } \\
\text { etiquetas en } \\
\text { forma simultánea. } \\
54\end{array}$ \\
\hline
\end{tabular}

${ }^{53} \mathrm{http}: / /$ maquinariamac.galeon.com/amigos $1209682 . \mathrm{html}$

54 http://maquinariamac.galeon.com/amigos1209682.html 


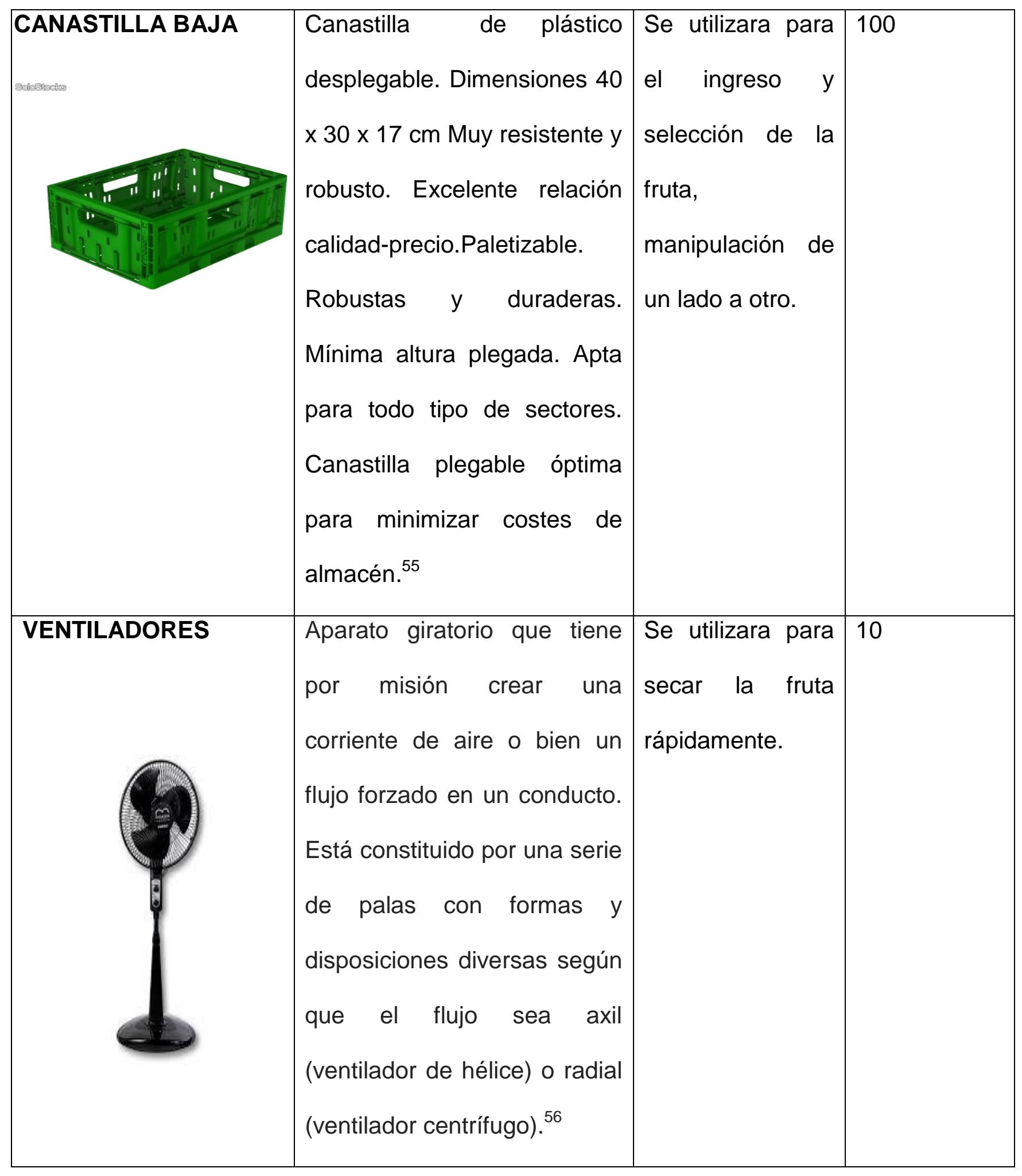

\footnotetext{
${ }^{55}$ http://www.solostocks.com.co/venta-productos/otros-productos-envasado-almacenaje/canastilla-deplastico-plegable-40x60x17-1420234

${ }^{56}$ http://diccionario.motorgiga.com/diccionario/ventilador-definicion-significado/gmx-niv15con195909.htm
} 


\begin{tabular}{|c|c|c|c|}
\hline MESAS & $\begin{array}{l}\text { Mesa de acero inoxidable } \\
\text { Cal. } 18 \text { y } 20 \text { tipo isla con } \\
\text { entrepaño en acero tubo de } 1 \\
1 / 2 \text { pulgadas y regatones } \\
\text { niveladores. ideal para } \\
\text { restaurantes, hoteles, } \\
\text { cocinas industriales etc. }{ }^{57}\end{array}$ & $\begin{array}{l}\text { Se utilizara para } \\
\text { sobre poner la } \\
\text { fruta, } \\
\text { empacado y el } \\
\text { pesado de la } \\
\text { misma. }\end{array}$ & 10 \\
\hline CAJA DE CARTON & $\begin{array}{l}\text { Es aquel que contiene el } \\
\text { empaque } \\
\text { otorgándole protección y } \\
\text { presentación para su } \\
\text { distribución comercial, se } \\
\text { utiliza para agrupar un } \\
\text { determinado número de } \\
\text { unidades de venta. }\end{array}$ & $\begin{array}{l}\text { Se usa para el } \\
\text { empaque } \\
\text { embalaje del } \\
\text { producto. }\end{array}$ & 100 \\
\hline ESTIBAS & $\begin{array}{l}\text { Las estibas están hechas } \\
\text { para transportar } \\
\text { eficientemente y minimizando } \\
\text { cualquier tipo de daño a los } \\
\text { productos. Podemos utilizar } \\
\text { estibas de madera o plásticas } \\
\text { según el tipo de mercancía o }\end{array}$ & $\begin{array}{l}\text { Es la herramienta } \\
\text { que ayuda a } \\
\text { proteger la } \\
\text { mercancía que se } \\
\text { almacena en la } \\
\text { bodega, no solo }\end{array}$ & 50 \\
\hline
\end{tabular}

\footnotetext{
${ }^{57}$ http://www.indupan.com.mx/MuseExport/mesas-de-trabajo-tipo-isla.html
} 


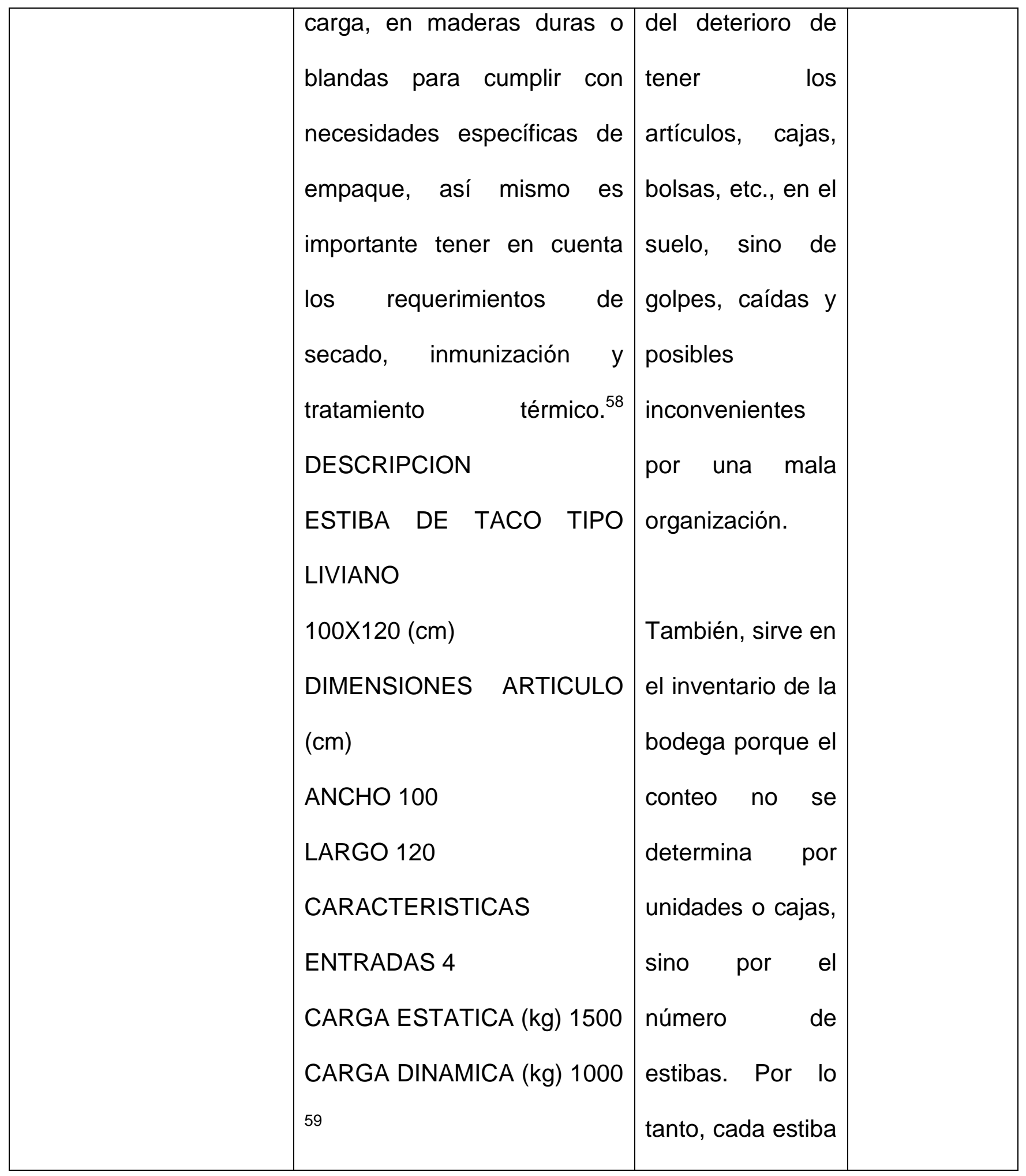

58

http://www.slideshare.net/Nataliafrancomora/estibas1http://www.slideshare.net/Nataliafrancomora/estib as1

${ }^{59}$ http://coprom-file.s3.amazonaws.com/963 estibas y embalajes reyes.pdf 


\begin{tabular}{|c|c|c|}
\hline & 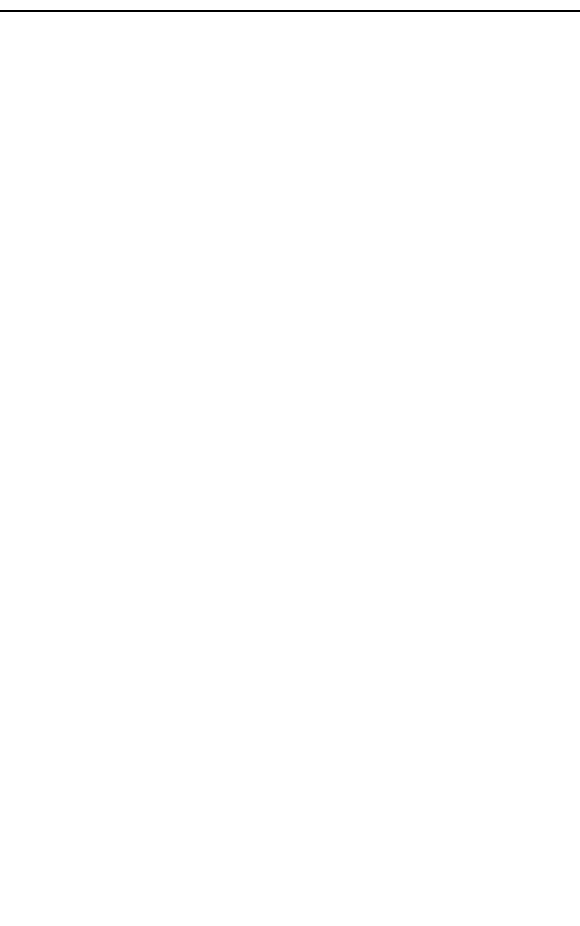 & $\begin{array}{l}\text { tiene un número } \\
\text { determinado de } \\
\text { productos que } \\
\text { puede soportar, } \\
\text { así la relación de } \\
\text { la mercancía } \\
\text { tiene un mayor } \\
\text { control y se hace } \\
\text { de manera más } \\
\text { eficiente. }\end{array}$ \\
\hline
\end{tabular}

\subsubsection{UTENCILIOS DEL PERSONAL (SEGURIDAD INDUSTRIAL)}

TABLA 4.UTENCILIOS DEL PERSONAL

\begin{tabular}{|c|c|c|c|}
\hline UTENCILIO & DESCRIPCION & USO & CANTIDAD \\
\hline GUANTES & $\begin{array}{l}\text { Las mascarillas tienen un } \\
\text { ajuste flojo, son máscaras } \\
\text { desechables que cubren la } \\
\text { nariz y la boca. Éstas incluyen } \\
\text { productos etiquetados como } \\
\text { quirúrgicos, dentales, } \\
\text { procedimientos médicos, } \\
\text { aislamiento y máscaras } \\
\text { láser. }^{61}\end{array}$ & 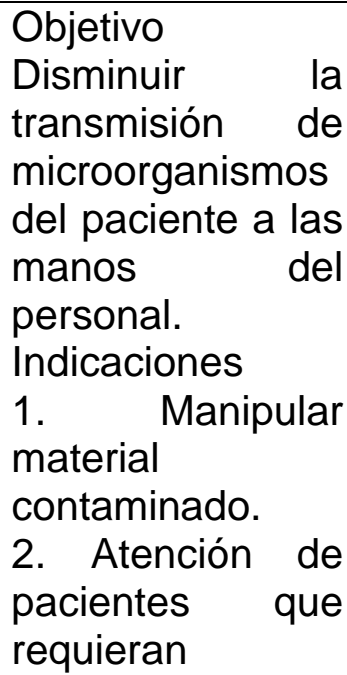 & 900 Pares \\
\hline
\end{tabular}

${ }^{60} \mathrm{http}: / /$ www.revistadelogistica.com/a-buena-estiba-buena-mercancia.asp

${ }^{61}$ http://lopcymatsha.blogspot.com/2010/03/sobre-el-uso-de-mascarillas-y-tapabocas.html 


\begin{tabular}{|c|c|c|c|}
\hline & & 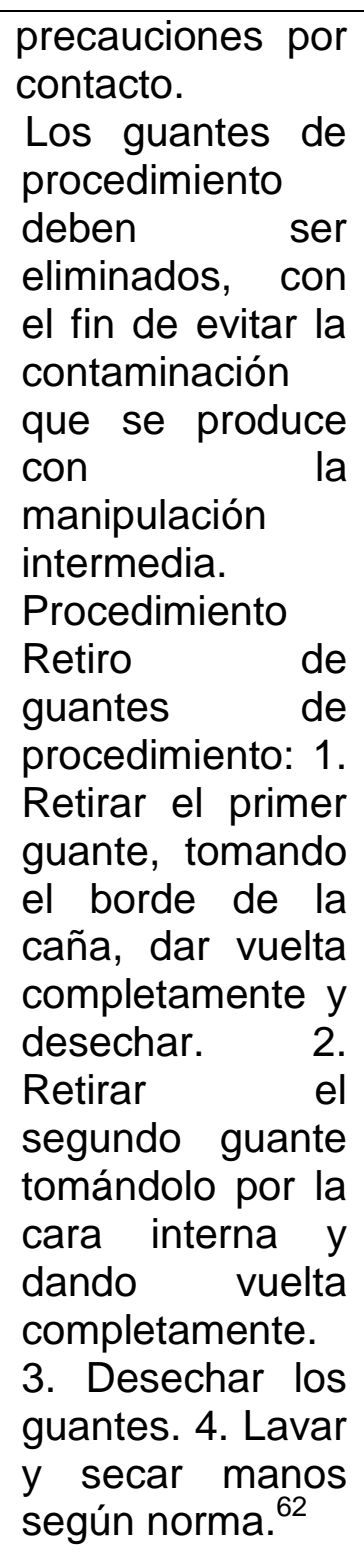 & \\
\hline TAPABOCAS & $\begin{array}{l}\text { Ideal para cumplir con las } \\
\text { normas de Bioseguridad y así } \\
\text { evitar contaminación de los } \\
\text { alimentos así como también } \\
\text { evitar el contagio de virus, } \\
\text { bacterias etc. }{ }^{63}\end{array}$ & $\begin{array}{l}\text { El uso del } \\
\text { tapabocas } \\
\text { también es } \\
\text { controvertido ya } \\
\text { que mal usado su } \\
\text { utilidad es nula y } \\
\text { puede convertirse } \\
\text { en un elemento } \\
\text { de } \\
\text { contaminación. } \\
\text { La propia } \\
\text { humedad de la }\end{array}$ & 900 Pares \\
\hline
\end{tabular}

${ }^{62}$ http://lopcymatsha.blogspot.com/2010/03/sobre-el-uso-de-mascarillas-y-tapabocas.html 


\begin{tabular}{|c|c|c|c|}
\hline & & $\begin{array}{l}\text { respiración, el } \\
\text { manoseo, el } \\
\text { tiempo excesivo } \\
\text { sin recambio } \\
\text { llevan a que los } \\
\text { tapabocas se } \\
\text { carguen de } \\
\text { bacterias. Por } \\
\text { eso su uso debe } \\
\text { limitarse aquellas } \\
\text { actividades y } \\
\text { áreas donde sea } \\
\text { estrictamente } \\
\text { necesario y con } \\
\text { estrecha } \\
\text { supervisión. }{ }^{64}\end{array}$ & \\
\hline GORROS & $\begin{array}{l}\text { Gorros desechables para } \\
\text { manipulación de alimentos. }\end{array}$ & $\begin{array}{l}\text { Para cubierta del } \\
\text { cabello, este } \\
\text { debe estar } \\
\text { totalmente } \\
\text { cubierto por gorro } \\
\text { o pañuelo para } \\
\text { evitar la caída del } \\
\text { mismo sobre los } \\
\text { alimentos y } \\
\text { también para } \\
\text { impedir que al } \\
\text { tocar el cabello } \\
\text { nos } \\
\text { contaminemos } \\
\text { las manos y las } \\
\text { uñas. }\end{array}$ & 900 pares \\
\hline DELANTALES & $\begin{array}{l}\text { Delantal de plástico para } \\
\text { industrias cárnicas y de } \\
\text { alimentos. }{ }^{67}\end{array}$ & $\begin{array}{l}\text { Los delantales } \\
\text { protectores } \\
\text { deberán ser } \\
\text { preferiblemente } \\
\text { largos e } \\
\text { impermeables. } \\
\text { Están indicados }\end{array}$ & 60 \\
\hline
\end{tabular}

\footnotetext{
${ }^{63}$ http://lopcymatsha.blogspot.com/2010/03/sobre-el-uso-de-mascarillas-y-tapabocas.html

${ }^{64} \mathrm{http}: / /$ lopcymatsha.blogspot.com/2010/03/sobre-el-uso-de-mascarillas-y-tapabocas.html

65 http://www.maldonado.gub.uy/documentos/pdf/2013/manipulacion-alimentos-13.pdf

66 ttp://www.maldonado.gub.uy/documentos/pdf/2013/manipulacion-alimentos-13.pdf

67 http://bioseguridadhospitalariia.weebly.com/uso-de-delantales-protectores.html
} 


\subsection{LOCALIZACION Y UBICACIÓN DE LA PLANTA}

\section{Mapa 3. Municipio De Arcabuco}

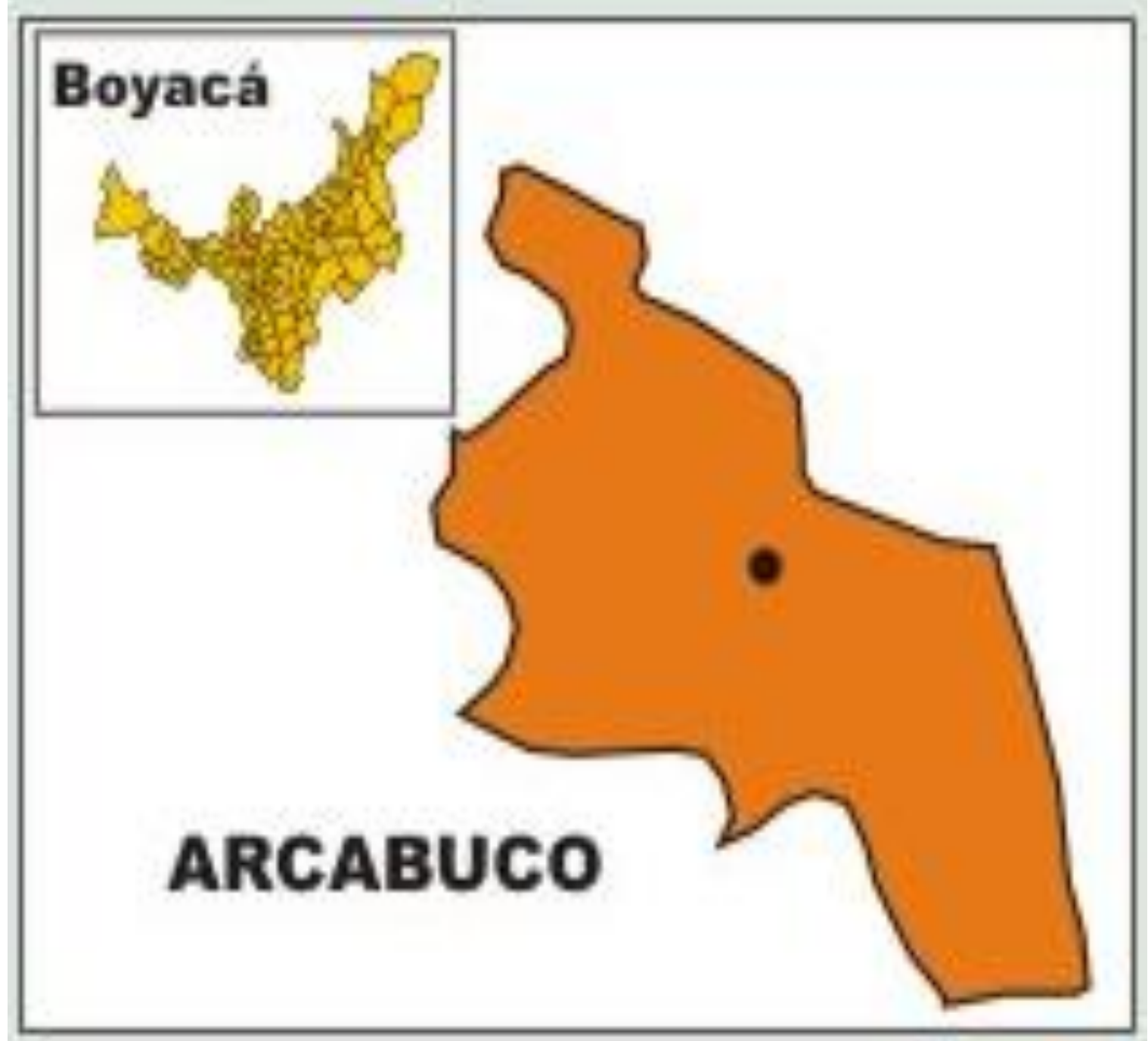

Fuente: Tomado de la pagina

http://www.confecampo.com/asociados/comites/boyaca/arcabuco_municipio.html 


\subsection{FACHADA PRINCIPAL DE LA PLANTA}

Figura 4. Fachada principal de la planta

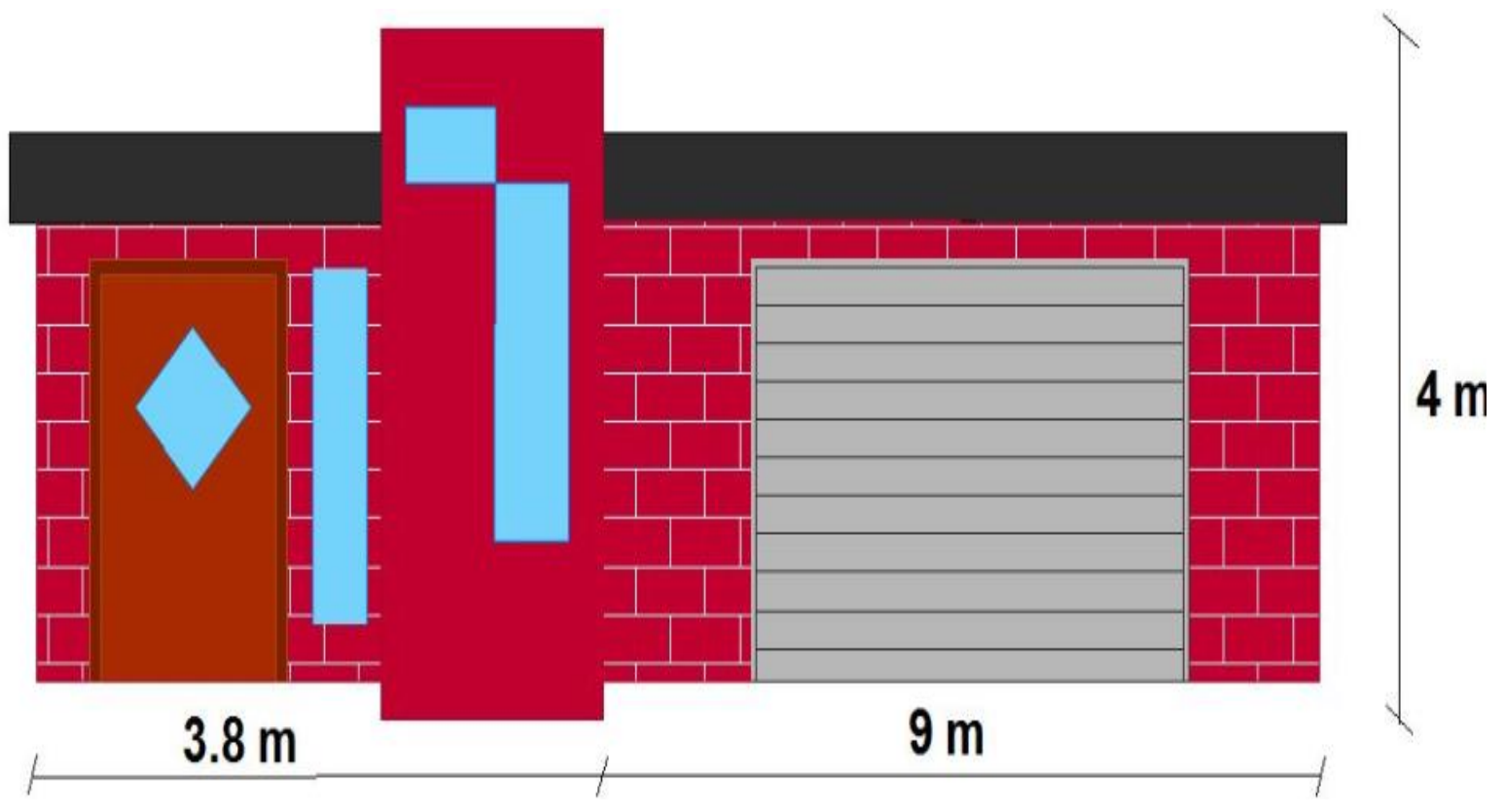

Fuente: Tomado De La Ayuda Del Estudiante de Ingeniería Mecánica, Daniel Felipe

Engativá, Universidad Santo Tomas Tunja.

\subsubsection{FACHADA DE LA PLANTA}

Foto 1. Fachada De La Bodega Actualmente 


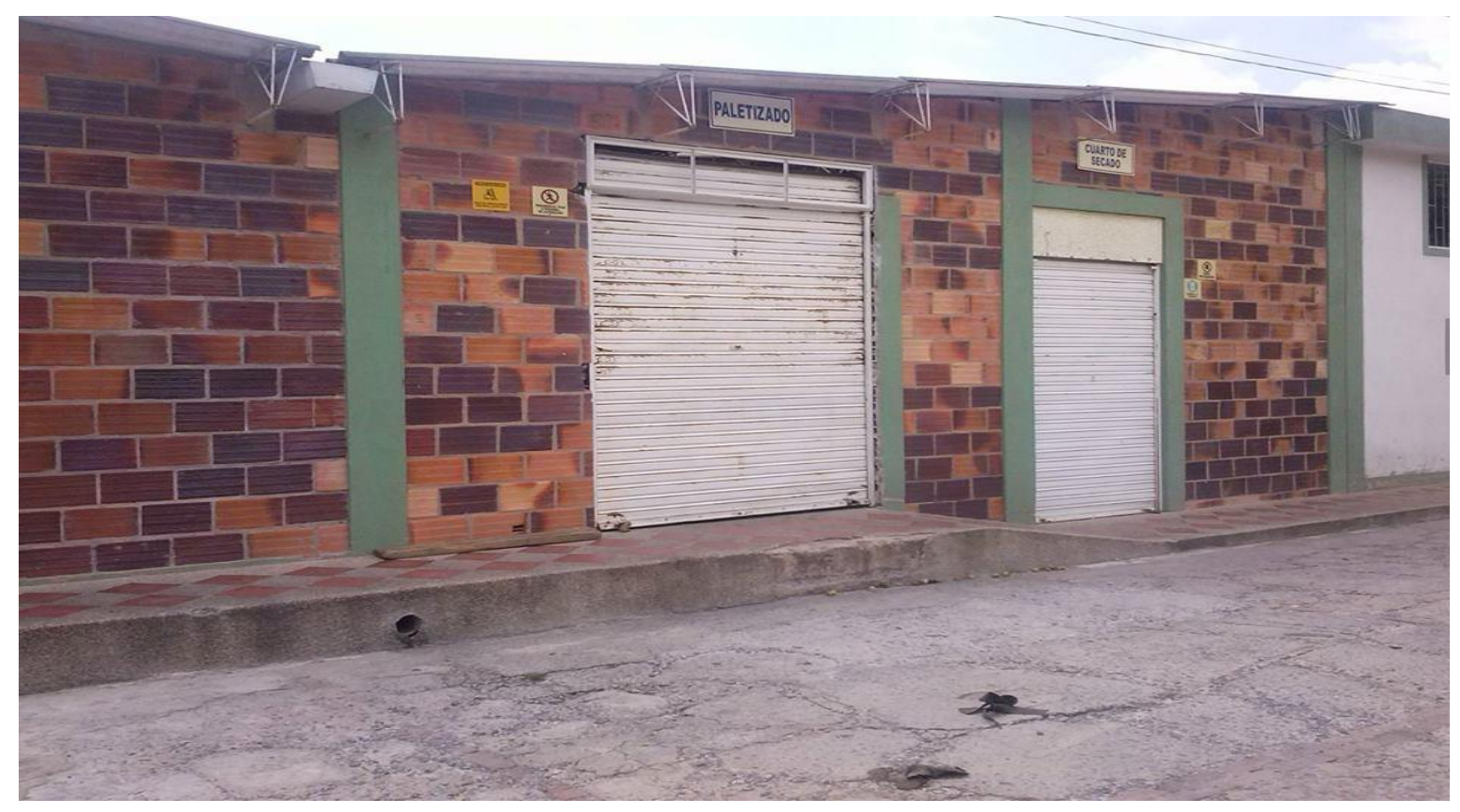

Foto 2 Fachada De La Bodega Actualmente

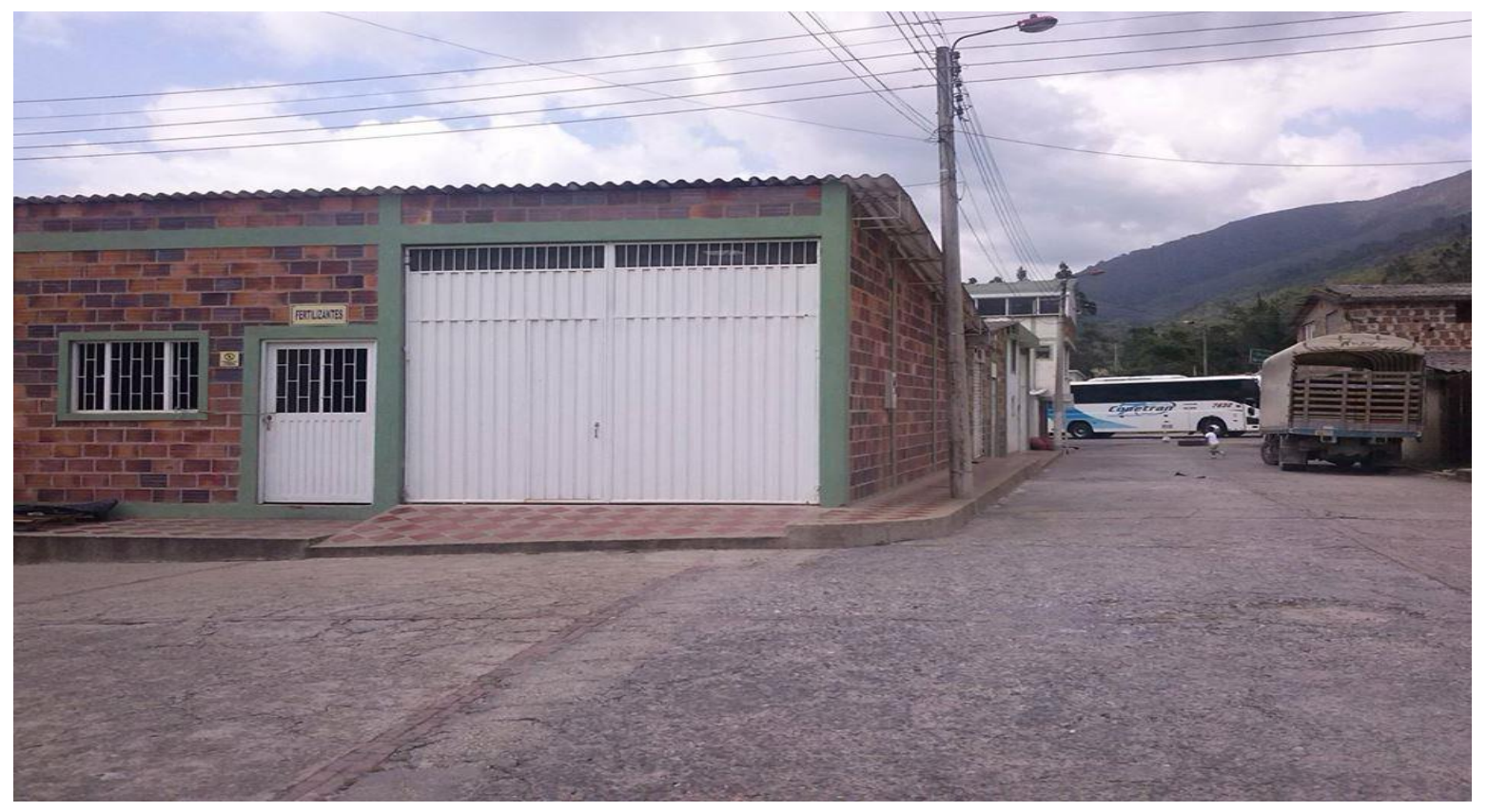

Fuente: Foto Tomada Por Las Autoras 


\subsection{DISTRIBUCIÓN DE LA PLANTA.}

Figura №5. DISTRIBUCIÓN DE LA PLANTA.

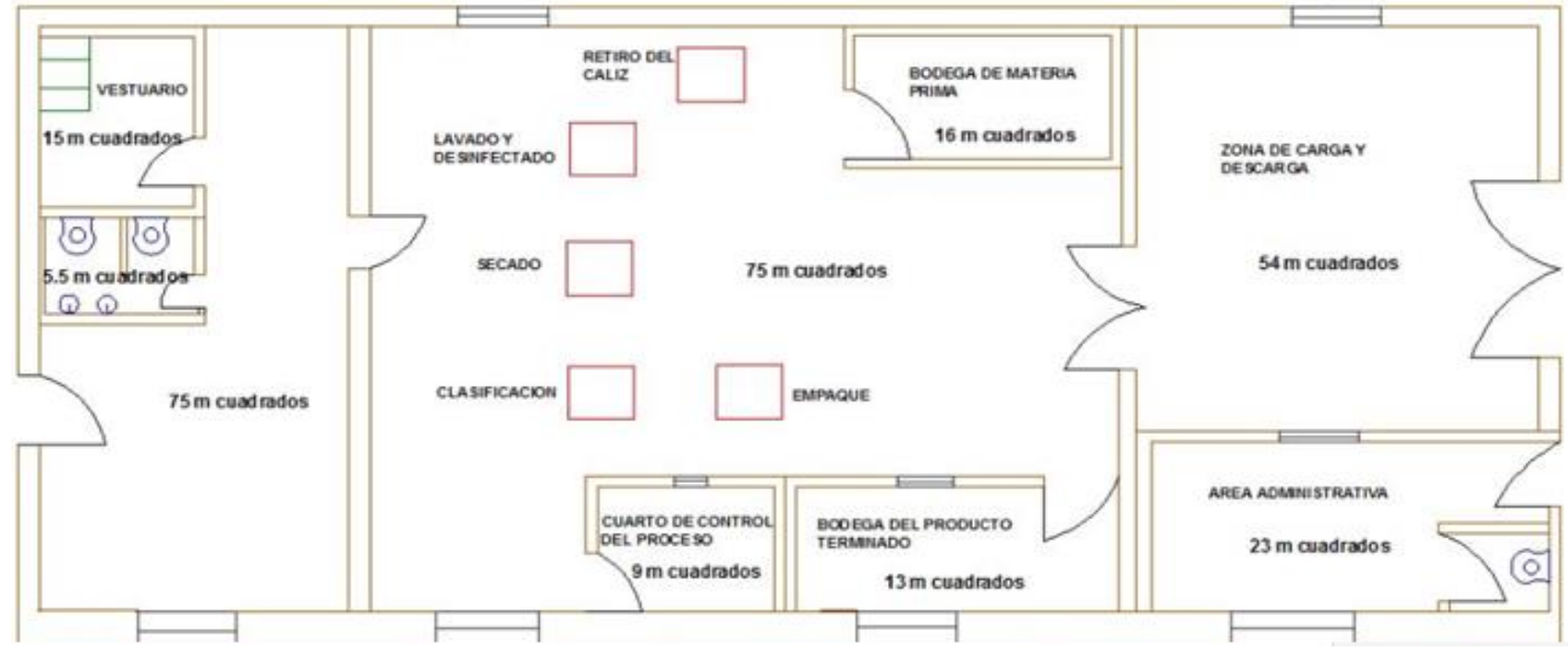

Fuente: Tomado De La Ayuda Del Estudiante de Ingeniera Mecánica, Daniel Felipe Engativá, Universidad Santo Tomas Tunja. 


\subsection{PLAN DE PRODUCCIÓN.}

\subsubsection{CONTROL DE CALIDAD.}

En este proceso la organización debe realizar procesos muy rigurosos que arrojen resultados de calidad mediante esfuerzo en cuanto a las funciones de trabajo en equipo sin dejar de lado las buenas relaciones personales y el trabajo en equipo y así compartan información necesaria para alcanzar metas propuestas en la empresa C I A\&D EXOTIC FRUIT S.A.S

La calidad de la uchuva se rige por la norma técnica Colombiana NTC 4580 de 1999; esta norma establece los requisitos que debe cumplir la uchuva destinada para el consumo en fresco o como materia prima para el procesamiento; para esto debe tener las siguientes características:

- Frutos enteros de forma esférica características de la uchuva.

- Coloración homogénea de los frutos dependiendo de estado de madurez.

- Aspecto fresco y consistencia firme.

- Corteza lisa y brillante.

- Frutos sanos libres de taques de insectos o enfermedades.

- Frutos libres de humedad externa anormal.

- Frutos exentos de cualquier olor, sabor y/o materiales extraños.

- Longitud de tallo que no exceda los $25 \mathrm{~mm}$.

- Con o sin capacho. 
- Para la exportación las uchuvas se presentan en empaques con dimensiones de $40 \mathrm{~cm} \times 30 \mathrm{~cm}$ o sub múltiplos de $12 \mathrm{~cm} \times 80 \mathrm{~cm}$.

- Los envases deberán brindar la suficiente protección al producto, de manera que se garantice la manipulación, transporte y conservación de las uchuvas.

- El contenido de cada envase debe ser homogéneo y estar constituido por uchuvas del mismo origen, variedad, categoría, color y calibre.

- Los materiales utilizados deben ser nuevos, limpios y no ocasionar ningún tipo de alteración al producto. Siempre que no sean tóxicos.

- Se permite la utilización de materiales, papeles o sellos.

\subsubsection{TALENTO HUMANO.}

Capacitar a los trabajadores y motivarlos al trabajo en equipo; así mismo dirigirlos y controlarlos con el fin de cumplir con los objetivos propuestos por la empresa sin dejar de lado el reconocimiento por todos y cada uno de sus esfuerzos.

\subsubsection{PAGO DE SALARIOS.}

Debe existir en la empresa C I A\&D EXOTIC FRUIT S.A.S una estabilidad laboral y salarial de todos los empleados con el fin de brindarles un mejor 
bienestar; y así poder controlar los costos, y de igual manera permita un desarrollo de la empresa en sus utilidades.

Así mismo se manejara un contrato de medio tiempo donde los operarios se turnaran en las labores correspondientes para así evitar fatigas y cansancio a la hora de laboral.

\subsubsection{TOMA DE DECISIONES.}

Las decisiones deben ser tomadas por el gerente de la empresa, estas decisiones deben ser eficientes, teniendo en cuenta la planeación, organización, dirección y control de la misma, Asumiendo sus responsabilidades.

\subsubsection{CLIENTE.}

Lograr la atención del cliente para estos utilizaremos diferentes estrategias de mercadeo para así posicionarnos y llegar a ser una de las más competitivas. Para así llegar a tener compras repetitivas. ${ }^{71}$

Como estrategias se utilizara el acompañamiento durante y después de la compra que hará que el cliente de Cl A\&D EXOTIC FRUIT S.A.S se fidelice y

\footnotetext{
${ }^{71}$ BELLO, Carlos. Manual de la Producción. Editorial Ecoe, 2010.
} 
crea en la empresa, a su vez los diferentes medios publicitarios para la acogida de estos mismos.

\subsubsection{MECANISMO DE COMPRAS (NEGOCIACIONES).}

- Comprar materia prima en el sector de calidad.

- Obtener la materia prima a gran escala con descuento.

- Buscar una estabilidad de los precios de la materia prima.

- Mantener los mismos proveedores para lograr mejores precios y descuentos.

- Comprar maquinaria con descuentos, de alta gama 


\section{CAPITULO 4. ADMINISTRATIVO Y ORGANIZACIONAL.}

El módulo de organización contiene el análisis de debilidades, oportunidades, fortalezas y amenazas que se identifican en el producto, la estructura organizacional donde describe los niveles directivos, administrativos y operativos con su manual de funciones. Igualmente los aspectos legales para la constitución de la empresa el tipo de sociedad que se conformaría y normas que regulan la actividad económica.

\subsection{TIPO DE COMERCIALIZADORA INTERNACIONAL}

Este plan de negocio tendrá la conformación de una sociedad por acciones simplificada (SAS) ya que nos presenta muchas ventajas las cuales vale la pena resaltar, estas ventajas son:

1. No tiene número mínimo ni máximo de accionistas.

2. Los accionistas responden hasta monto de aportes.

3. Permite libertad contractual, protege patrimonios filiares.

4. Los títulos representativos de las acciones circulan igual que una anónima.

5. Documento de constitución es privado no requiere escritura pública.

6. Protección de socios minoristas.

7. No requiere revisor fiscal (Sólo si supera topes). 
8. Posibilidad de transformación a SAS, de cualquier sociedad.

9. Supresión de prohibiciones del Código del Comercio.

10. Hay plena libertad para determinar la administración y organización de la sociedad:

-Definen la forma de administración y la facultad de los administradores.

- El representante legal es designado según estatutos.

- Junta directiva no es obligatoria (se puede pactar).

- Se puede escoger el mecanismo de elección más conveniente. ${ }^{72}$

Además de ser una sociedad S.A.S tendrá la conformación de una Comercializadora Internacional ya que con este tipo de sociedad podemos gozar de beneficios como líneas de Crédito Bancoldex, tener acceso directo o indirecto a los sistemas especiales de importación y exportación, así como la exención del IVA y del impuesto de retención en la fuente; además poder alcanzar los objetivos incluyendo diferentes actividades de promoción y comercialización de productos colombianos en el exterior. Crear una comercializadora en el departamento de Boyacá genera un gran impacto ya que todos y cada uno de los habitantes se favorecen con empleos y mejor calidad de vida. ${ }^{73}$

\subsection{FIGURA JURIDICA}

C.I A\&D EXOTIC FRUIT S.A.S

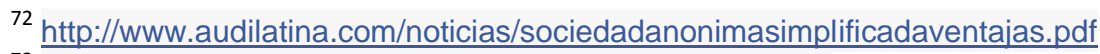

${ }^{73}$ http://www.icesi.edu.co/blogs/icecomex/2008/08/01/7/
} 


\subsection{DOMICILIO}

Este proyecto se realizara en el municipio de Arcabuco departamento de Boyacá en la dirección Av. $3-365$ ya que es apto para el almacenamiento de la fruta por su clima.

\subsection{IMAGEN CORPORATIVA}

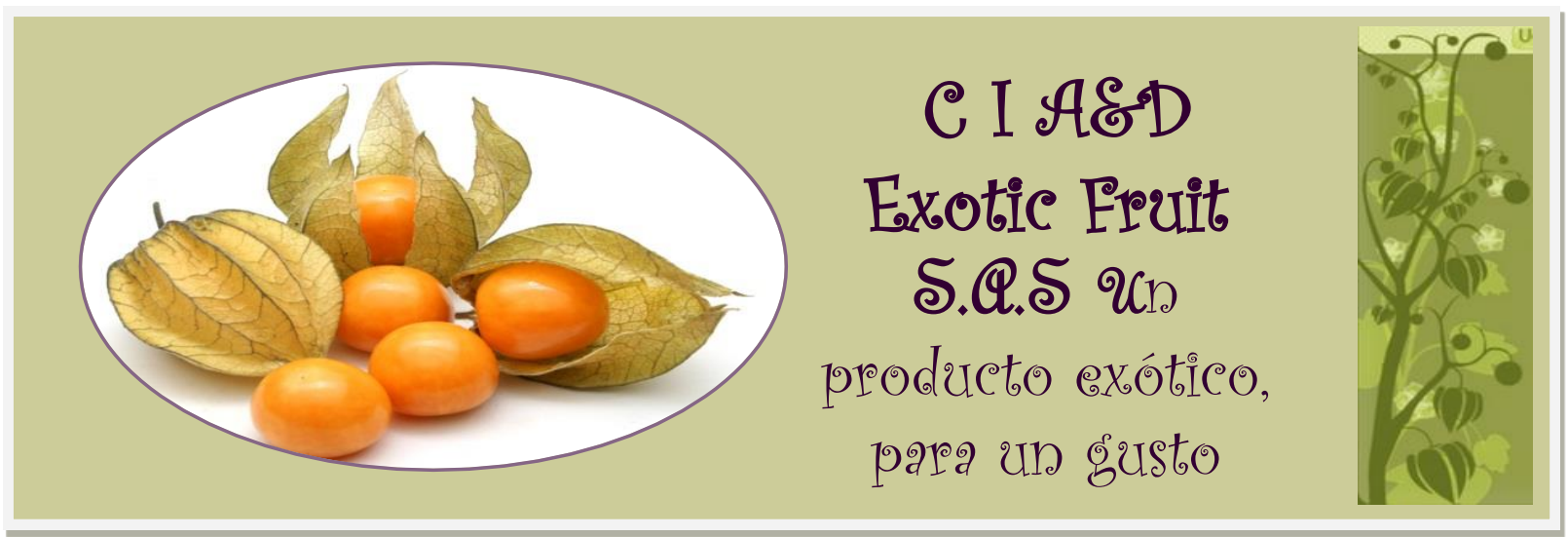




\subsection{ESTRUCTURA ORGANIZACIONAL}

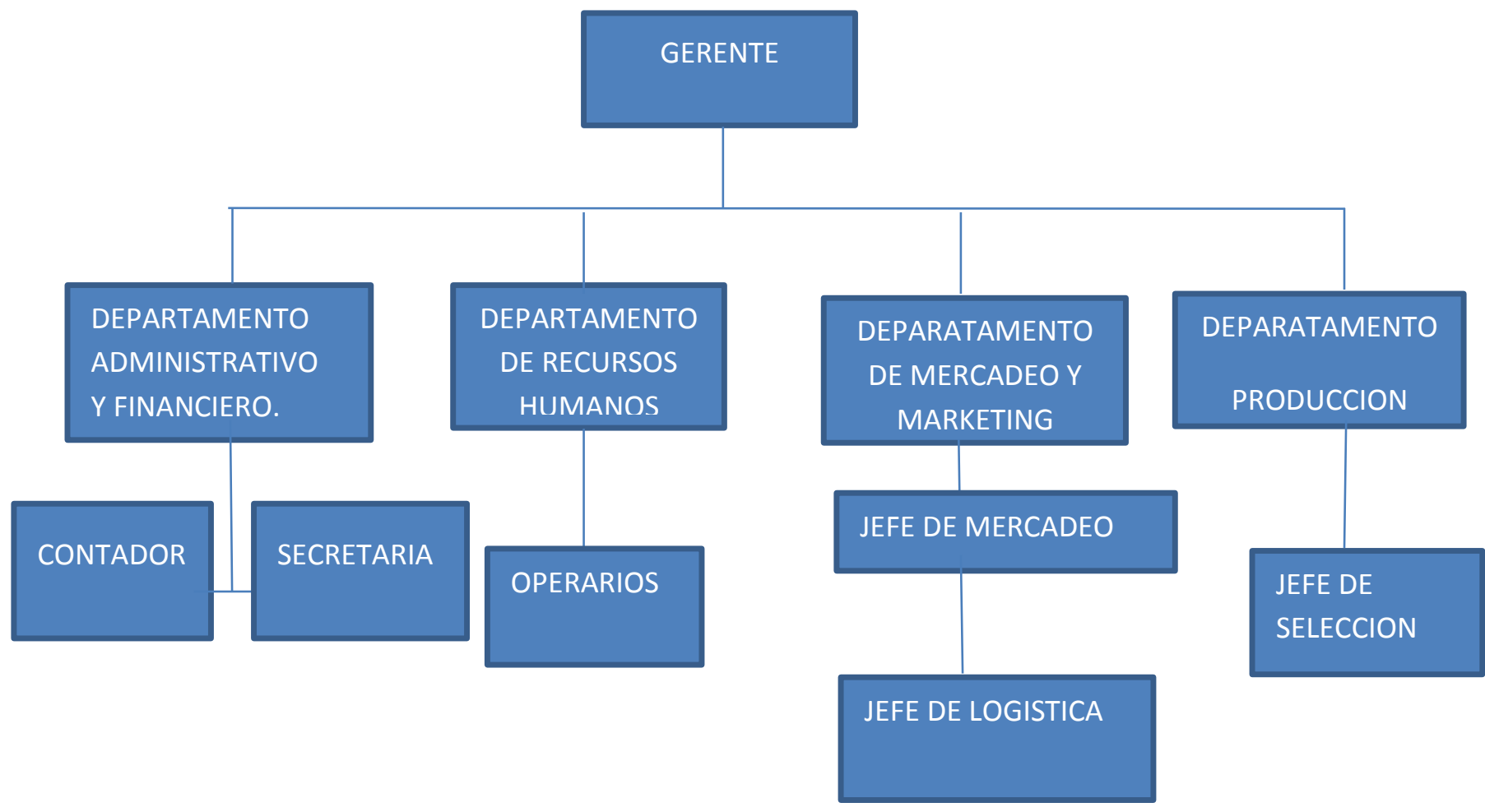

Fuente: Las autoras

\subsection{MANUAL DE FUNCIONES}

Tabla 5. Manual de funciones por cargos

\begin{tabular}{|c|c|c|c|c|}
\hline $\begin{array}{l}\text { NOMBRE DEL } \\
\text { CARGO }\end{array}$ & $\begin{array}{l}\text { FUNCION } \\
\text { PRINCIPAL }\end{array}$ & $\begin{array}{l}\text { DETALLE } \\
\text { FUNCIONES }\end{array}$ & SALARIO & $\begin{array}{l}\text { TIPO DE } \\
\text { CONTRATO }\end{array}$ \\
\hline ADMINISTRADOR & $\begin{array}{l}\text { Planificar, } \\
\text { organizar, } \\
\text { dirigir, } \\
\text { coordinar }\end{array}$ & $\begin{array}{lll}\text { Analizar } & \text { los } \\
\text { resultados } & & \\
\text { relacionados } & \text { con } & \text { lo } \\
\text { planeado } & y\end{array}$ & 2.000 .000 & Indefinido \\
\hline
\end{tabular}




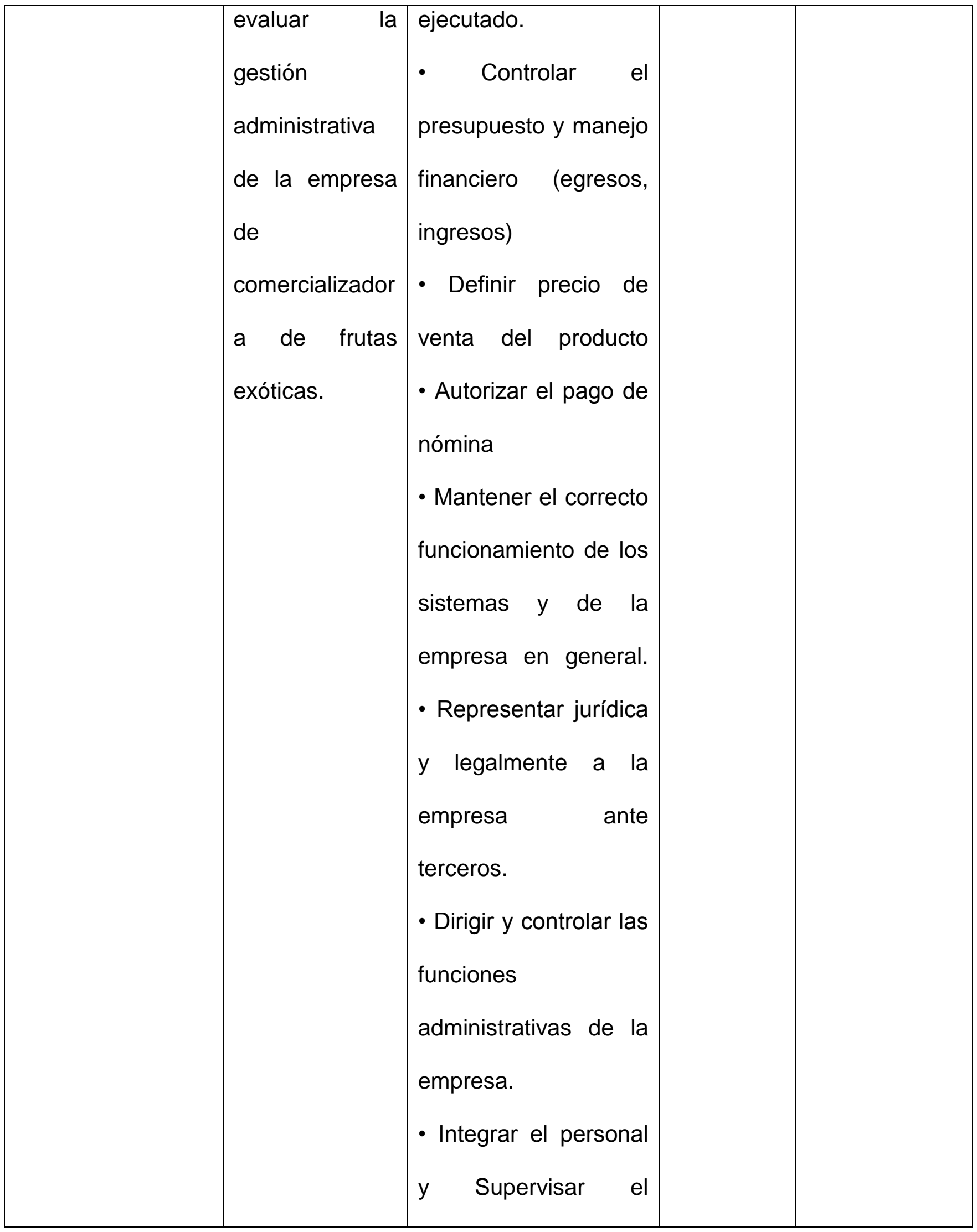




\begin{tabular}{|c|c|c|c|c|}
\hline & & $\begin{array}{l}\text { correcto y oportuno } \\
\text { cumplimiento de las } \\
\text { funciones del } \\
\text { personal analizando } \\
\text { la eficiencia del } \\
\text { desempeño del } \\
\text { trabajo. } \\
\text { - Autorizar las } \\
\text { compras. } \\
\text { - Autorizar todo } \\
\text { cheque expedido. } \\
\text { - Atender y promover } \\
\text { nuevos clientes y } \\
\text { rutas de ventas. } \\
\text { - Realizar estrategias } \\
\text { para el cumplimiento } \\
\text { de las metas. } \\
\text { - Analizar los informes } \\
\text { de las áreas. } \\
\text { actividades. }\end{array}$ & & \\
\hline SECRETARIA & Auxiliar & - Digitar y redactar & 800.000 & Termino Fijo \\
\hline
\end{tabular}




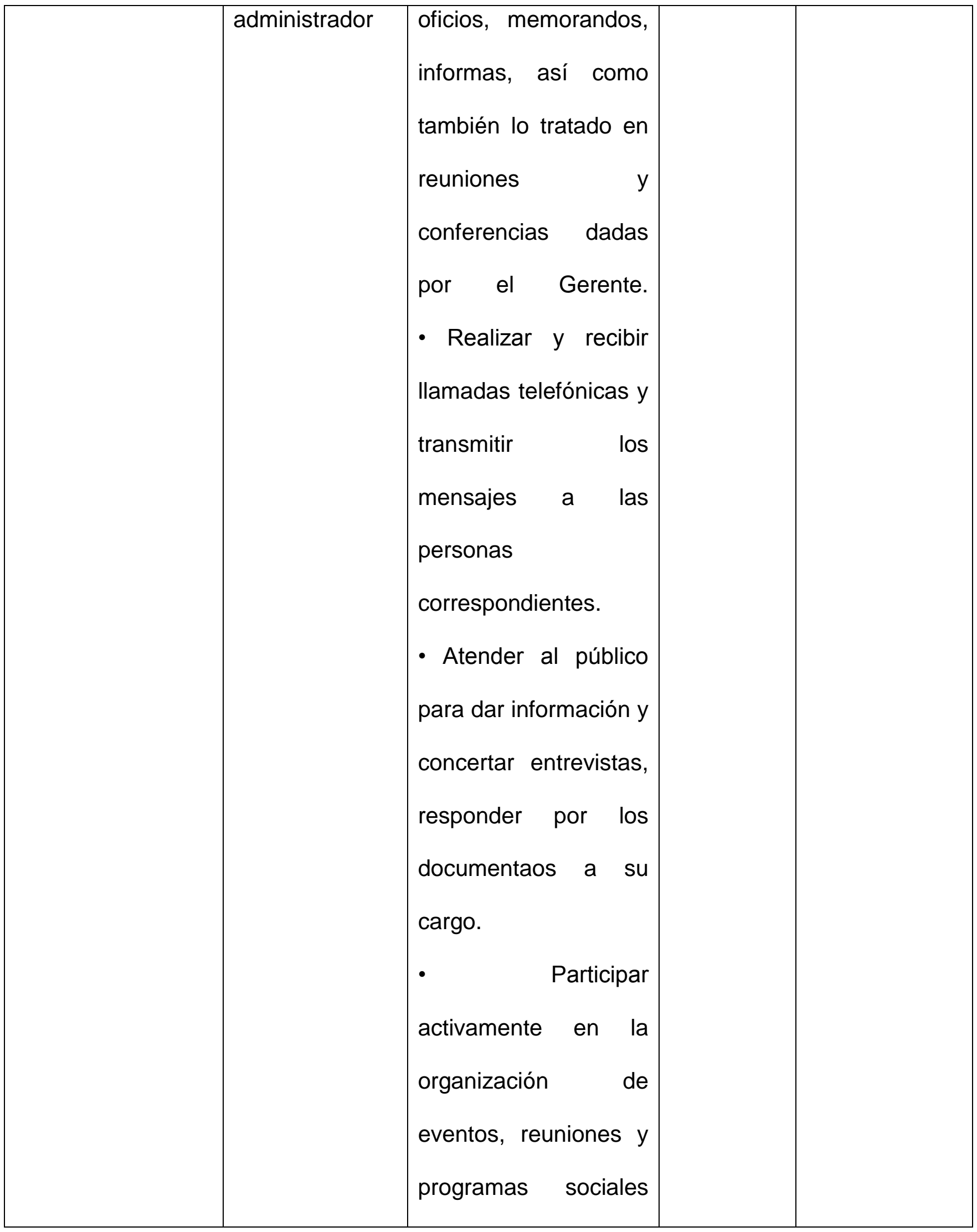




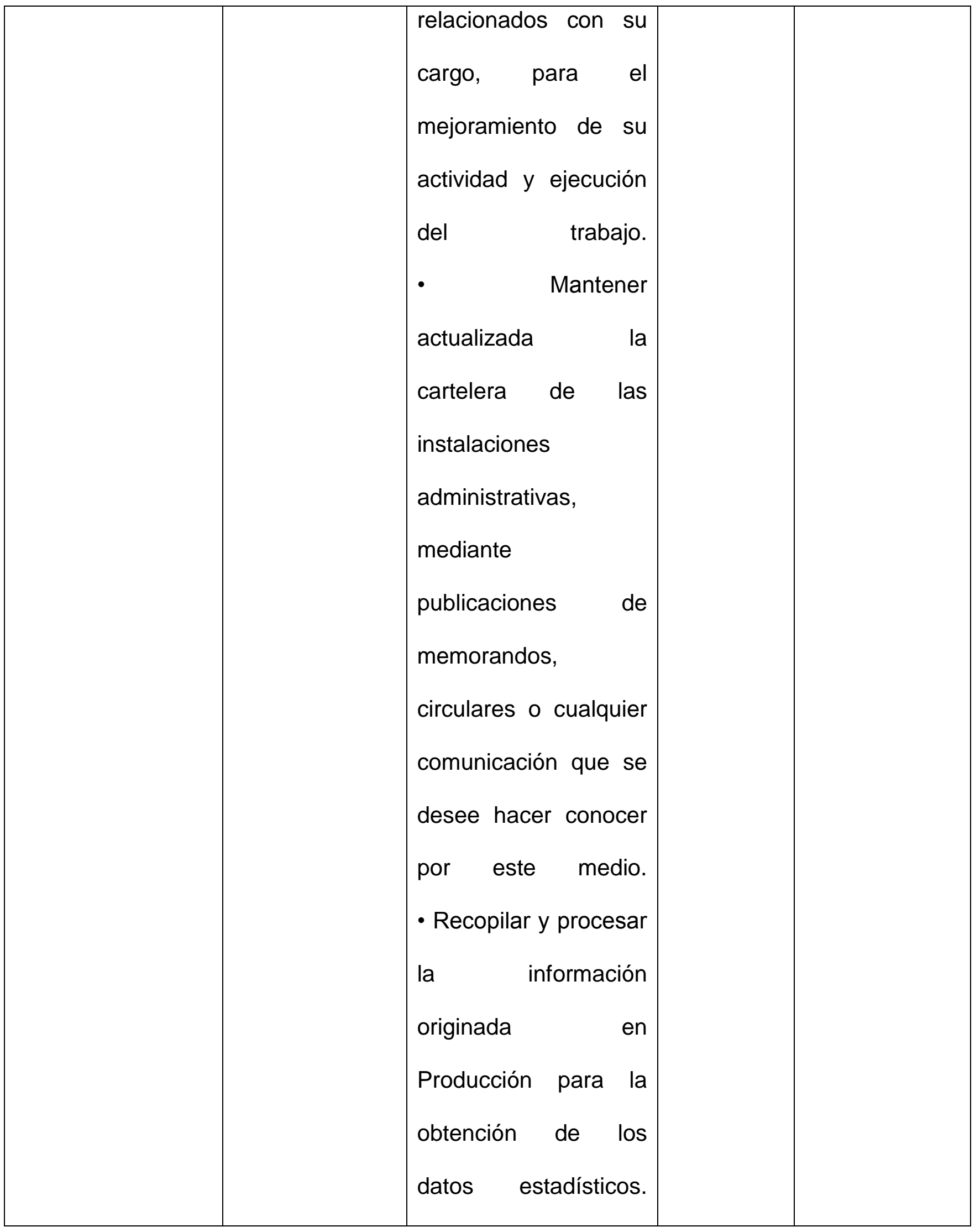




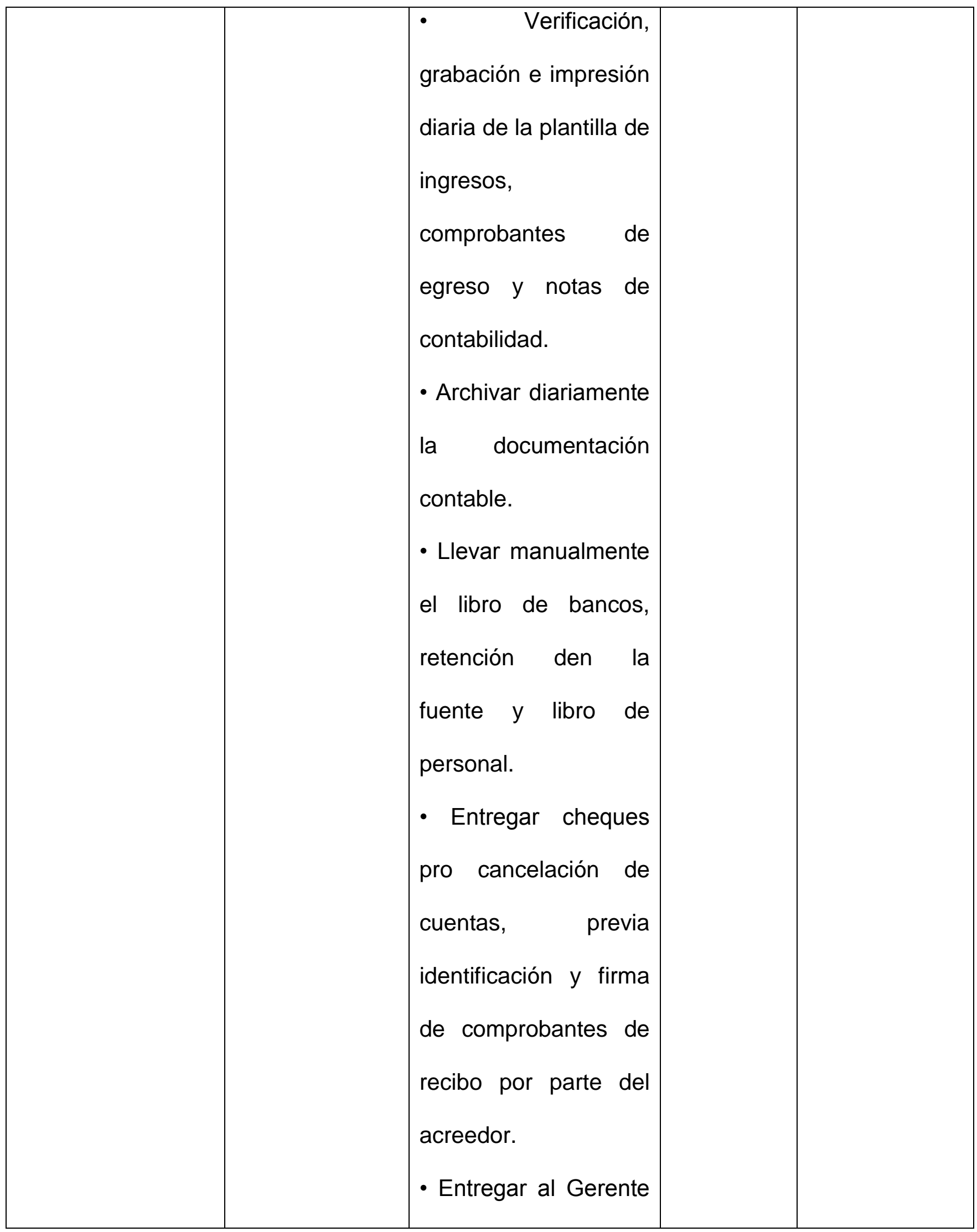




\begin{tabular}{|c|c|c|c|c|}
\hline & & $\begin{array}{l}\text { los cheques que éste } \\
\text { debe firmar, } \\
\text { adjuntando } \\
\text { comprobantes, } \\
\text { facturas y orden de } \\
\text { compra } \\
\text { correspondientes, } \\
\text { previo visto bueno. } \\
\text { - Las demás } \\
\text { funciones que por } \\
\text { relacionadas con el } \\
\text { cargo, legal, } \\
\text { disposición } \\
\text { emergencia } \\
\text { económica } \\
\text { necesidades } \\
\text { servicio sea necesario } \\
\text { asignarle. }\end{array}$ & & \\
\hline $\begin{array}{l}\text { OPERARIO } \\
\text { RECEPTOR DE } \\
\text { LA FRUTA. }\end{array}$ & $\begin{array}{l}\text { Realizar los } \\
\text { procesos de } \\
\text { producción de } \\
\text { acuerdo a las } \\
\text { especificacione }\end{array}$ & $\begin{array}{l}\text { Se encargaran de } \\
\text { todos los procesos } \\
\text { de producción del } \\
\text { yogurt de uchuva } \\
\text { pasteurizado de la }\end{array}$ & $\begin{array}{l}\text { Salario } \\
\text { mínimo } \\
616.000\end{array}$ & Termino fijo \\
\hline
\end{tabular}




\begin{tabular}{|l|l|l|}
\hline S & recepción de la \\
materia prima \\
hasta el \\
almacenaje del \\
producto \\
terminado. \\
Capacidad para el \\
control de calidad \\
del producto. \\
Elaborar la \\
producción de \\
acuerdo a las \\
especificaciones y \\
la fecha de \\
entrega. \\
informar \\
oportunamente los \\
irregularidades del \\
producto \\
terminado.
\end{tabular} \mid




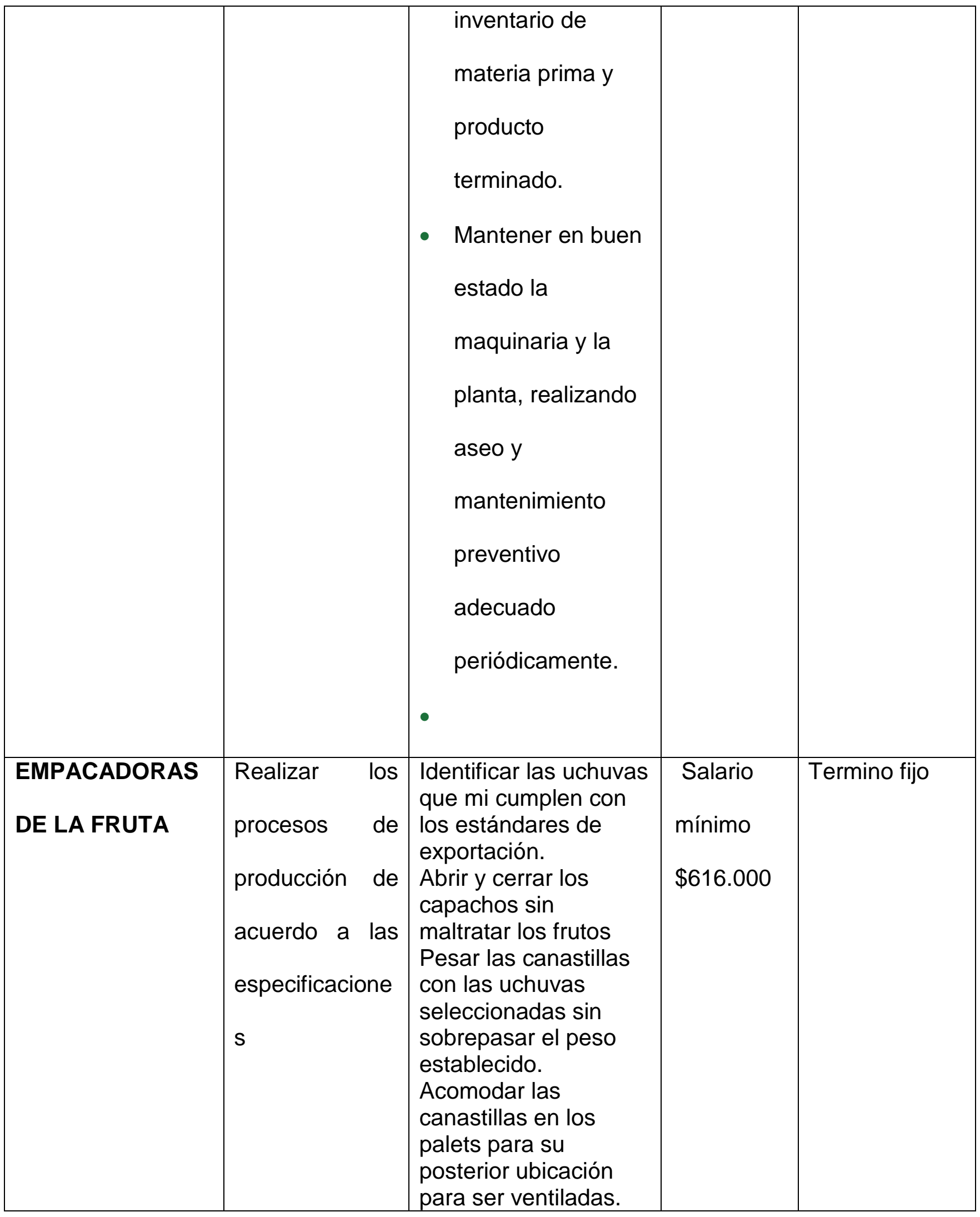


Fuente: Tomado de la pagina

http://wwwolgaluciasenacom.blogspot.com/p/manual-de-funciones-empresaprocesadora.html.

\begin{tabular}{|c|c|c|}
\hline \multicolumn{3}{|l|}{ NOMBRE : } \\
\hline $\begin{array}{l}\text { ÁREA: } \\
\text { Administrativa }\end{array}$ & CARGO: Gerente / Administrador. & CÓDIGO: 001 \\
\hline \multicolumn{2}{|c|}{ OBJETIVO: Gerencia y Administración de la empresa } & FECHA: \\
\hline \multicolumn{2}{|c|}{ JEFE INMEDIATO: JUNTA DIRECTIVA } & VERSIÓN No. 01 \\
\hline \multicolumn{3}{|l|}{ FUNCIONES } \\
\hline \multicolumn{3}{|c|}{-Realizar las negociaciones con los proveedores del producto } \\
\hline \multicolumn{3}{|c|}{-Representar legalmente a la empresa. } \\
\hline \multicolumn{3}{|c|}{-Responder por la rentabilidad y sostenibilidad de la empresa } \\
\hline \multicolumn{3}{|c|}{-Verificar y Certificar los estados financieros de la organización } \\
\hline \multicolumn{3}{|c|}{$\begin{array}{l}\text {-Realizar negociaciones con los clientes potenciales del producto y buscar } \\
\text { nuevos nichos de mercado. }\end{array}$} \\
\hline \multicolumn{3}{|c|}{$\begin{array}{l}\text {-Verificar y hacer cumplir las funciones de cada uno de los colaboradores, según } \\
\text { el manual de cada cargo. }\end{array}$} \\
\hline \multicolumn{3}{|c|}{-Generación de estrategias diferenciadoras para la empresa } \\
\hline \multicolumn{3}{|c|}{$\begin{array}{l}\text {-Planificar, organizar, dirigir, las políticas de la empresa para el logro de los } \\
\text { objetivo. }\end{array}$} \\
\hline PERFIL Y/O EX & IENCIA REQUERIDA & \\
\hline
\end{tabular}




\begin{tabular}{|l|l|}
\hline -Profesional en Administración de & - Habilidades: liderazgo, planeación, \\
Empresas & organización \\
\hline -1 año de experiencia en Gerencia & - Dirección, control, relaciones \\
& interpersonales \\
\hline
\end{tabular}

\begin{tabular}{|l|l|}
\hline \multicolumn{2}{|l|}{ NOMBRE : } \\
\hline ÁREA: & CÓDIGO: 002 \\
\hline $\begin{array}{l}\text { OBJETIVO: } \\
\text { financieros de la organización. }\end{array}$ & FECHA: \\
\hline CARGO A QUIEN REPORTA: Gerente & VERSIÓN No. 01 \\
\hline FUNCIONES & \\
\hline -Realizar y controlar la contabilidad de la organización, verificar facturas de \\
compra y venta del producto.
\end{tabular}




\begin{tabular}{|c|c|c|c|}
\hline \multicolumn{4}{|l|}{ NOMBRE : } \\
\hline $\begin{array}{l}\text { ÁREA: } \\
\text { Administrativa }\end{array}$ & \multicolumn{2}{|c|}{ CARGO: Secretaria } & CÓDIGO: 003 \\
\hline \multicolumn{3}{|c|}{$\begin{array}{l}\text { OBJETIVO: Tomar nota y llevar registro de cada uno de } \\
\text { los asuntos administrativos de la empresa. }\end{array}$} & FECHA: \\
\hline \multicolumn{3}{|c|}{ JEFE INMEDIATO: Gerente } & VERSIÓN No. 01 \\
\hline \multicolumn{4}{|l|}{ FUNCIONES } \\
\hline \multicolumn{4}{|c|}{$\begin{array}{l}\text { - Digitar y redactar oficios, memorandos, informas, así como también lo tratado } \\
\text { en reuniones y conferencias dadas por el Gerente. }\end{array}$} \\
\hline \multicolumn{4}{|c|}{$\begin{array}{l}\text { - Realizar y recibir llamadas telefónicas y transmitir los mensajes a las personas } \\
\text { correspondientes. }\end{array}$} \\
\hline \multicolumn{4}{|c|}{$\begin{array}{l}\text { - Atender al público para dar información y concertar entrevistas, responder por } \\
\text { los documentaos a su cargo }\end{array}$} \\
\hline \multicolumn{4}{|c|}{$\begin{array}{l}\text {-Planificar, organizar, dirigir, las políticas de la empresa para el logro de los } \\
\text { objetivo. }\end{array}$} \\
\hline \multicolumn{4}{|c|}{ PERFIL Y/O EXPERIENCIA REQUERIDA } \\
\hline \multicolumn{2}{|c|}{$\begin{array}{l}\text {-Profesional en Secretariado } \\
\text { Ejecutivo Sistematizado }\end{array}$} & \multicolumn{2}{|c|}{$\begin{array}{l}\text { - Habilidades: liderazgo, planeación, } \\
\text { organización }\end{array}$} \\
\hline \multicolumn{2}{|c|}{-1 año de experiencia en el cargo } & \multicolumn{2}{|c|}{$\begin{array}{l}\text { - Cumplimiento, control, relaciones } \\
\text { interpersonales }\end{array}$} \\
\hline
\end{tabular}




\begin{tabular}{|c|c|c|c|}
\hline \multicolumn{4}{|l|}{ NOMBRE : } \\
\hline $\begin{array}{l}\text { ÁREA: } \\
\text { Administrativa }\end{array}$ & \multicolumn{2}{|c|}{ CARGO: Operario } & CÓDIGO: 004 \\
\hline \multicolumn{3}{|c|}{$\begin{array}{l}\text { OBJETIVO: Realizar los procesos de producción de } \\
\text { acuerdo a las especificaciones. }\end{array}$} & FECHA: \\
\hline \multicolumn{3}{|c|}{ JEFE INMEDIATO: Gerente } & VERSIÓN No. 01 \\
\hline \multicolumn{4}{|l|}{ FUNCIONES } \\
\hline \multicolumn{4}{|c|}{ - Capacidad para el control de calidad del producto } \\
\hline \multicolumn{4}{|c|}{ - Elaborar la producción de acuerdo a las especificaciones y la fecha de entrega. } \\
\hline \multicolumn{4}{|c|}{$\begin{array}{l}\text { - Mantener en buen estado la maquinaria y la planta, realizando aseo y } \\
\text { mantenimiento preventivo adecuado periódicamente. }\end{array}$} \\
\hline \multicolumn{4}{|c|}{ - Informar oportunamente los defectos e irregularidades del producto terminado } \\
\hline \multicolumn{4}{|c|}{ PERFIL Y/O EXPERIENCIA REQUERIDA } \\
\hline & & \multicolumn{2}{|c|}{$\begin{array}{l}\text { - Habilidades: liderazgo, tener } \\
\text { conocimiento en funcionamiento de } \\
\text { maquinarias }\end{array}$} \\
\hline \multicolumn{2}{|c|}{-1 año de experiencia en el cargo } & \multicolumn{2}{|c|}{$\begin{array}{l}\text { - Cumplimiento, control, relaciones } \\
\text { interpersonales }\end{array}$} \\
\hline
\end{tabular}

Fuente: Las autoras 


\begin{tabular}{|c|c|c|c|}
\hline \multicolumn{4}{|l|}{ NOMBRE : } \\
\hline $\begin{array}{l}\text { ÁREA: } \\
\text { Administrativa }\end{array}$ & \multicolumn{2}{|c|}{ CARGO: Operaria } & CÓDIGO: 005 \\
\hline \multicolumn{3}{|c|}{$\begin{array}{l}\text { OBJETIVO: Realizar los procesos de producción de } \\
\text { acuerdo a las especificaciones }\end{array}$} & FECHA: \\
\hline \multicolumn{3}{|c|}{ JEFE INMEDIATO: JUNTA DIRECTIVA } & VERSIÓN No. 01 \\
\hline \multicolumn{4}{|l|}{ FUNCIONES } \\
\hline \multicolumn{4}{|c|}{ - Identificar las uchuvas q mi cumplen con los estándares de exportación } \\
\hline \multicolumn{4}{|c|}{ - Abrir y cerrar los capachos sin maltratar los frutos } \\
\hline \multicolumn{4}{|c|}{$\begin{array}{l}\text { - Pesar las canastillas con las uchuvas seleccionadas sin sobrepasar el peso } \\
\text { establecido }\end{array}$} \\
\hline \multicolumn{4}{|c|}{$\begin{array}{l}\text { - Acomodar las canastillas en los palets para su posterior ubicación para ser } \\
\text { ventiladas }\end{array}$} \\
\hline \multicolumn{4}{|c|}{ PERFIL Y/O EXPERIENCIA REQUERIDA } \\
\hline \multicolumn{2}{|l|}{-Bachiller } & \multicolumn{2}{|c|}{$\begin{array}{l}\text { - Habilidades: liderazgo, planeación, } \\
\text { organización }\end{array}$} \\
\hline \multicolumn{2}{|c|}{$\begin{array}{l}-6 \text { Meses de experiencia en } \\
\text { Gerencia }\end{array}$} & \multicolumn{2}{|c|}{ - Relaciones interpersonales } \\
\hline
\end{tabular}

\subsection{MISIÓN}

Comercializar uchuvas frescas convencionales contribuyendo al desarrollo del departamento de Boyacá dirigido hacia mercados internacionales satisfaciendo las necesidades y deseos de los clientes bajo estándares de calidad. 


\subsection{VISIÓN.}

En el año 2017 posicionarnos en el mercado internacional como uno de los principales exportadores de uchuvas frescas de Boyacá.

\subsection{VALORES.}

Respeto, compromiso, honestidad, lealtad, trabajo en equipo.

\subsubsection{ESPÍRITU CONSTRUCTIVO.}

Se refiere al optimismo, actitud positiva, al incremento de la cadena de valor, a la creatividad y a la buena fe que deben prevalecer en la intención y en la acción de quienes trabajamos en C I A\&D EXOTIC FRUITS S.AS.

\subsubsection{RESPETO POR LOS DEMÁS.}

Este valor nos lleva a la cordialidad, armonía, aceptación e inclusión que son dignos de distintivos de las relaciones interpersonales y así mismo entre las áreas dentro del entorno laboral de Cl A\&D EXOTICS FRUITS S.AS. 


\subsubsection{LEALTAD.}

Se refiere a la fidelidad, compromiso, identificación, confidencialidad y defensa de intereses que en todo momento debemos demostrar en nuestra empresa y entre quienes laboramos allí.

\subsubsection{PROFESIONALISMO.}

Se refiere a la responsabilidad, seriedad, constancia, involucramiento, entrega, dedicación y esmero que cada integrante del equipo de trabajo debe transmitir en cada una de sus funciones y tareas.

\subsubsection{HONESTIDAD.}

Este valor tiene que ver con rectitud, honorabilidad, decoro, respeto y modestia que debemos manifestar cada uno de los integrantes de $\mathbf{C l}$ A\&D EXOTIC FRUITS S.A.S.

\section{10 ANALISIS DOFA \\ 4.10.1 MATRIZ DOFA}

A continuación se diferenciaran las fortalezas, debilidades, oportunidades y amenazas que se pueden obtener en la comercializadora C I A\&D EXOTIC FRUITS S.A.S 
Cuadro N 4 MATRIZ DOFA.

\begin{tabular}{|c|c|}
\hline FORTALEZAS. & DEBILIDADES. \\
\hline $\begin{array}{l}\text { - Elevado nivel de compromiso } \\
\text { con la empresa. }\end{array}$ & $\begin{array}{l}\text { - Sistema de comercialización a } \\
\text { través de intermedios. }\end{array}$ \\
\hline $\begin{array}{l}\text { - Empresarias con capacidad de } \\
\text { tomar riesgos. } \\
\text { - Relación de confianza }\end{array}$ & $\begin{array}{l}\text { - Cultivos desarrollados son } \\
\text { técnicas no certificación ( } \\
\text { NTC4580 de 1999) }\end{array}$ \\
\hline $\begin{array}{l}\text { existente con varios de los } \\
\text { empresarios dedicados a este } \\
\text { sector. }\end{array}$ & $\begin{array}{l}\text { - Bajo volumen de producción. } \\
\text { - Deficiente capacidad } \\
\text { organizativa de la empresa. }\end{array}$ \\
\hline $\begin{array}{l}\text { - Esta fruta cuenta con uno de } \\
\text { los bancos de germoplasma } \\
\text { más completos de Colombia, }\end{array}$ & $\begin{array}{l}\text { - Poca preocupación por la } \\
\text { calidad del fruto por parte de } \\
\text { los comercializadores internos. }\end{array}$ \\
\hline $\begin{array}{l}\text { obtenido al identificar la } \\
\text { diversidad genética de nuestra } \\
\text { segunda fruta más exportada }{ }^{74} \\
\text { así logrando ser conservada } \\
\text { naturalmente y no con } \\
\text { químicos. }\end{array}$ & $\begin{array}{l}\text { - De acuerdo a normas } \\
\text { fitosanitarias no se permite el } \\
\text { ingreso a otros países ej. } \\
\text { estados unidos, de la uchuva } \\
\text { colombiana. }\end{array}$ \\
\hline
\end{tabular}

${ }^{74}$ http://historico.unperiodico.unal.edu.co/ediciones/62/11.htm 


\begin{tabular}{|c|c|}
\hline OPORTUNIDADES. & AMENAZAS. \\
\hline $\begin{array}{l}\text { - Mayor poder de negociación y } \\
\text { de abarcar nuevos mercados } \\
\text { en el extranjero ya que esta } \\
\text { futa es muy apetecida en ese } \\
\text { mercado y puede ser } \\
\text { aprovechada de manera } \\
\text { diferente. } \\
\text { - En el futuro poder transformar } \\
\text { la uchuva y así poder ofrecer } \\
\text { nuevos productos en el } \\
\text { mercado. } \\
\text { Fruta exótica cosechada en el } \\
\text { departamento de Boyacá que } \\
\text { puede ser aprovechada no solo } \\
\text { en el mercado interno sino } \\
\text { también en el extranjero. } \\
\text { Es un producto muy apetecido } \\
\text { en el exterior. }\end{array}$ & $\begin{array}{l}\text { - Cambios bruscos de tiempo, } \\
\text { debido a fenómenos } \\
\text { climatológicos ( fenómeno del } \\
\text { niño) } \\
\text { - Generación de una mala fama, } \\
\text { debido a productores que } \\
\text { estafen al comprador. } \\
\text { - Competencia desleal por parte } \\
\text { de otros exportadores y } \\
\text { comercializadores de uchuva. }\end{array}$ \\
\hline
\end{tabular}

Fuente. Las autoras Del Proyect 


\subsection{MAPA DE PROCESOS.}

FIGURA 6. MAPA PROCESOS
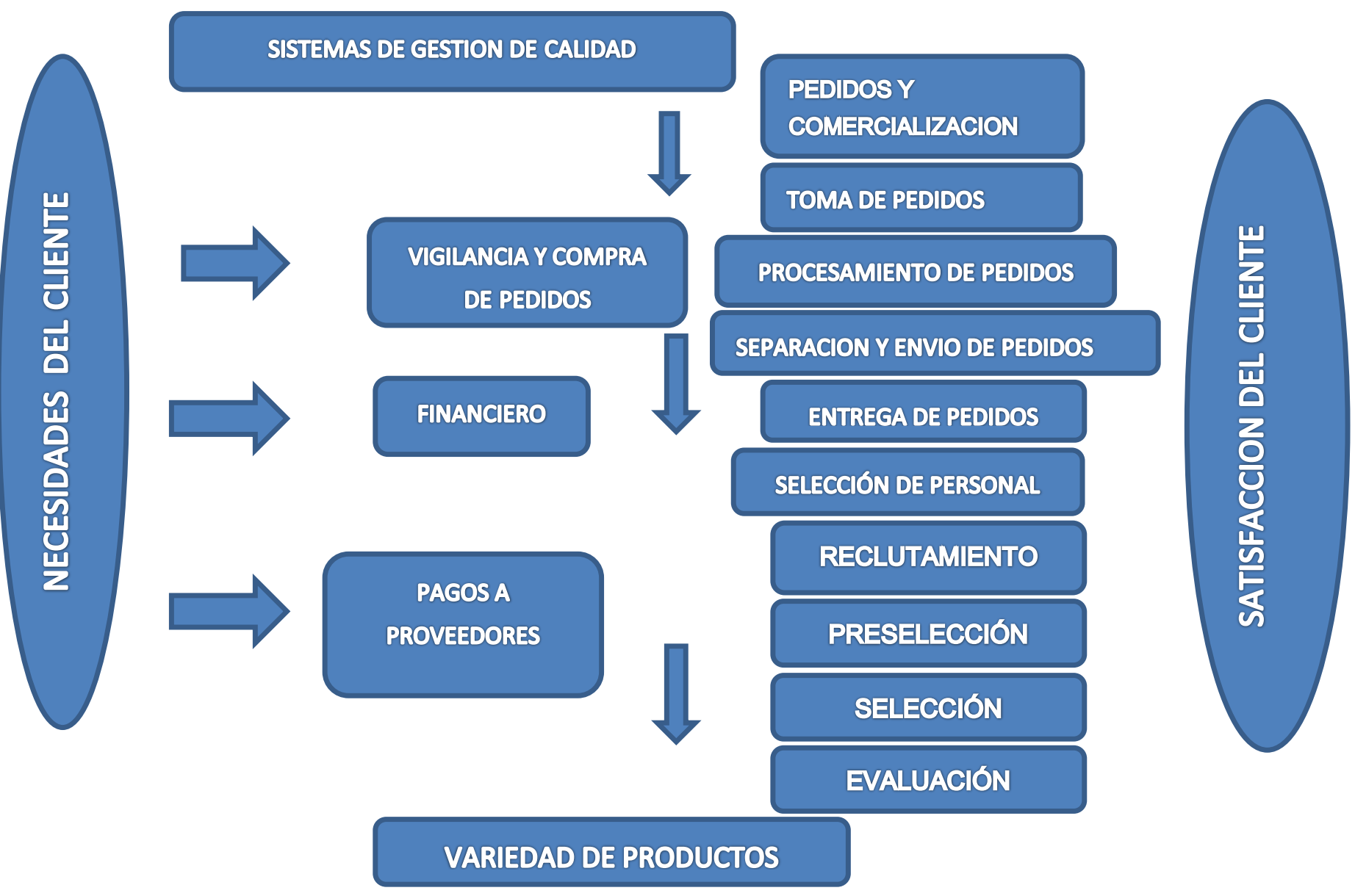

Fuente: Las Autoras 


\section{CAPITULO 5. DE EVALUACION ECONOMICA Y FINANCIERA}

La información presentada en los Estados Financieros de C I A\&D EXOTICS FRUITS S.A.S y que serán analizados a continuación, son una fuente de información contable primordial para los directivos de la empresa ya que estos tomaran todas las decisiones de la empresa con relación a la información encontrada en la contabilidad, es por eso que debe conocer muy bien cómo está operando la empresa y las cifras le darán una visión clara de ello que junto al análisis permitirá un mejor entendimiento del movimiento de la organización.

Otros usuarios de la información son los asesores que tenga la empresa pues sobre las partidas y el análisis de las mismas podrán emitir conceptos con bases sólidas que reflejen la realidad de la empresa.

El análisis de la información contable es muy importante para los socios de La empresa pues les muestra la rentabilidad de su inversión, por ello están pendientes del comportamiento operativo y financiero de la empresa. Además si se desea buscar inversionistas para la empresa, la información contable se convierte en la fuente para anticiparse de alguna forma al comportamiento futuro de la empresa y les ayudara a tomar la decisión de hacer parte de la organización. 
Nuestros proveedores estarán muy interesados en la información financiera de C I A\&D EXOTICS FRUITS S.A.S, ya que esta muestra la estabilidad financiera de la empresa y la capacidad de pago que se tiene, generando con ello confianza para que los proveedores tengan la seguridad de que su dinero en las ventas producidas se cancelara según lo convenido.

Otros usuarios de la información interesados en la situación financiera de la empresa sin duda serán las entidades financieras que exigirán estos documentos como fuente principal para otorgar financiamiento de ser necesario y las de control estatal vigilando que los montos que se declaran o tributan correspondan a la realidad de los movimientos financieros velando por los intereses del Estado. 


\subsection{INVERSIONES}

A continuación se presenta el consolidado de detalles de las inversiones que se realizaran para este proyecto.

Tabla 6. Inversiones

\begin{tabular}{|c|c|c|c|}
\hline \multicolumn{4}{|c|}{ INVERSIONES } \\
\hline DETALLE DE INVERSION & CANTIDAD & $\begin{array}{c}\text { COSTO } \\
\text { UNITARIO }\end{array}$ & $\begin{array}{l}\text { COSTO } \\
\text { TOTAL }\end{array}$ \\
\hline \multicolumn{4}{|l|}{ MAQUINARIA Y EQUIPO } \\
\hline Cuarto Frio & 1 & 12.500 .000 & 12.500 .000 \\
\hline Bascula & 4 & 450.000 & 1.800 .000 \\
\hline Gramera & 15 & 16.000 & 240.000 \\
\hline Ventiladores & 10 & 123.000 & 1.230 .000 \\
\hline TOTAL MAQUINARIA Y EQUIPO & 30 & 13.089 .000 & 15.770 .000 \\
\hline \multicolumn{4}{|l|}{ HERRAMIENTAS Y MATERIALES } \\
\hline Canastilla Baja & 100 & 12.000 & 1.200 .000 \\
\hline Grapadoras & 5 & 38.000 & 190.000 \\
\hline Estampadoras & 2 & 780.000 & 1.560 .000 \\
\hline Estibas & 50 & 33.000 & 1.650 .000 \\
\hline TOTAL HERRAMIENTAS Y MATERIALES & 100 & 12.000 & 4.600 .000 \\
\hline \multicolumn{4}{|l|}{ MUEBLES Y ENSERES } \\
\hline Mesas & 10 & 440000 & 4400000 \\
\hline Sillas escritorio & 6 & 100000 & 600000 \\
\hline sillas rimax & 30 & 25000 & 750000 \\
\hline Escritorio & 2 & 320000 & 640000 \\
\hline Telefono & 2 & 60000 & 120000 \\
\hline Computador & 2 & 830.000 & 1660000 \\
\hline Impresora & 1 & 240.000 & 240000 \\
\hline TOTAL MUEBLES Y ENSERES & 53 & 2.015 .000 & 8.410 .000 \\
\hline \multicolumn{4}{|l|}{ OTRAS INVERSIONES } \\
\hline Caja Carton & 100 & 2.700 & 270.000 \\
\hline Estibas & 50 & 33.000 & 1.650 .000 \\
\hline Guantes & 900 & 108 & 97.200 \\
\hline Tapabocas & 900 & 160 & 144.000 \\
\hline Gorros & 900 & 200 & 180.000 \\
\hline Delantales & 60 & 15.000 & 900.000 \\
\hline Botas & 60 & 25.000 & 1.500 .000 \\
\hline Papeleria & 5 & 100.000 & 500.000 \\
\hline TOTAL & 183 & 15.116 .000 & 28.780 .000 \\
\hline
\end{tabular}

\section{ANALISIS}

De acuerdo a cada uno de los ítems de inversiones podemos ver que la inversión más significativa es la maquinaria y equipo que corresponde a un valor de 
15.770.000 ya que esto es primordial para llevar acabo nuestro proceso de exportación; la siguiente inversión corresponde al ítem de muebles y enseres con un valor de 8. 410.000 ya que como su nombre lo dice son todas aquellas cosas que intervienen de una u otra forma en el proceso, y por último en este proyecto se invertirá en herramientas y materiales por un monto de $\$ 4.600 .000$ los cuales serán representados en las canastillas para recepción de fruta.

\subsection{REINVERSION}

A continuación se muestra la reinversión de algunas de las inversiones que se realizaran año tras año y se determinó un aumento del 1,5\%.

Tabla 7. Reinversión

\begin{tabular}{|c|c|c|c|c|c|}
\hline \multicolumn{6}{|c|}{ REINVERSION } \\
\hline \multirow[b]{3}{*}{ DETALLE } & \multicolumn{5}{|c|}{ AÑOS } \\
\hline & 1 & 2 & 3 & 4 & 5 \\
\hline & 1,5 & 1,5 & 1,5 & 1,5 & 1,5 \\
\hline GRAMERA & - & & - & & 243.600 \\
\hline CANASTILLA BAJA & - & - & - & & 1.218 .000 \\
\hline VENTILADORES & - & - & - & - & 1.248 .450 \\
\hline ESTIBAS & 1.674 .750 & 1.699 .871 & 1.725 .369 & 1.751 .250 & 1.777 .519 \\
\hline GUANTES & 98.658 & 100.138 & 101.640 & 103.165 & 104.712 \\
\hline TAPABOCAS & 146.160 & 148.352 & 150.578 & 152.836 & 155.129 \\
\hline GORROS & 182.700 & 185.441 & 188.222 & 191.045 & 193.911 \\
\hline DELANTALES & 913.500 & 927.203 & 941.111 & 955.227 & 969.556 \\
\hline COMPUTADOR & 0 & 0 & 1.684 .900 & 0 & 1.710 .174 \\
\hline IMPRESORA & 0 & 0 & 243.600 & 0 & 247.254 \\
\hline TOTAL & 17.415 .768 & 17.677 .005 & 19.870 .660 & 18.211.292 & 23.151 .939 \\
\hline
\end{tabular}

\section{ANALISIS}

Se puede observar que la mayor reinversión será en el año 5 ya que la mayoría de las inversiones se harán en este año. 
Teniendo en cuenta que se tomó el $1,5 \%$ valor promedio de los incrementos anuales de cada uno.

\subsubsection{INVERSION DIFERIDA}

Tabla 8. Inversión diferida

\begin{tabular}{|c|c|}
\hline \multicolumn{2}{|c|}{ INVERSION DIFERIDA } \\
\hline ITEM & COSTO TOTAL \\
\hline MANO DE OBRA & 15.000 .000 \\
\hline & \\
\hline & \\
\hline TOTAL INVERSION DIFERIDA & $\mathbf{1 5 . 0 0 0 . 0 0 0}$ \\
\hline
\end{tabular}

ANALISIS

En cuanto a la mano de obra se evidencia el costo que tiene la elaboración de este proyecto y comprende todo lo que tiene que ver con el levantamiento de la información y desplazamientos. 


\subsection{COSTOS DE INSUMOS}

A continuación se presenta el costo de insumos que se necesitaran para el proceso que lleva la comercialización de la uchuva.

Tabla 9. Costo insumos

\begin{tabular}{|c|c|c|c|c|c|c|c|c|c|c|c|c|c|c|c|c|}
\hline \multicolumn{17}{|c|}{ COSTO DE INSUMOS } \\
\hline \multirow[b]{2}{*}{ DETALLE } & \multirow[b]{2}{*}{ UNIDAD } & \multicolumn{3}{|c|}{ AÑ01 } & \multicolumn{3}{|c|}{ AÑO2 } & \multicolumn{3}{|c|}{ AÑ03 } & \multicolumn{3}{|c|}{ AÑ 4} & \multicolumn{3}{|c|}{ AÑ05 } \\
\hline & & \begin{tabular}{|l|} 
VALOR \\
UNITARIO
\end{tabular} & $\begin{array}{l}\text { UNIDAD A } \\
\text { COMPRAR }\end{array}$ & COSTO ANUAL & \begin{tabular}{|l|} 
VALOR \\
UNITARIO
\end{tabular} & $\begin{array}{l}\text { UNIDADA } \\
\text { COMPRAR }\end{array}$ & COSTO ANUAL & \begin{tabular}{|l|} 
VALOR \\
UNITARIO
\end{tabular} & $\begin{array}{l}\text { UNIDAD A } \\
\text { COMPRAR }\end{array}$ & $\begin{array}{l}\text { COSTO } \\
\text { ANUAL }\end{array}$ & $\begin{array}{l}\text { VALOR } \\
\text { UNITARIO }\end{array}$ & $\begin{array}{l}\text { UNIDAD A } \\
\text { COMPRAR }\end{array}$ & $\begin{array}{l}\text { COSTO } \\
\text { ANUAL }\end{array}$ & VALOR UNITARIO & $\begin{array}{l}\text { UNIDAD A } \\
\text { COMPRAR }\end{array}$ & $\begin{array}{l}\text { COSTO } \\
\text { ANUAL }\end{array}$ \\
\hline CANASTLLA PLASTICA & 1 & 12.000 & 100 & 1.200 .000 & 12.180 & 100 & 1.218 .000 & 12.363 & 100 & 1.236 .270 & 12.548 & 100 & 1.254 .814 & 12.736 & 100 & 1.273 .636 \\
\hline CAJAS DE CARTON & 1 & 2.700 & 100 & 270.000 & 2.741 & 100 & 274.050 & 2.782 & 100 & 278.161 & 2.823 & 100 & 282.333 & 2.866 & 100 & 286.568 \\
\hline ZUNCHO & 1 & 25000 & 20 & 500.000 & 25.375 & 20 & 515.113 & 25.756 & 20 & 515.113 & 26.142 & 20 & 530.682 & 26.534 & 20 & 530.682 \\
\hline ESQUINEROS & 1 & 14.000 & 600 & 8.400 .000 & 14.210 & 600 & 8.526 .000 & 14.423 & 600 & 8.653 .890 & 14.639 & 600 & 8.783 .698 & 14.859 & 600 & 8.915 .454 \\
\hline CAUCHOS & 1 & 5.000 & 400 & 2.000 .000 & 5.075 & 400 & 2.030 .000 & 5.151 & 400 & 2.060 .450 & 5.228 & 400 & 2.091 .357 & 5.307 & 400 & 2.122 .727 \\
\hline ETIQUETAS & 1 & 500 & 5.000 & 2.500 .000 & 508 & 5.000 & 2.537 .500 & 515 & 5.000 & 2.575 .563 & 523 & 5.000 & 2.614 .196 & 531 & 5.000 & 2.653 .409 \\
\hline GRAPADOORAS & 1 & 38.000 & 5 & 190.000 & 38.570 & 5 & 192.850 & 39.149 & 5 & 195.743 & 39.736 & 5 & 198.679 & 40.332 & 5 & 201.659 \\
\hline ESTAMPADORA & 1 & 780.000 & 2 & 1.560 .000 & 791.700 & 5 & 3.958 .500 & 803.576 & 5 & 4.017 .878 & 815.629 & 5 & 4.078 .146 & 827.864 & 5 & 4.139 .318 \\
\hline \multicolumn{2}{|c|}{ TOTAL COSTOS INSUMOS } & & 6.227 & 16.620 .000 & & 6.230 & 19.252 .013 & & 6.220 & 15.319 .446 & & 6.220 & 15.557 .080 & & 6.220 & 15.782 .476 \\
\hline
\end{tabular}

\section{ANALISIS}

En cuanto a los costos de insumos, podemos observar que la inversión más grande es en la compra de esquineros, ya que estos son indispensables a la hora de proteger las cajas al ser enviadas al país de destino. 


\subsubsection{COSTOS DE MATERIA PRIMA}

A continuación se puede observar que para el desarrollo de este proyecto se tendrán los siguientes costos de materia prima.

Tabla 10. Costos de materia prima

\begin{tabular}{|c|c|c|c|c|c|c|c|c|c|c|c|c|c|c|c|}
\hline \multicolumn{16}{|c|}{ COSTO DE MATERIA PRIMA } \\
\hline \multirow[b]{2}{*}{ DETALLE } & \multicolumn{3}{|c|}{ AÑ 1} & \multicolumn{3}{|c|}{ AÑO2 } & \multicolumn{3}{|c|}{ AÑO3 } & \multicolumn{3}{|c|}{ AÑ 4} & \multicolumn{3}{|c|}{ AÑO5 } \\
\hline & $\begin{array}{c}\text { CANTIDAD } \\
\text { EN } \\
\text { TONELADAS }\end{array}$ & $\begin{array}{c}\text { VALOR } \\
\text { UNITARIO }\end{array}$ & $\begin{array}{l}\text { COSTO } \\
\text { ANUAL }\end{array}$ & CANTIDAD & $\begin{array}{c}\text { VALOR } \\
\text { UNITARIO }\end{array}$ & COSTO ANUAL & CANTIDAD & $\begin{array}{c}\text { VALOR } \\
\text { UNITARIO }\end{array}$ & COSTO ANUAL & CANTIDAD & $\begin{array}{l}\text { VALOR } \\
\text { UNITARIO }\end{array}$ & COSTO ANUAL & CANTIDAD & \begin{tabular}{|} 
VALOR \\
UNITARIO
\end{tabular} & $\begin{array}{l}\text { COSTO } \\
\text { ANUAL }\end{array}$ \\
\hline UCHUVA & 1,000 & $2,500,000$ & $2,500,000,000$ & 1,000 & $2,537,500$ & $2,537,500,000$ & 1,000 & $2,575,563$ & $2,575,562,500$ & 1,000 & $2,614,196$ & $2,614,195,938$ & 1,000 & $2,653,409$ & $2,653,408,877$ \\
\hline TOTAL COSTOS DE MP & 1,000 & & $2,500,000,000$ & 1,000 & & $2,537,500,000$ & 1,000 & & 2575.562500 & 1000 & & 2614.195 .938 & 1.000 & & 2653.408 .877 \\
\hline
\end{tabular}

\section{ANALISIS}

La inversión en materia prima durante el primer año corresponde a la compra de uchuva ya que esta es la única que vamos a utilizar para obtener nuestro producto a exportar. 


\subsection{COSTO DE MANO DE OBRA}

A continuación se evidencia el costo que se tendrá por cada uno de los jefes, operarios y administrativos de la organización año tras año.

Tabla 11. Costo de mano de obra

\begin{tabular}{|l|r|r|r|r|r|}
\hline \multicolumn{7}{|c|}{ COSTO MANO DE OBRA } \\
\hline CARGO & \multicolumn{1}{|c|}{ AÑO1 } & \multicolumn{1}{|c|}{ AÑ̃ 2 } & \multicolumn{1}{|c|}{ AÑ 3 } & \multicolumn{1}{|c|}{ AÑO 4 } & AÑO 5 \\
\hline ADMINISTRADOR & $24,000,000$ & $24,360,000$ & $24,725,400$ & $25,096,281$ & $25,472,725$ \\
\hline GERENTE & $24,000,000$ & $24,360,000$ & $24,725,400$ & $25,096,281$ & $25,472,725$ \\
\hline SECRETARIA & $9,600,000$ & $9,744,000$ & $9,890,160$ & $10,038,512$ & $10,189,090$ \\
\hline JEFE DE COORDINACION & $10,800,000$ & $10,962,000$ & $11,126,430$ & $11,293,326$ & $11,462,726$ \\
\hline JEFE DE RECEPCION DE FRUTA & $10,800,000$ & $10,962,000$ & $11,126,430$ & $11,293,326$ & $11,462,726$ \\
\hline JEFE DE CALIDAD & $10,800,000$ & $10,962,000$ & $11,126,430$ & $11,293,326$ & $11,462,726$ \\
\hline JEFE DE SELECCIÓN DE FRUTA & $10,800,000$ & $10,962,000$ & $11,126,430$ & $11,293,326$ & $11,462,726$ \\
\hline OPERARIOS & $221,770,000$ & $225,096,550$ & $228,472,998$ & $231,900,093$ & $235,378,595$ \\
\hline TOTAL COSTO MO & $322,570,000$ & $327,408,550$ & $332,319,678$ & $337,304,473$ & $342,364,041$ \\
\hline
\end{tabular}

\section{ANALISIS}

De acuerdo al cuadro anterior, el costo de mano de obra más significativo es el de los operarios, ya que estos son indispensables y los más importantes para realizar los procesos. 


\subsubsection{COSTO DE SERVICIOS}

A continuación se muestra los gastos que se tendrán de los servicios que se adquirirán para el proceso de la comercialización de la uchuva.

Tabla 12. Costos de servicios

\begin{tabular}{|l|r|r|r|r|r|}
\hline \multicolumn{7}{|c|}{ COSTOS SERVICIOS } \\
\hline DETALLE & \multicolumn{1}{|c|}{ AÑO1 } & AÑO 2 & AÑO 3 & AÑO 4 & AÑO 5 \\
\hline AGUA & $2,000,000$ & $2,030,000$ & $2,060,450$ & $2,091,357$ & $2,122,727$ \\
\hline LUZ & $3,600,000$ & $3,654,000$ & $3,708,810$ & $3,764,442$ & $3,820,909$ \\
\hline TELEFONIA CELULAR & $2,400,000$ & $2,436,000$ & $2,472,540$ & $2,509,628$ & $2,547,273$ \\
\hline INTERNET & 420,000 & 426,300 & 432,695 & 439,185 & 445,773 \\
\hline TOTAL SERVICIOS & $\mathbf{8 , 4 2 0 , 0 0 0}$ & $\mathbf{8 , 5 4 6 , 3 0 0}$ & $\mathbf{8 , 6 7 4 , 4 9 5}$ & $\mathbf{8 , 8 0 4 , 6 1 2}$ & $\mathbf{8 , 9 3 6 , 6 8 1}$ \\
\hline
\end{tabular}

\section{ANALISIS}

Podemos observar que el costo más alto lo tenemos en el servicio de luz, ya que esta es necesaria para el desempeño de la maquinaria y equipo requerida para el proceso en este caso el cuarto frio. 


\subsection{COSTO DE TRANSPORTE}

A continuación se observa el costo del traslado que tendrá la uchuva hasta el lugar pactado con el comprador.

Tabla 13. Costo de transporte

\begin{tabular}{|c|c|c|c|c|c|c|c|c|c|c|c|c|c|c|c|}
\hline \multicolumn{16}{|c|}{ COSTO DE TRANSPORTE } \\
\hline & \multicolumn{3}{|c|}{ AÑO1 } & \multicolumn{3}{|c|}{ AÑO 2} & \multicolumn{3}{|c|}{ AÑO 3} & \multicolumn{3}{|c|}{ AÑO 4} & \multicolumn{3}{|c|}{ AÑO 5} \\
\hline DESTINO & \begin{tabular}{|l|} 
UNIDADE \\
S
\end{tabular} & \begin{tabular}{|l|} 
COSTOX X \\
UNIDAD
\end{tabular} & $\begin{array}{l}\text { COSTO } \\
\text { ANUAL }\end{array}$ & \begin{tabular}{|l|} 
UNIDAD \\
ES
\end{tabular} & \begin{tabular}{|l} 
COSTOX \\
UNIDAD
\end{tabular} & $\begin{array}{l}\text { COSTO } \\
\text { ANUAL }\end{array}$ & \begin{tabular}{|l|} 
UNIDA \\
DES
\end{tabular} & \begin{tabular}{|l|} 
COSTOX X \\
UNIDAD
\end{tabular} & $\begin{array}{l}\text { COSTO } \\
\text { ANUAL }\end{array}$ & $\begin{array}{l}\text { UNIDA } \\
\text { DES }\end{array}$ & $\begin{array}{l}\text { COSTOXX } \\
\text { UNIDAD }\end{array}$ & $\begin{array}{l}\text { COSTO } \\
\text { ANUAL }\end{array}$ & \begin{tabular}{|l|} 
UNIDA \\
DES
\end{tabular} & \begin{tabular}{|l|} 
COSTO X \\
UNIDAD
\end{tabular} & $\begin{array}{l}\text { COSTO } \\
\text { ANUAL }\end{array}$ \\
\hline ARCABUCO - BARRANQ & 1000 & 120,000 & $120,000,000$ & 1000 & 121,800 & $121,800,000$ & 1000 & 123,627 & $123,627,000$ & 1000 & 125,481 & $125,481,405$ & 1000 & 127,364 & $127,363,626$ \\
\hline & & & & & & & & & & & & & & & \\
\hline TOTAL COSTO DE TRAN & ISPORTE & & $120,000,000$ & 1,000 & & $121,800,000$ & 1,000 & & $123,627,000$ & 1,000 & & $125,481,405$ & 1,000 & & 127,36 \\
\hline
\end{tabular}

\section{ANALISIS}

En el costo de transporte se tuvo en cuenta el valor aproximado por tonelada desde la planta de Arcabuco hasta el puerto de barranquilla donde la carga será entregada al comprador y el será el que se encargue de ahí en delante de el producto y los riesgos ya correrían por parte de este. 


\subsection{CALCULO DE VENTAS}

Se observara a continuación el total de las ventas que se tendrán año a año respecto al aumento que se realizó principalmente del $1,5 \%$.

Tabla 14. Calculo de ventas.

\begin{tabular}{|c|c|c|c|c|c|c|c|c|c|c|c|c|c|c|c|}
\hline \multicolumn{16}{|c|}{ CALCULODEVENTAS } \\
\hline AÑO & \multicolumn{3}{|c|}{ AÑO1 } & \multicolumn{3}{|c|}{ AÑO2 } & \multicolumn{3}{|c|}{ AÑO3 } & \multicolumn{3}{|c|}{ AÑO4 } & \multicolumn{3}{|c|}{ AÑO5 } \\
\hline TIPODE INGRESOS & $\begin{array}{l}\text { TONELADAS } \\
\text { AVENDER }\end{array}$ & $\begin{array}{l}\text { PRECIODE } \\
\text { VENTA }\end{array}$ & $\begin{array}{l}\text { TOTAL } \\
\text { INGRESOS }\end{array}$ & $\begin{array}{l}\text { UNIDADESA } \\
\text { VENDER }\end{array}$ & $\begin{array}{l}\text { PRECIO DE } \\
\text { VENTA }\end{array}$ & \begin{tabular}{|l|} 
TOTAL \\
INGRESOS
\end{tabular} & $\begin{array}{l}\text { UNIDADES A } \\
\text { VENDER }\end{array}$ & $\begin{array}{l}\text { PRECIODE } \\
\text { VENTA }\end{array}$ & $\begin{array}{l}\text { TOTAL } \\
\text { INGRESOS }\end{array}$ & \begin{tabular}{|l|} 
UNIDADES \\
AVENDER
\end{tabular} & $\begin{array}{l}\text { PRECIODE } \\
\text { VENTA }\end{array}$ & $\begin{array}{l}\text { TOTAL } \\
\text { INGRESOS }\end{array}$ & $\begin{array}{l}\text { UNIDADES } \\
\text { AVENDER }\end{array}$ & \begin{tabular}{|l} 
PRECIODE \\
VENTA
\end{tabular} & \begin{tabular}{|l|} 
TOTAL \\
INGRESOS
\end{tabular} \\
\hline UCHUVA ENFRESCO & 1.000 & 10.000 .000 & 10.0000 .000 .000 & 1.000 & 10.150 .000 & 10.150 .000 .000 & 1.000 & \begin{tabular}{l|l}
0 & 10.302 .250
\end{tabular} & 10.302 .250 .000 & 1.000 & 10.456 .784 & 10.456 .783 .750 & 1.000 & 10.613 .636 & 10.613 .635 .506 \\
\hline NO OPERATINO (UCHUVA MALTRATADA & 4 & 3.000 .000 & 12.000 .000 & 4 & 3.045 .000 & 12.180 .000 & 4 & 3.090 .675 & 12.362 .700 & 4 & 3.137 .035 & 12.548.141 & 4 & 3.184 .091 & 12.736 .363 \\
\hline TOTALVENTAS XAÑO & 1.004 & 13000000 & 10012000000 & 1004 & 13195000 & 10162180000 & 1004 & 13392925 & 10314612700 & 1004 & 13593819 & 10469331891 & 1004 & 13797726 & 10626371869 \\
\hline
\end{tabular}

\section{ANALISIS}

Para los ingresos en ventas se tuvieron en cuenta el valor de la uchuva a exportar y también el ingreso no operativo de la uchuva que no cumple con las condiciones a exportar. 


\subsubsection{DEPRECIACION}

Se evidencia a continuación la depreciación que tendrá la maquinaria según la vida útil que este tenga.

Tabla 15. Depreciación

\begin{tabular}{|c|c|c|c|c|c|c|c|}
\hline \multicolumn{8}{|c|}{ DEPRECIACION } \\
\hline DETALLE & \begin{tabular}{|l} 
VIDA UTIL \\
\end{tabular} & ALOR TOTAL & AÑO 1 & AÑO 2 & AÑO 3 & AÑO 4 & AÑO5 \\
\hline COMPUTADOR & 5 AÑOS & 830,000 & $(415,000.00)$ & $290,500.00$ & $(203,350.00)$ & $142,345.00$ & $(99,641.50)$ \\
\hline SILLAS & 10 AÑOS & 100,000 & $(90,000)$ & 81,000 & $(72,900)$ & 65,610 & $(59,049)$ \\
\hline ESCRITORIO & 10 AÑOS & 320,000 & $(288,000)$ & 259,200 & $(233,280)$ & 209,952 & $(188,957)$ \\
\hline IMPRESORA & 5 AÑOS & 240,000 & $(238,800)$ & 167,160 & $(117,012)$ & 81,908 & $(57,336)$ \\
\hline
\end{tabular}

\section{ANALISIS}

Como podemos observar, vamos a tener mayor depreciación en el cuarto frio ya que este tiene el precio más alto y su depreciación sería la más significativa; teniendo depreciación desde el premier año con un indicador del 10\%. 


\subsection{BALANCE GENERAL}

Tabla 16. Balance general

\begin{tabular}{|c|c|c|c|c|c|}
\hline \multicolumn{6}{|c|}{ BALANCE GENERAL } \\
\hline AÑOS & AÑO 1 & AÑO 2 & AÑO 3 & AÑO 4 & AÑO 5 \\
\hline \multicolumn{6}{|l|}{ ACTIVOS CORRIENTES } \\
\hline CLIENTES & $5,012,000,000$ & $5,087,180,000$ & $5,163,487,700$ & $5,240,940,016$ & $5,319,554,116$ \\
\hline INVENTARIO & $2,500,000,000$ & $2,537,500,000$ & $2,575,562,500$ & $2,614,195,938$ & $2,653,408,877$ \\
\hline DISPONIBLE & $20,000,000$ & $20,300,000$ & $20,604,500$ & $20,913,568$ & $21,227,271$ \\
\hline \multicolumn{6}{|l|}{ ACTIVOS NO CORRIENTES } \\
\hline DEPRECIACION & $(13,082,800)$ & $11,643,760$ & $(10,387,852)$ & $9,284,994$ & $(8,311,644)$ \\
\hline MUEBLES Y ENSERES & $8,410,000$ & $8,536,150$ & $8,664,192$ & $8,794,155$ & $8,926,067$ \\
\hline MAQUINARIA Y EQUIPO & $15,770,000$ & $16,006,550$ & $16,246,648$ & $16,490,348$ & $16,737,703$ \\
\hline PROPIEDAD PLANTA Y EQUIPO & $14,400,000$ & $14,616,000$ & $14,835,240$ & $15,057,769$ & $15,283,635$ \\
\hline TOTAL ACTIVOS & $7,557,497,200$ & $7,670,859,658$ & $7,785,922,553$ & $7,902,711,391$ & $8,021,252,062$ \\
\hline \multicolumn{6}{|l|}{ PASIVO CORRIENTE } \\
\hline PROVEEDORES & $2,500,000,000$ & $2,537,500,000$ & $2,575,562,500$ & $2,614,195,938$ & $2,653,408,877$ \\
\hline
\end{tabular}




\begin{tabular}{|c|c|c|c|c|c|}
\hline OBLIGACIONES LABORALES & $322,570,000$ & $327,408,550$ & $332,319,678$ & $337,304,473$ & $342,364,041$ \\
\hline IMPUESTOS POR PAGAR & $20,000,000$ & $20,300,000$ & $20,604,500$ & $20,913,568$ & $21,227,271$ \\
\hline $\begin{array}{l}\text { CUENTAS POR PAGAR A CORTO } \\
\text { PLAZO }\end{array}$ & $2,500,000,000$ & $2,537,500,000$ & $2,575,562,500$ & $2,614,195,938$ & $2,653,408,877$ \\
\hline \multicolumn{6}{|l|}{ PASIVO A LP } \\
\hline OBLIGACIONES FINANCIERAS & $30,000,000$ & $30,450,000$ & $30,906,750$ & $31,370,351$ & $31,840,907$ \\
\hline TOTAL PASIVO & $5,342,570,000$ & $5,453,158,550$ & $5,534,955,928$ & $5,617,980,267$ & $5,702,249,971$ \\
\hline PATRIMONIO & $2,214,927,200$ & $2,248,151,108$ & $2,281,873,375$ & $2,316,101,475$ & $2,350,842,997$ \\
\hline CAPITAL SOCIAL & $40,000,000$ & $40,600,000$ & $41,209,000$ & $41,827,135$ & $42,454,542$ \\
\hline SUPER AVIT CAPITAL & $5,000,000$ & $5,075,000$ & $5,151,125$ & $5,228,392$ & $5,306,818$ \\
\hline REVALORIZACION DEL PATRIMONIO & $4,429,854,400$ & $4,496,302,216$ & $4,563,746,749$ & $4,632,202,950$ & $4,701,685,995$ \\
\hline RESULTADOS DEL EJERCICIO & $2,174,927,200$ & $2,207,551,108$ & $2,240,664,375$ & $2,274,274,340$ & $2,308,388,455$ \\
\hline TOTAL PASIVO Y PATRIMONIO & $7,557,497,200$ & $7,701,309,658$ & $7,816,829,303$ & 7,934,081,742 & $8,053,092,969$ \\
\hline
\end{tabular}

\section{ANALISIS}

En el balance general podemos observar que tenemos unos activos de $\$ 7.557 .497 .200$ y un pasivo de $\$ 5.342 .570 .000$ lo cual nos muestra que en la planta las deudas no superan lo que se tiene, al contrario al cancelar los pasivos aún nos queda liquidez. 


\subsection{ESTADO DE RESULTADOS}

Tabla 17. Estado de resultados

\begin{tabular}{|l|r|r|r|r|r|}
\hline \multicolumn{2}{|c|}{ ESTADO DE RESULTADOS } \\
\hline \multicolumn{1}{|c|}{ AÑOS } & \multicolumn{1}{c|}{ AÑO 1 } & \multicolumn{1}{c|}{ AÑO 2 } & \multicolumn{1}{c|}{ AÑO 3 } & \multicolumn{1}{c|}{ AÑO 4 } & \multicolumn{1}{c|}{ AÑO 5} \\
\hline VENTAS O INGRESOS OPERACIONALES & 10.000 .000 .000 & 10.150 .000 .000 & 10.302 .250 .000 & 10.456 .783 .750 & 10.613 .635 .506 \\
\hline COSTOS DE VENTAS & 2.862 .010 .000 & 2.892 .706 .863 & 2.599 .556 .440 & 2.975 .862 .103 & 3.020 .492 .074 \\
\hline UTILIDAD BRUTA & 7.137 .990 .000 & 7.257 .293 .138 & 7.702 .693 .560 & 7.480 .921 .647 & 7.593 .143 .432 \\
\hline GASTOS DE ADMINISTRACIÓN & 500.000 & 507.500 & 515.113 & 522.839 & 530.682 \\
\hline GASTOS DE VENTAS & 120.000 .000 & 121.800 .000 & 123.627 .000 & 125.481 .405 & 127.363 .626 \\
\hline DEPRECIACION & $(13.082 .800)$ & 11.643 .760 & $(10.387 .852)$ & 9.284 .994 & $(8.311 .644)$ \\
\hline UTILIDAD OPERACIONAL & 7.030 .572 .800 & 110.663 .740 & 134.529 .965 & 116.719 .250 & 136.205 .952 \\
\hline INGRESOS NO OPERACIONALES & 12.000 .000 & 12.180 .000 & 12.362 .700 & 12.548 .141 & 12.736 .363 \\
\hline GASTOS NO OPERACIONALES & 100.000 & 101.500 & 103.023 & 104.568 & 106.136 \\
\hline UTILIDAD ANTES DE IMPUESTOS & 7.042 .472 .800 & 122.742 .240 & 146.789 .642 & 129.162 .822 & 148.836 .178 \\
\hline IMPUESTOS & 2.324 .016 .024 & 40.504 .939 & 48.440 .582 & 42.623 .731 & 49.115 .939 \\
\hline UTILIDAD NETA O PERDIDA & 4.718 .456 .776 & 82.237 .301 & 98.349 .060 & 86.539 .091 & 99.720 .240 \\
\hline
\end{tabular}

\section{ANALISIS}

En el estado de resultados podemos observar que nuestra operación tiene una utilidad bruta de 7.137.990.000 lo cual es muy positivo para la empresa puesto que todas sus actividades financieras durante el periodo arrojaron una utilidad y así aumentar sus activos disponibles. 


\subsection{FLUJO DE CAJA}

Tabla 18. Flujo de caja

\begin{tabular}{|c|c|c|c|c|c|c|}
\hline \multicolumn{7}{|c|}{ FLUJO DE CAJA } \\
\hline DETALLE & AÑO 0 & AÑO1 & AÑO 2 & AÑO 3 & AÑO 4 & AÑO 5 \\
\hline \multicolumn{7}{|l|}{ INGRESOS } \\
\hline Ingresos no operacionales & & 12.000 .000 & 12.180 .000 & 12.362 .700 & 12.548 .141 & 12.736 .363 \\
\hline TOTAL INGRESOS & & 10.012 .000 .000 & 10.162 .180 .000 & 10.314 .612 .700 & 10.469.331.891 & 10.626 .371 .869 \\
\hline EGRESOS & & & - & - & - & - \\
\hline Costos (cuadros uno por uno) & & 2.967 .610 .000 & $3.012 .124 .150,0$ & 3.057 .306 .012 & 3.103 .165 .602 & 3.149 .713 .086 \\
\hline TOTAL EGRESOS & & 2.967 .610 .000 & 3.012 .124 .150 & 3.057 .306 .012 & 3.103 .165 .602 & 3.149 .713 .086 \\
\hline UTILIDAD OPERACIONAL & & 7.044 .390 .000 & 7.150 .055 .850 & 7.257 .306 .688 & 7.366 .166 .288 & 7.476 .658 .782 \\
\hline Imprevistos & & 3.000 .000 & 3.045 .000 & 3.090 .675 & 3.137 .035 & 3.184 .091 \\
\hline Impuestos & & 15.000 .000 & 15.225 .000 & 15.453 .375 & 15.685 .176 & 15.920 .453 \\
\hline FLUJO NETO OPERACIONAL & $(43.780 .000)$ & 7.026 .390 .000 & 7.131 .785 .850 & 7.238.762.638 & 7.347.344.077 & 7.457 .554 .238 \\
\hline TASA & & $1,50 \%$ & & & & \\
\hline
\end{tabular}

ANALISIS: Podemos ver que las ventas son mayores que los egresos, lo cual nos da una utilidad operacional muy positiva que a su vez nos permite cubrir imprevistos y los impuestos que debemos cancelar para así llevar a cabo nuestro proceso de exportación y al final obtener una utilidad neta para seguir creciendo. 


\subsection{INDICADORES}

Tabla 18. Indicadores

\begin{tabular}{|c|c|c|}
\hline NDICADOR & CALCULO & ANALISSS \\
\hline Rentabilididad Operativa & & \% Utilidad operativa por cada cien pesos de activos operacionales \\
\hline Rentabilildad del Patrimonio & & \% Utilidad neta en pesos que se genera por cada cien pesos invertidos en patrimonio. \\
\hline Productividad de Activos Totales & & \% Pesos de ingreso por cada peso invertido en activos \\
\hline Productividad Activos Operativos & & \% Pesos de ingreso por cada peso de activos operativos \\
\hline Productividad KTO & $1251200000000,0 \%$ & \% Pesos de ingreso por cada peso invertido en capital de trabajojoperativo \\
\hline Productividad Capital Fijo & $2748280000,0 \%$ & $\begin{array}{l}\% \text { \%esos de ingreso por cada peso invertido en capital fijo } \\
\end{array}$ \\
\hline Margen Neto & & $\%$ Tiempo promedio entre la venta yel recaudo del ingreso \\
\hline Margen Operativo & $70,3 \%$ & \% Tiempo promedio entre la compra de mercancias yel momentio de la venta. \\
\hline Margen Bruto & $71,4 \%$ & \% Utilididad neta por cada cien pesos de ingreso operacional \\
\hline Gastos de Administración & & \% (Utilidad bruta por cada cien pesos de ingreso operacional \\
\hline Gastos de Ventas & & \% Valor del gasito operacional por cada cien pesos de ingreso operacional \\
\hline
\end{tabular}




\section{CAPITULO 6. LEGAL}

\subsection{TIPO DE SOCIEDAD}

Este plan de negocio tendrá la conformación de una Comercializadora Internacional ya que con este tipo de sociedad podemos gozar de beneficios como líneas de Crédito Bancoldex, tener acceso directo o indirecto a los sistemas especiales de importación y exportación, así como la exención del IVA y del impuesto de retención en la fuente; además poder alcanzar los objetivos incluyendo diferentes actividades de promoción y comercialización de productos colombianos en el exterior.

Crear una comercializadora en el departamento de Boyacá genera un gran impacto ya que todos y cada uno de los habitantes se favorecen con empleos y mejor calidad de vida. ${ }^{75}$

\footnotetext{
${ }^{75}$ http://www.icesi.edu.co/blogs/icecomex/2008/08/01/7/
} 


\subsection{NORMA ICONTEC NTC 4580 DE LA UCHUVA}

Esta norma establece los requisitos que debe cumplir la uchuva (Physalis peruviana L.), destinada para el consumo fresco o como materia prima para el procesamiento. $^{76}$

\subsection{LEGISLACIÓN DE EMPAQUES}

El objetivo de esta legislación es proteger la salud de los consumidores, proteger la salud de los consumidores y proteger la actividad económica nacional. ${ }^{77}$

\subsection{NORMA DE BUENAS PRÁCTICAS AGRÍCOLAS (BPA)}

El Ica tiene la jurisdicción en todo el territorio nacional, siendo su domicilio principal la ciudad de Bogotá, D.C., cuenta con 32 Gerencias Seccionales, una por departamento, con un recurso humano altamente calificado. El Ica diseña y ejecuta estrategias para, prevenir, controlar y reducir riesgos sanitarios, biológicos y químicos para las especies animales y vegetales, que puedan afectar la producción agropecuaria, forestal, pesquera y acuícola de Colombia. ${ }^{78}$

\footnotetext{
${ }^{76} \mathrm{http}: / /$ tienda.icontec.org/brief/NTC4580.pdf

77 http://virtual.esumer.edu.co/

${ }^{78}$ http://www.ica.gov.co/El-ICA.aspx
} 
Las Buenas Prácticas Agrícolas se consideran como una forma específica de producir o procesar productos agropecuarios; esto quiere decir que, el modo como se lleva a cabo el proceso de siembra, cosecha y pos cosecha para los cultivos o el manejo que se le da a los animales para aprovechar sus carnes o lácteos, cumple con requerimientos específicos de producción limpia. ${ }^{79}$

Las normas, la legislación y los demás documentos citados anteriormente hacen referencia a cada una de las normas y los procesos que se deben tener en cuenta para manipular, transformar y transportar alimentos en especial en este caso la uchuva, además también hace referencia a los estándares que debe cumplir la uchuva tipo exportación.

\subsection{NORMA DE CALIDAD ICONTEC PARA LA UCHUVA.}

La calidad de la uchuva está normalizada en la Norma Técnica Colombiana NTC 4580 de 1999 la cual hace referencia también a las características anteriormente mencionadas. $^{80}$

\footnotetext{
${ }^{79}$ http://www.agronet.gov.co/www/peqprod/imagenes agricultura/agro_apl_pdfBpa.pdf

80 - Importancia de la Logística y Cadena de Abastecimientos en la Competitividad.

Disponible en http// www.logyca.org. Documento PDF
} 


\subsection{NORMA SISTEMA DE ANÁLISIS DE PELIGROS Y DE PUNTOS CRÍTICOS DE CONTROL (HACCP) Y DIRECTRICES PARA SU APLICACIÓN}

El sistema de HACCP, que tiene fundamentos científicos y carácter sistemático, permite identificar peligros específicos y medidas para su control con el fin de garantizar la inocuidad de los alimentos. Es un instrumento para evaluar los peligros y establecer sistemas de control que se centran en la prevención en lugar de basarse principalmente en el ensayo del producto final. Todo sistema de HACCP es susceptible de cambios que pueden derivar de los avances en el diseño del equipo, los procedimientos de elaboración o el sector tecnológico.

El sistema de HACCP puede aplicarse a lo largo de toda la cadena alimentaria, desde el productor primario hasta el consumidor final, y su aplicación deberá basarse en pruebas científicas de peligros para la salud humana, además de mejorar la inocuidad de los alimentos, la aplicación del sistema de HACCP puede ofrecer otras ventajas significativas, facilitar asimismo la inspección por parte de las autoridades de reglamentación, y promover el comercio internacional al aumentar la confianza en la inocuidad de los alimentos. ${ }^{81}$

\subsection{LEGISLACIÓN PARA EMBALAJES.}

Cuando se diseñan empaques y embalajes destinados para el almacenamiento, Transporte, y distribución de frutas y hortalizas, es importante tener en cuenta que en la gran mayoría de los mercados internacionales, e incluso en el país, existe una tendencia cada vez más fuerte a utilizar embalajes de dimensiones estandarizadas, este hecho hace que cuando se diseñan empaques para frutas y

\footnotetext{
${ }^{81}$ http://www.fao.org/docrep/005/y1579s/y1579s03.htm
} 
hortalizas sea imprescindible ajustar sus dimensiones de tal manera, que sean compatibles con las de elementos estandarizados

Como: estibas, contenedores, y bodegas de barco, aviones y ferrocarriles ${ }^{82}$.

\subsection{EL INSTITUTO COLOMBIANO AGROPECUARIO ICA.}

Al ICA le corresponde establecer los procedimientos que garanticen el eficaz cumplimiento de las normas que expida el gobierno nacional para evitar la llegada a Colombia de plagas que pueden ser introducidas con las importaciones de material vegetal o a través de las diferentes operaciones de los medios de transporte que llegan por puertos, aeropuertos y pasos fronterizos al país. Le corresponde al ICA igualmente ejercer el control sobre la sanidad de las exportaciones colombianas. La Secretaría de la Convención Internacional de Protección Fitosanitaria CIPF, expidió en marzo de 2002 la Norma Internacional de Medida Fitosanitaria No. 15 por la cual se establecen las directrices para reglamentar el embalaje de madera utilizado en el comercio internacional; mediante Resolución No. 0245 de 10 de noviembre de 2003, el Ministerio de Agricultura, responsabiliza al ICA de establecer los procedimientos Fitosanitarios, técnicos y logísticos que deberán cumplir las personas naturales y jurídicas que apliquen el tratamiento fitosanitario a los embalajes de madera acordes a las

\footnotetext{
${ }^{82}$ Manual del Exportador de Frutas, Hortalizas y Tubérculos en Colombia, CCl, Ministerio de Agricultura y Desarrollo rural.
} 
normas internacionales sobre la materia. ${ }^{83}$

\subsection{NORMA BUSINESS ALLIANCE FOR SECURE COMMERCE}

Las organizaciones no operan en vacío; varias partes pueden tener un interés legítimo en la propuesta de las organizaciones para el control y seguridad. Estas son, entre otras: empleados, clientes / proveedores, comunidad, accionistas, contratistas, así como entidades oficiales.

Estos intereses deben ser reconocidos. La importancia de la Gestión en Control y Seguridad ha sido destacada en informes oficiales recientes y en buena cantidad de legislación sobre el tema.

La seguridad no depende del azar. Las organizaciones deben dar la misma o mayor importancia al logro de altos estándares de Gestión en Control y Seguridad, que dan a otros aspectos de sus actividades empresariales. Esto exige adoptar una propuesta estructurada para la identificación de los peligros y la evaluación y control de los riesgos relacionados con el las actividades de comercio internacional que realizan.

Esta norma está destinada a ayudar a las organizaciones en el desarrollo de una propuesta de gestión en Control y Seguridad en el Comercio Internacional, que proteja a las empresas, a sus empleados y otras personas cuya seguridad puedan verse afectadas por sus actividades. Muchas de las características de una administración efectiva no se pueden distinguir de las prácticas propuestas de administración de calidad y excelencia empresarial.

Estas directrices se basan en los principios generales de buena administración y están diseñadas para favorecer la integración de la Gestión en Control y Seguridad al sistema general de administración. ${ }^{84}$

\footnotetext{
${ }^{83}$ La Cadena de Frío y los Procesos Logísticos EAN Panamá, boletín informativo 5 de mayo de 2004
} 


\section{CAPITULO 7. IMPACTOS}

Este módulo muestra como tal el fin de las metas propuestas a nivel social de la empresa constituida, con la ayuda de la salud ocupacional que se entornara dentro de la planta, el impacto social y el impacto ambiental que tendrá la misma.

\subsection{COMPONENTE AMBIENTAL}

- Realizar junto con entidades que promueven programas con el medio ambiente charlas y capacitaciones para que nuestro equipo de trabajo tenga conocimiento de este componente.

- El Sena y Corpoboyacà serán de gran ayuda para este componente ya que estos tendrán el conocimiento suficiente para llenar de información a cada uno de los miembros de la empresa.

- La empresa C I A\&D EXOTIC FRUIT S.A.S estará comprometida con el medio ambiente así como el impacto que este tendrá, respetando a su vez las normas que rigen como tal el medio ambiente.

${ }^{84}$ http://www.wbasco.org/espanol/normas.htm 
- Además de tener un conocimiento en el tema ambiental dentro de la empresa se tendrá como objetivos la verificación y el control de un adecuado funcionamiento de las maquinarias para que a su vez no perjudique la salud ocupacional de los colaboradores.

- Se tendrá un estricto control con el debido proceso a realizar en la planta de uchuva, ya que se tendrá en cuenta que los químicos o como tal el procedimiento no interfiera en la salud ocupacional del personal.

- El agua y los desechos tendrán tratamiento especial donde no se vea la falta de higiene dentro de la empresa, así mismo cuidar y velar por el bienestar de los trabajadores.

\subsection{COMPONENTE SOCIAL}

- Ofrecer programas de capacitación para que cada uno de los trabajadores crezcan en su conocimiento.

- Brindar la oportunidad para que el personal puede surgir con carreras acordes con la empresa para que a su vez tengan crecimiento dentro de la misma. 
- Compromiso con la empresa ofreciendo al consumidor final productos de calidad, 100 \% naturales así mismo superando a las demás empresas logrando ser líderes en el departamento.

- Comprometiendo a cada uno de los trabajadores para elaborar campañas donde ellos participen en labores sociales dentro del municipio creador de la empresa, colaborando en cualquier evento de este impacto.

- Apoyando cada una de las familias colaboradoras a la empresa para que a su vez ellos se sientan motivados, y comprometidos con la planta.

\begin{tabular}{|l|l|l|l|}
\hline ASP & & PLANES DE & \multicolumn{1}{|c|}{ MITIGACIÓN } \\
OCT & RESULTADOS & SOSTENIMIENTO O CORRECCIÓN \\
\hline S & & Plan de sostenimiento, se debe \\
O & Se mejora el nivel social & conservar el nivel de ventas para a su vez \\
C & y el nivel de vida de los & mantener los empleados dentro de la \\
I & consumidores de uchuva & empresa para así tener la generación de \\
\hline
\end{tabular}




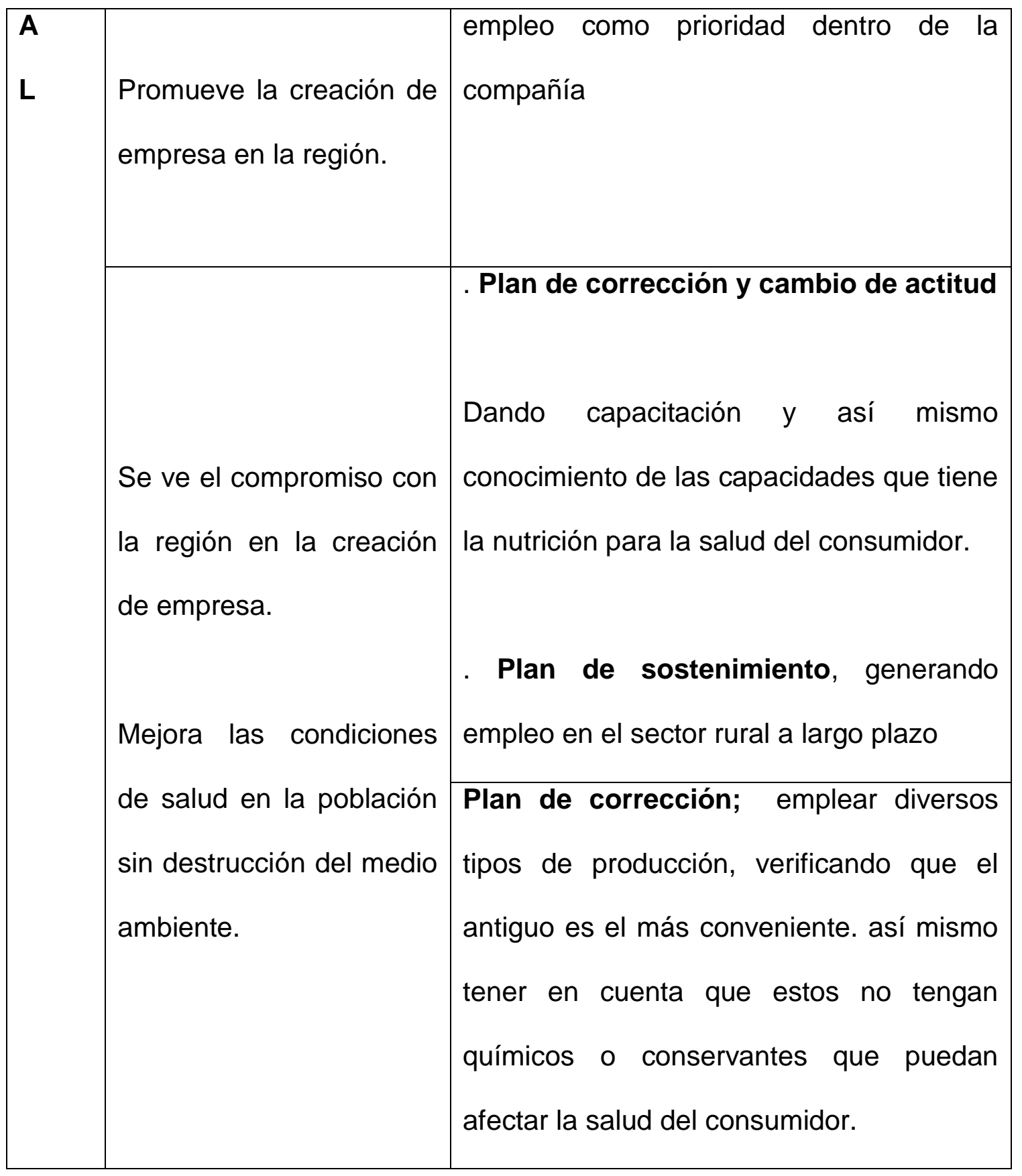




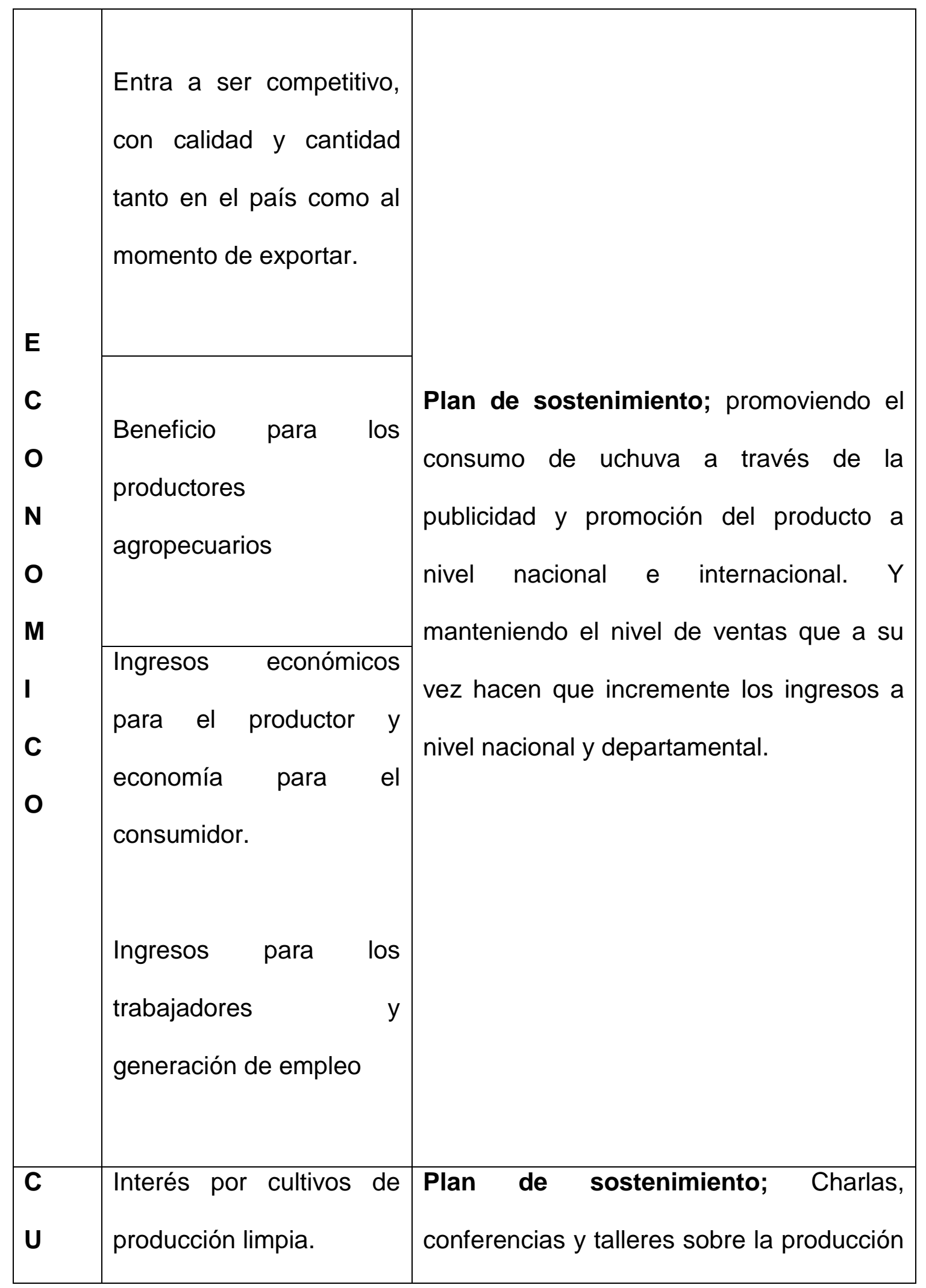




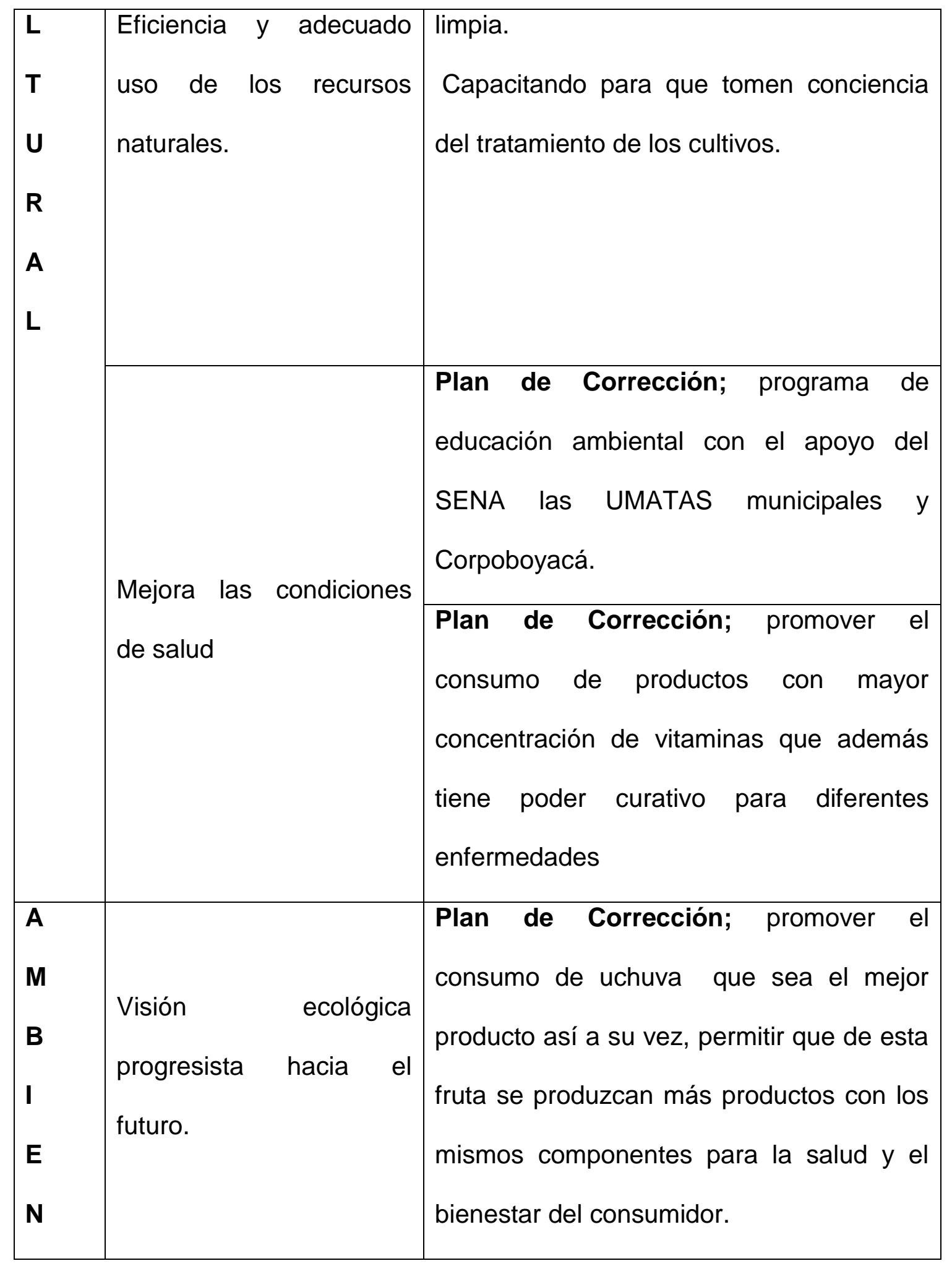




\begin{tabular}{|l|l|l|l|}
\hline T & Reconocimiento & y & Plan de Corrección; programa de \\
L & valoración de la relación & educación ambiental con el apoyo del \\
& Hombre - Naturaleza & SENA las UMATAS municipales y \\
& & Corpoboyacá. \\
\hline
\end{tabular}

Fuente: Las Autoras

Cuadro $N^{\circ} 6$ POSIBLES IMPACTOS NEGATIVOS

\begin{tabular}{|c|c|c|}
\hline ASPECTO & IMPACTO & PLAN DE MITIGACIÓN \\
\hline SOCIAL & $\begin{array}{l}\text { - } \text { Empresa tecnificada, } \\
\text { no da mayor } \\
\text { oportunidad laboral. }\end{array}$ & $\begin{array}{l}\text { - Ampliación de la capacidad productiva } \\
\text { a largo plazo y así tener más } \\
\text { oportunidad laboral. }\end{array}$ \\
\hline ECONÓMICO & $\begin{array}{llll}\text { - falta de } & \text { recursos } \\
\text { suficientes } & \text { para } & \text { el } \\
\text { crecimiento } & \text { de } & \text { la } \\
& & \\
\text { empresa. } & & \end{array}$ & $\begin{array}{l}\text { - Adquiriendo préstamos a largo plazo } \\
\text { ante las entidades bancarias para hacer } \\
\text { uso en adquisidores para la empresa. }\end{array}$ \\
\hline CULTURAL & $\begin{array}{l}\text { - No existe como tal el } \\
\text { consumo de la uchuva } \\
\text { conociéndose como } \\
\text { vitamina. }\end{array}$ & $\begin{array}{l}\text { - Crear o ingeniar estrategias de venta } \\
\text { para el consumidor, para que estos } \\
\text { tengan el conocimiento del producto } \\
\text { que se venderá y que a su vez se } \\
\text { pueden generar diversos tipos de } \\
\text { productos. }\end{array}$ \\
\hline
\end{tabular}




\begin{tabular}{|c|c|c|}
\hline AMBIENTAL & $\begin{array}{l}\text { - Contaminación visual } \\
\text { y ambiental con los } \\
\text { empaques de los } \\
\text { productos utilizados. }\end{array}$ & $\begin{array}{l}\text { - promover grupos de apoyo para que } \\
\text { intervengan en el reciclaje de los } \\
\text { productos utilizados. } \\
\text { - organizar eventos donde se vean } \\
\text { involucrados los adultos, jóvenes y } \\
\text { niños en el cubrimiento de brigadas } \\
\text { para cooperar con la contaminación. }\end{array}$ \\
\hline
\end{tabular}

Fuente: Las Autoras

\subsection{MATRIZ Y ANÁLISIS DEL RIESGO}

Cuadro № 7. ANÁLISIS DE RIESGO DE MATERIAS PRIMAS

\begin{tabular}{|c|c|c|c|}
\hline $\begin{array}{l}\text { MATERIA } \\
\text { PRIMA }\end{array}$ & PELIGRO & $\begin{array}{l}\text { FACTORES } \\
\text { DE RIESGO }\end{array}$ & MEDIDAS DE CONTROL \\
\hline 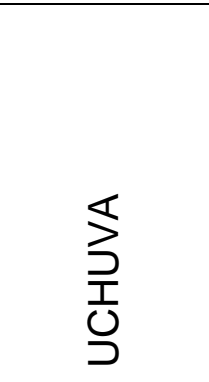 & $\begin{array}{l}\text { Contaminación } \\
\text { microbiología } \\
\text { (controles } \\
\text { fitosanitarios) }\end{array}$ & $\begin{array}{l}\text { Fallas en el } \\
\text { procesamient } \\
0 \text { de la }\end{array}$ & $\begin{array}{l}\text { Certificación de calidad de } \\
\text { las asociaciones agremiadas } \\
\text { a la cultivación de uchuva. }\end{array}$ \\
\hline
\end{tabular}




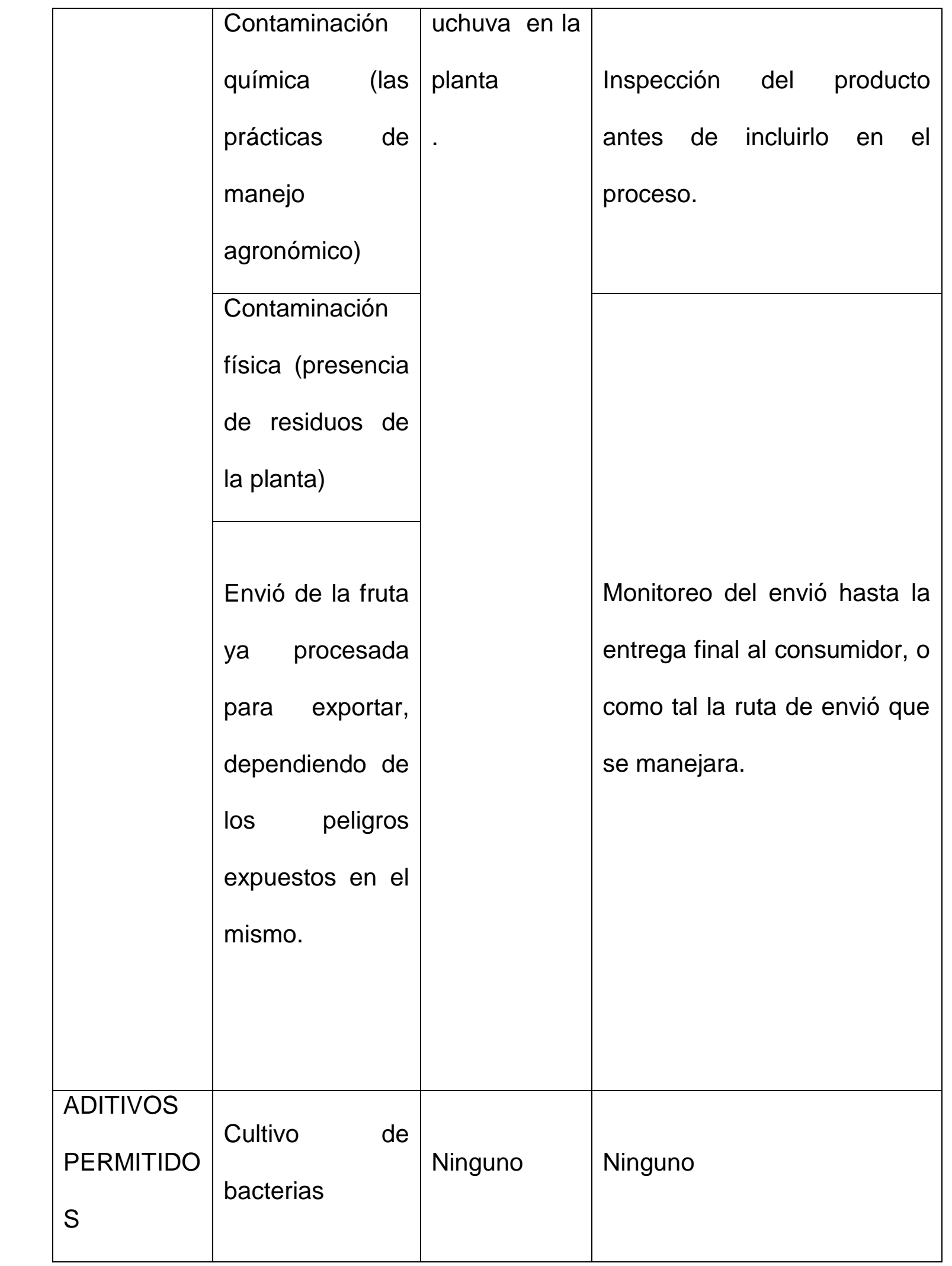

Fuente: Autoras 
Cuadro N 8. ANÁLISIS DE RIESGOS EN EL PROCESO PRODUCTIVO

\begin{tabular}{|c|c|}
\hline ETAPA & PELIGRO \\
\hline 1. Selección & No seleccionar la fruta adecuada \\
\hline \multirow{4}{*}{ 2. Lavado } & Residuos de mugre \\
\hline & Contaminación química \\
\hline & Contaminación microbiológica \\
\hline & $\begin{array}{l}\text { Contaminación química producida por mal manejo de } \\
\text { desinfectantes y detergentes }\end{array}$ \\
\hline 3. secado & Contaminación microbiológica \\
\hline 4.Envase $\quad y$ & Contaminación microbiológica \\
\hline Sellado & Contaminación química \\
\hline $\begin{array}{l}\text { 5.Almacenam } \\
\text { iento } \\
\text { refrigerar }\end{array}$ & Contaminación microbiológica \\
\hline
\end{tabular}

Fuente: Autoras 
CUADRO N 9. FACTORES DE RIESGO

\begin{tabular}{|l|}
\hline FACTORES DE RIESGO \\
\hline - Demoras o fallas en la inspección de la materia prima. \\
- Falta de control microbiológico en fincas y zonas en el cultivo de uchuva. \\
uchuva.
\end{tabular}

- Manejo del transporte de la uchuva, llegada y salida de la planta.

- Alteración en las propiedades fisicoquímicas por la presencia de productos químicos como adulterantes, inhibidores y antibióticos.

- Condiciones inadecuadas para el procesamiento de la uchuva.

- Inadecuado acoplamiento de la maquinaria.

- Condiciones de operación inadecuadas

- Falta de esterilización de empaques contaminados por el medio ambiente o uso.

- Limpieza ineficiente de la maquinaria.

- Crecimiento de microorganismos en caso de manejo inadecuado del producto.

Fuente: Las Autoras 
CUADRO N ${ }^{\circ}$ 10. MEDIDAS DE CONTROL

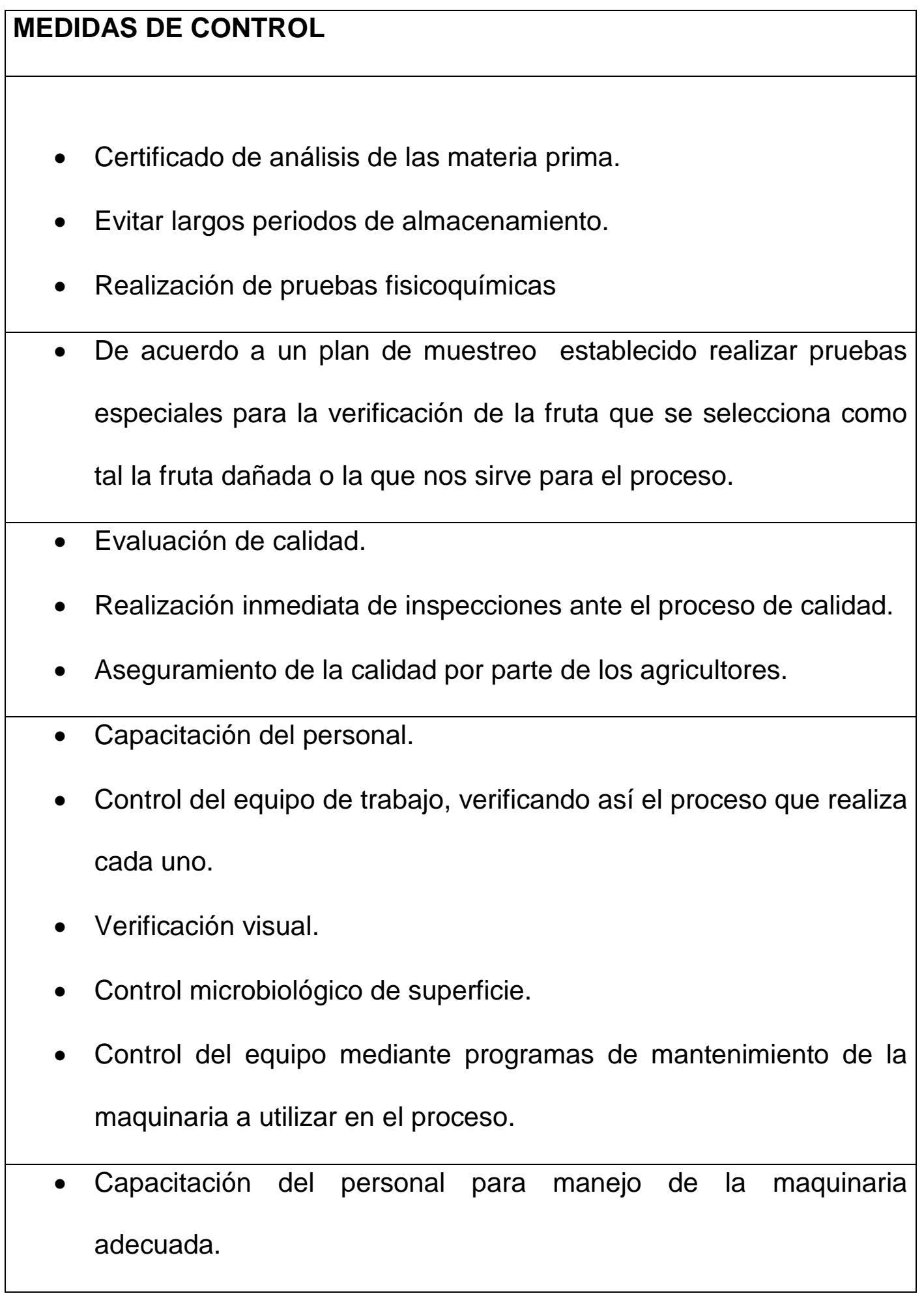


- Verificación en la asistencia de los programas que se harán para el manejo adecuado de la maquinaria.

- Comprobar si se cumplen las condiciones de operación antes de iniciar el empaque.

- Verificar de manera manual los sellos del empaque.

- Verificar el proceso como tal, en cada uno de sus pasos a seguir desde el inicio hasta el final.

- Chequeo constante del producto

- Temperatura de refrigeración a 4 grados centígrados

- Despacho del lote

Fuente: Autoras

\subsection{SALUD OCUPACIONAL}

La empresa C I A\&D EXOTIC FRUIT S.A.S Tiene como perspectiva velar por el bienestar y seguridad de cada uno de los trabajadores teniendo en cuenta que se debe tener el conocimiento pertinente para permanecer con las instalaciones adecuadas para que a su vez los trabajadores se puedan desempeñar en su campo adecuadamente. 
Así mismo verificando que nuestro equipo de trabajo se sienta físicamente y psicológicamente con las actitudes y el ánimo puesto para continuar día a día con su labor.

\subsection{UTENSILIO DEL TRABAJO}

- Ropa de trabajo adecuada (overol, botas, tapabocas)

- Protección para la cabeza

- Uñas cortas, cabello recogido ( mujeres)

- Usar tapabocas para prevención de enfermedades

- Prohibida las bebidas, las comidas, fumar etc...

- Guantes, gafas, cascos

Gracias a estos utensilios de trabajo los trabajadores C I A\&D EXOTIC FRUIT S.A.S, tendrán la mayor seguridad posible frente a la tarea que se le es asignada dentro de la planta. A su vez se capacitara y se dará información acerca de los riesgos que puede traer la operación en la empresa.

Se contara con la ayuda de la capacitación de seguridad industrial, para así evitar enfermedades, accidentes o riesgos que intervengan en la productividad y calidad del proceso que se realizara dentro de la empresa. 


\subsection{PRODUCCIÓN LIMPIA}

Se tendrá en cuenta en la mente de cada uno de los trabajadores la mejora continua de cada uno de los procedimientos, mejorando cada día. Así mismo mejorando la utilización de la maquinaria manteniendo la limpieza absoluta en cada uno de ellos.

Se debe tener en cuenta que se debe tratar muy bien la fruta para así disminuir las quejas y reclamos que se tendrán de los consumidores para evitar esto se tendrá en cuenta el control sanitario que es exigida directamente por las normas de calidad.

Así mismo se tendrá un adecuando manejo de los alimentos que se encuentren en las instalaciones de la planta, verificando los lugares donde se tendrán los mismos controlando que no estén sustancias químicas dentro del mismo evitando así enfermedades. 


\section{CONCLUSIONES.}

- Se realizó un estudio de mercado donde se establecieron las condiciones de oferta y demanda teniendo en cuenta la cantidad de uchuva que se producirá y el mercado al cual será exportado, viendo la opción más viable a Alemania donde se tuvo en cuenta la población, economía y la participación de esta en el mercado.

- Con el estudio técnico se puede determinar la maquinaria, la materia prima y la mano de obra necesaria para poder realizar el proceso de exportación.

- Se determinó el tipo de sociedad que se implementara siendo esta una S.A.S la cual nos brinda muchas ventajas en el mercado y a su vez también se realiza la estructura organizacional de nuestra empresa teniendo en cuenta todos los aspectos legales a seguir para poder llevar el producto al mercado extranjero.

- Con el estudio financiero se pudo determinar que C I A\&D EXOTICS FRUIT S.A.S es una empresa muy rentable alcanzando desde el primer año un punto de equilibrio favorable lo cual le permitirá ir creciendo año tras año. 


\title{
REFERENCIAS BIBLIOGRAFICAS.
}

\author{
http://repository.lasalle.edu.co/bitstream/10185/5146/1/12002004.pdf
}

Secretaria de fomento agropecuario, dirección de mercadeo Gobernación de Boyacá “ óscar González"

Fuente: Secretaría de Fomento Agropecuario - Dirección de Mercadeo.AUTOR: AMELIA CEPEDA MORA 2009.

http://es.scribd.com/doc/60586337/25/Atributos-de-la-uchuva.

http://co.globedia.com/uvilla-uchuva-fruta-grandes-beneficios-salud-belleza.

MAG, 2006.

Guía de procesos para la elaboración de néctares, mermeladas uvas pasas y vinos .diana Ximena Suarez Moreno año 2003. Editorial convenio Andrés Bello.

http://www.colombiaexport.com/frutexpo/Uchuva.htm.

http://www.asohofrucol.com.co/archivos/Cadenas/caracterizacion frutales exporta 2005

.. $\mathrm{pdf}$

En el “Acuerdo de competitividad de productos hortofrutícolas promisorios exportables en Colombia,2001", se distingue entre productos promisorios exportables de primera generación, a la cual pertenecen las seis frutas mencionadas y productos promisorios exportables de segunda generación, queincluye todas las demás frutas y hortalizas que potencialmente podría exportar Colombia y a las cualespretenden hacerse extensivas en el largo plazo las líneas estratégicas de acción del acuerdo. Secretaría Técnica: Corporación Colombia Internacional, Bogotá, diciembre de 2001. 
Aquí se incluyen las siguientes frutas: aguacate, badea, banano, banano de exportación, borojó,brevo, caducifolios, chirimoya, chontaduro, ciruela, cítricos, coco, curuba, dátiles, durazno, feijoa,fresa, granadilla, guanábana, guayaba, higo, limón, lulo, macadamia, mamoncillo, mandarina, mango, manzana, maracuyá, melón, mora, morón, naranja, níspero, papaya, papayuela, patilla, pera,piña, pitahaya, sagú, tamarindo, tomate de árbol, uchuva, uva y zapote.

http://www.finagro.com.co/html/i portals/index.php?p origin=internal\&p name=content

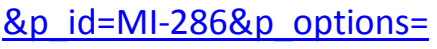

http://ricasuchuvas.galeon.com/

http://www.slideshare.net/guest289e51/proyecto-uchuva?from search=2

http://www.slideshare.net/guest289e51/proyecto-uchuva?from search=2

http://www.legiscomex.com/BancoMedios/Documentos\%20PDF/exportaciones-estudio-

frutas-exoticas.pdf.

http://freddyaguaba.wikispaces.com/EXPORTACION+UCHUVA+(Freddy+A.+Guaba)

http://www.finagro.com.co/html/i portals/index.php?p origin=internal\&p name=content

$\underline{\text { \& } \mathrm{id}=\mathrm{Ml}-286 \& \mathrm{p} \text { options= }}$

http://www.slideshare.net/guest289e51/proyecto-uchuva?from search=2

http://www.angelfire.com/ia2/ingenieriaagricola/uchuva.htm.

http://uchuva.wordpress.com/tag/almibar/

http://www.finagro.com.co/productos-y-servicios/informaci\%C3\%B3n-sectorial

http://www.indexmundi.com/es/alemania/poblacion perfil.html

http://eldia.com.do/columnas/2013/6/4/115757/Holanda-en-dificultades

http://www.euroxpress.es/index.php/noticias/2013/6/4/guerra-comercial-ue-china-por-

el-mercado-europeo-de-paneles-solares/

http://www.invertia.com/noticias/fmi-revisa-baja-prevision-pib-alemania-2866168.htm 
http://interletras.com/manualCCl/Alemania/alemania17.htm.

Manual del exportador de frutas, hortalizas y tubérculos en Colombia 2000.

El cambio estructural en el comercio alimentario europeo. En: Horticultura, abril de 1999, pág.60.

http://www.agronet.gov.co/www/docs agronet/200512992425 Bolet\%C3\%ADn\%20CCI.Al $\underline{\text { emaniadoc.pdf }}$

El mercado hortofrutícola alemán. En: Horticultura Internacional. Febrero 23 de 1999, pág.

88.

http://www.agronet.gov.co/www/docs agronet/200512992425 Bolet\%C3\%ADn\%20CCl.Al emaniadoc.pdf

http://www.freshplaza.es/article/75477/Alemania-aumenta-el-consumo-de-la-fruta-percapita-al-a\%C3\%B10

http://countrymeters.info/es/Germany

http://www.agrowww.com/productorhome.php?cod prod=05

http://uchuva.wordpress.com/

http://www.colombia.com/vida-sana/nutricion/sdi/13374/la-uchuva-una-fruta-con-

propiedades-terapeuticas

http://www.megamarcas.net/icopor.html

http://es.wikipedia.org/wiki/PI\%C3\%A1stico

http://www.corpacero.com/econtent/homeproducts.asp?id=94\&idcompany=2

http://www.slideshare.net/Nataliafrancomora/estibas1http://www.slideshare.net/Nataliafr ancomora/estibas1

http://www.slideshare.net/VirgilioRivera/25-estrategias-de-venta-2

http://www.slideshare.net/VirgilioRivera/25-estrategias-de-venta-2 
http://manuramirezdiseno.blogspot.com/2009/07/empaque-uchuva-para-exportacion.html http://www.slideshare.net/linaec/estrategia-de-producto-branding-y-packaging http://www.slideshare.net/VirgilioRivera/25-estrategias-de-venta-2 http://www.slideshare.net/VirgilioRivera/25-estrategias-de-venta-2 http://www.slideshare.net/linaec/estrategia-de-producto-branding-y-packaging http://www.slideshare.net/VirgilioRivera/25-estrategias-de-venta-2 http://www.monografias.com/trabajos82/estrategia-push-y-pull/estrategia-push-ypull2.shtml

https://sites.google.com/site/iojooa/crm/retencin-de-clientes http://marketingemprendedor.wordpress.com/2010/12/13/como-recuperar-clientesperdidos/

http://www.monografias.com/trabajos82/estrategia-push-y-pull/estrategia-push-y pull2.shtml http://www.tripadvisor.es/Restaurants-g187275-Germany.html http://www.tripadvisor.es/Hotels-g187275-Germany-Hotels.html http://www.slideshare.net/guest289e51/proyecto-uchuva http://www.asohofrucol.com.co/archivos/biblioteca/biblioteca 124 FRUTAS.pdf DÍAZ, Arturo; LÓPEZ Magda. Empaques y Embalajes para Frutas y Hortalizas Frescas. NRI, SENA, DFID.

SANTAELLA, Juan. Resolución No. 01079 (03 Junio - 2008), Instituto gy Agropecuario, ICA. Documento PDF

Documento PDF. http://www.megabelzyce.pl/es/sortowanie oczyszczanie i kalibrowanie produktow 02.html http://www.fomesa.net/Maquinaria/1.htm 
http://www.fomesa.net/Maquinaria/2.htm

Importancia de la Logística y Cadena de Abastecimientos en la Competitividad. Disponible en http// www.logyca.org. Documento PDF

Manual del Exportador de Frutas, Hortalizas y Tubérculos en Colombia, CCl, Ministerio deAgricultura y Desarrollo rural.

La Cadena de Frío y los Procesos Logísticos EAN Panamá, boletín informativo 5 de mayo de 2004

BELLO, Carlos. Manual de la Producción. Editorial Ecoe, 2010.

http://historico.unperiodico.unal.edu.co/ediciones/62/11.htm

https://www.google.com.co/search?q=mapa+procesos+de+produccion\&tbm=isch\&tbo=u\&so urce=univ\&sa=X\&ei=8CeSUoKTK46SkQf544GgAQ\&ved=0CEYQsAQ\&biw=962\&bih=538\#q=ma pa+procesos + de + una + procesadora \&tbm $=i s c h \& f a c r c=$ \&imgdii $=$ \&imgrc $=u 6 y R 0 Q s c e N 4 Z M \%$ 3A\%3BzFX4yBMwJAwCoM\%3Bhttp\%253A\%252F\%252Fgestionalimentaria.files.wordpress.co m\%252F2007\%252F12\%252Fmapa-deprocesos.jpg\%3Bhttp\%253A\%252F\%252Fgestionalimentaria.wordpress.com\%252F2007\%252 F12\%252F26\%252Fel-mapa-de-procesos\%252F\%3B564\%3B481

http://wwwolgaluciasenacom.blogspot.com/p/manual-de-funciones-empresaprocesadora.html.

http://www.icesi.edu.co/blogs/icecomex/2008/08/01/7/

http://tienda.icontec.org/brief/NTC4580.pdf

http://www.slideshare.net/VirtualEsumer/legislacin-y-normatividad

http://www.ica.gov.co/El-ICA.aspx

http://www.agronet.gov.co/www/peqprod/imagenes_agricultura/agro_apl_pdfBpa.pdf 


\section{ANEXOS.}

\section{Foto. 1}

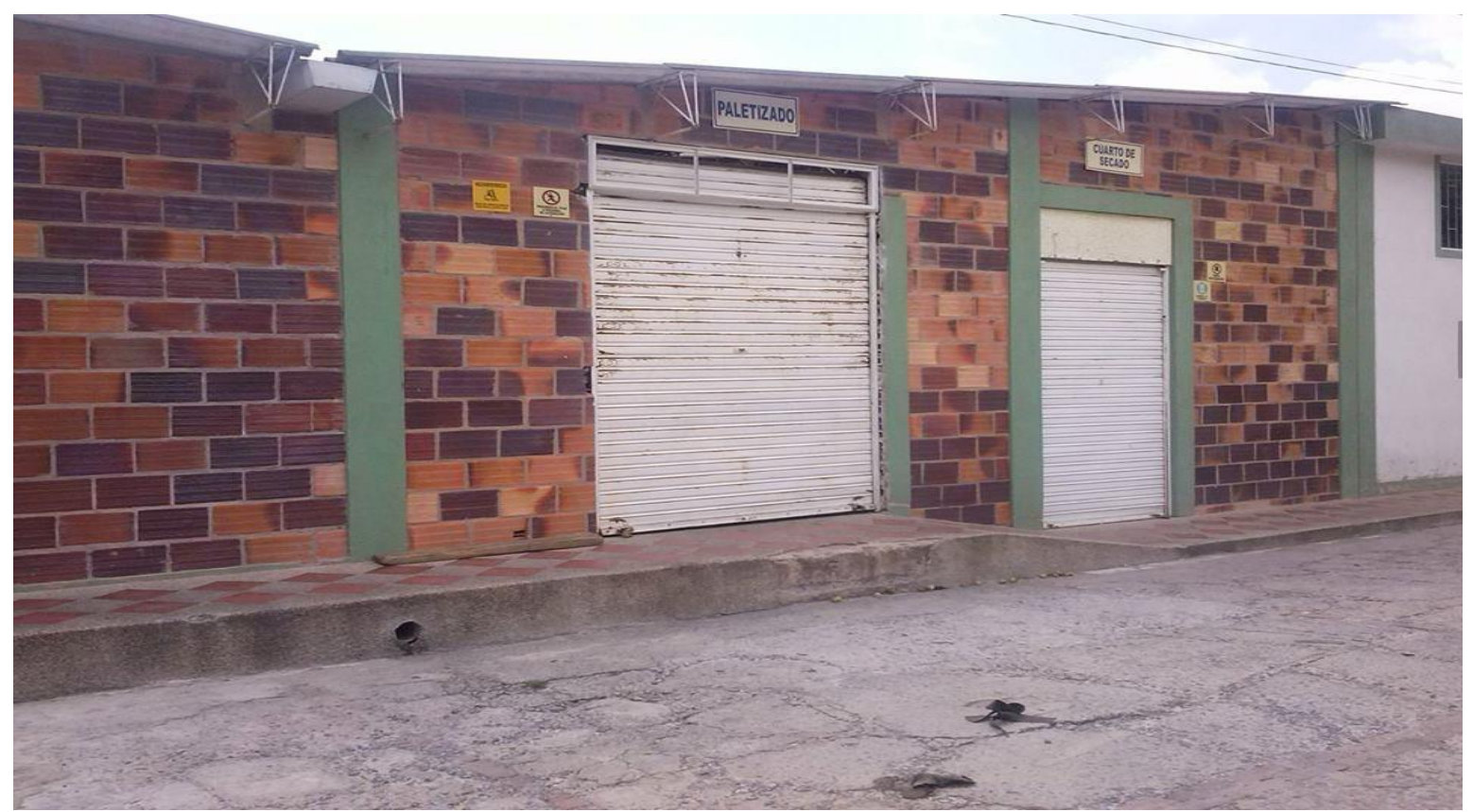

\section{Foto. 2}

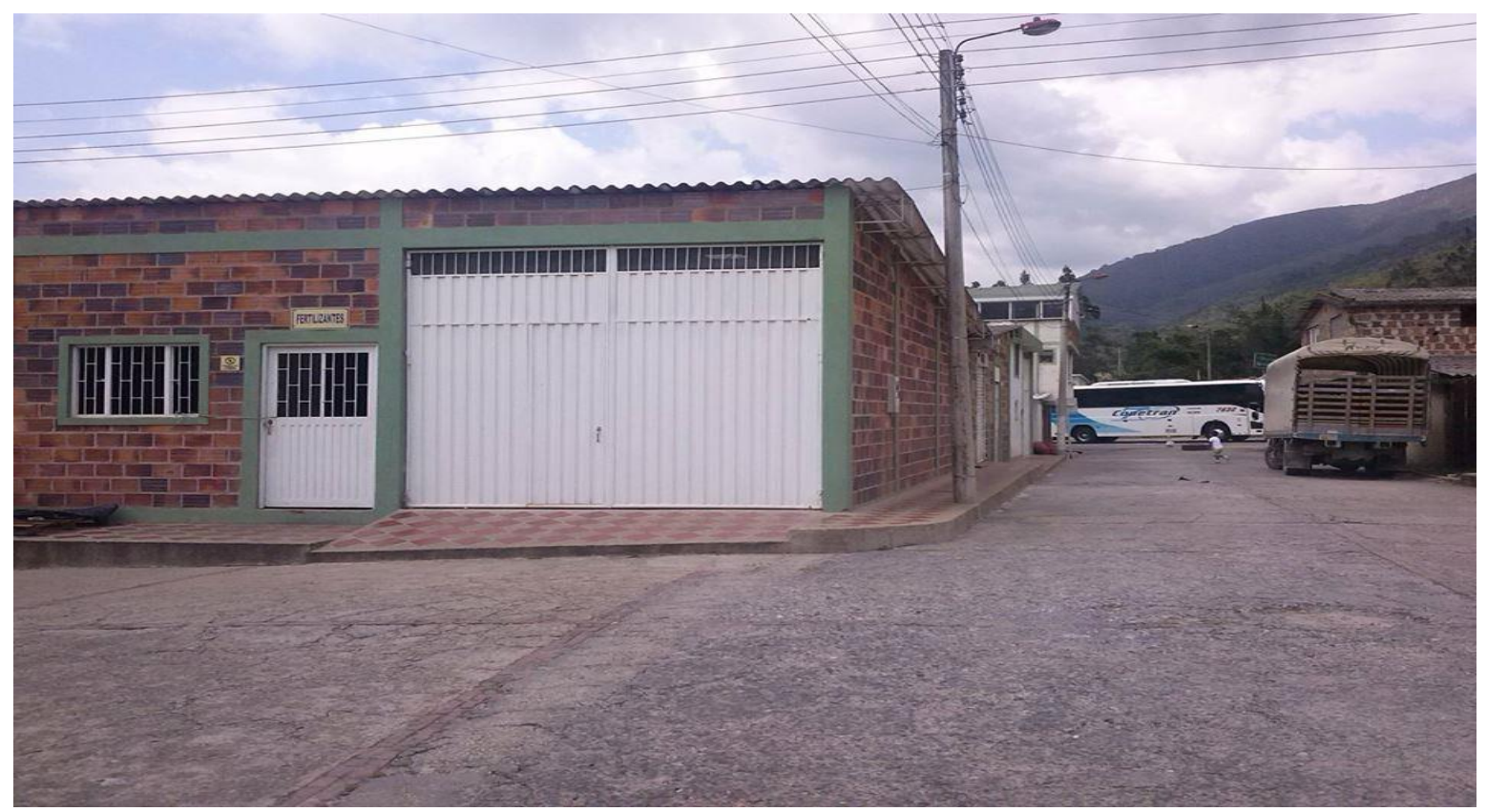


